University of Louisville

ThinkIR: The University of Louisville's Institutional Repository

Electronic Theses and Dissertations

$12-2013$

\title{
AMP-activated protein kinase regulation of myeloid antigen presenting cell activity.
}

Kelly Casey Carroll

University of Louisville

Follow this and additional works at: https://ir.library.louisville.edu/etd

\section{Recommended Citation}

Carroll, Kelly Casey, "AMP-activated protein kinase regulation of myeloid antigen presenting cell activity." (2013). Electronic Theses and Dissertations. Paper 215.

https://doi.org/10.18297/etd/215

This Doctoral Dissertation is brought to you for free and open access by ThinkIR: The University of Louisville's Institutional Repository. It has been accepted for inclusion in Electronic Theses and Dissertations by an authorized administrator of ThinkIR: The University of Louisville's Institutional Repository. This title appears here courtesy of the author, who has retained all other copyrights. For more information, please contact thinkir@louisville.edu. 


\title{
AMP-ACTIVATED PROTEIN KINASE REGULATION OF MYELOID ANTIGEN PRESENTING CELL ACTIVITY
}

\author{
By \\ Kelly Casey Carroll \\ B.S., Bellarmine University, 2009 \\ M.S. University of Louisville, 2011
}

\begin{abstract}
A Dissertation
Submitted to the Faculty of the Medical School of the University of Louisville In Partial Fulfillment of the Requirements for the Degree of
\end{abstract}

\author{
Doctor of Philosophy \\ Department of Microbiology and Immunology \\ University of Louisville \\ Louisville, Kentucky
}

December 2013 



\title{
AMP-ACTIVATED PROTEIN KINASE REGULATION OF MYELOID ANTIGEN PRESENTING CELL ACTIVITY
}

\author{
By \\ Kelly Casey Carroll \\ B.S., Bellarmine University, 2009 \\ M.S. University of Louisville, 2011 \\ A Dissertation Approved on
}

September 13, 2013

by the following Dissertation Committee:

Jill Suttles, Ph.D.

Dissertation Director

Robert Mitchell, Ph.D.

Paula Chilton, Ph.D.

Pascale Alard, Ph.D. 


\section{DEDICATION}

Dedicated to my husband Colin and our family. 


\section{ACKNOWLEDGMENTS}

I first want to thank my mentor, Dr. Jill Suttles, for giving me the opportunity to work in a wonderful lab on an exciting project. I really appreciate her guidance, support, and friendship. I also want to thank the members of my dissertation committee, Dr.

Pascale Alard, Dr. Paula Chilton, and Dr. Robert Mitchell, for their valuable comments and suggestions. I also want to express my gratitude for the late Dr. Robert Stout for his contribution to my education at the University of Louisville.

I would also like to thank all the members of the Suttles and Stout lab that I have worked with. I especially want to thank Courtney George, Yan Fang "Pei Pei” Zhu, Meena Vanchinathan, Ashley Triplett, Lihua Zhang, and Kim Head for making my years at $\mathrm{U}$ of $\mathrm{L}$ a pleasure. You have been daily cheerleaders of this project and words cannot express my gratitude.

Lastly, I want to thank my family. To my best friend and husband Colin, I could not have done this without you. Thank you for being my biggest fan. We have waded our ways through the waters of college and graduate school together, and I could not have asked for a better companion. To my parents, Chuck and Kim Casey, I can never thank you enough for all you have done for me. Thank you for giving me the best educational opportunities and insisting that no goal is too high. Much gratitude also to my sister Kara, my longest and most faithful friend, whose sense of humor always finds a way to lift me up. I also want to thank my in-laws Pat, Vikki, Sean, Sarah, and Conor Carroll, who always make sure I am taken care of. Many thanks to my extended family, who as a 
village have raised me from a painfully shy, fluffy-haired girl. I consider my family my greatest blessing. 


\begin{abstract}
AMP-ACTIVATED PROTEIN KINASE REGULATION OF MYELOID ANTIGEN PRESENTING CELL ACTIVITY

Kelly Casey Carroll

December 6, 2013

Inflammatory and metabolic processes are critical to the survival of multicellular organisms. Inflammation and metabolism are closely linked, and many pathologies are associated with dysregulation of both of these processes, including obesity, cancer, diabetes, and atherosclerosis. Understanding the mechanistic links of inflammation and metabolism are critical for the development of treatments of metabolic and inflammatory diseases.
\end{abstract}

AMP-activated protein kinase, AMPK, is a serine/threonine kinase that regulates energy homeostasis and metabolic stress in eukaryotes. When cellular ATP is low, AMPK is activated and turns off ATP-consuming anabolic pathways and turns on ATPgenerating catabolic pathways. Previous work from our laboratory, as well as by others, has provided evidence that AMPK $\alpha 1$ acts as a negative regulator of TLR-induced inflammatory function. The goal of this dissertation was to investigate the role of AMPK $\alpha 1$ in myeloid antigen presenting cell activity.

Herein we demonstrate that AMPKa1-deficient macrophages and dendritic cells (DCs) exhibit heightened inflammatory function and an enhanced capacity for antigen presentation favoring the promotion of Th1 and Th17 responses. Macrophages and DCs 
generated from AMPKa1-deficient mice produced higher levels of proinflammatory cytokines and decreased production of the anti-inflammatory cytokine IL-10 in response to both TLR and CD40 stimulation as compared to AMPK $\alpha 1+/+$ cells. In assays of antigen presentation, AMPK $\alpha 1$ deficiency in both the myeloid APC and T cell populations contributed to enhanced IL-17 and IFN $\gamma$ production. Focusing on the CD154-CD40 interaction, we found that CD40 stimulation resulted in increased phosphorylation of ERK1/2, p38, and NF-אB p65 and decreased activation of the antiinflammatory Akt - GSK3 $\beta$ - CREB pathway in DCs deficient for AMPK $\alpha 1$. AMPK $\alpha 1$ serves to attenuate LPS and CD40-mediated proinflammatory activity of myeloid APC and AMPK $\alpha 1$ activity in both APC and T cells antagonizes the development of proinflammatory $\mathrm{T}$ cell responses during antigen presentation.

Additionally, we sought to investigate the influence of macrophage-expressed AMPK $\alpha 1$ on tumor-macrophage interactions and macrophage polarization in the tumor microenvironment. Our studies show that macrophage-expressed AMPK $\alpha 1$ polarizes tumor-infiltrating macrophages (TIMs) to an anti-inflammatory phenotype and contributes to tumor growth. To evaluate the role of myeloid cell-expressed AMPK $\alpha 1$ in tumor growth and metastasis, we used an AMPKal Cre-lox transgenic mouse model. AMPK $\alpha 1$ flox/flox LysM-Cre+ (described subsequently as MacAMPK $\alpha 1$ KO) mice had reduced Lewis lung carcinoma (LLC) tumor growth and metastasis compared to AMPKa1flox/- LysM-Cre- (WT) mice. Additionally, TIMs isolated from MacAMPK $\alpha 1$ KO mice exhibited higher production of proinflammatory cytokines and matrix metalloproteinases (MMPs). Furthermore, TIMs isolated from MacAMPK $\alpha 1 \mathrm{KO}$ mice had higher phosphorylation of p65 NF- $\mathrm{kB}$ and reduced phosphorylation of Akt and 
CREB. Overall, deficiency of myeloid AMPK $\alpha 1$ results in higher proinflammatory activity of TIMs and decreased tumor growth.

Our studies herein demonstrate that AMPK $\alpha 1$ counter-regulates myeloid cell TLR- and CD154-induced inflammatory activity and antagonizes the development of proinflammatory effector $\mathrm{T}$ cell responses. Furthermore, myeloid-expressed AMPK $\alpha 1$ contributes to the polarization of TIMs to an anti-inflammatory phenotype and leads to increased tumor growth and metastasis. These studies demonstrate that AMPKa1 is an important link to inflammation and metabolism and is a valuable potential target for the treatment of inflammatory and metabolic diseases. Additionally, these studies provide evidence that activation of AMPK $\alpha 1$ in cancer therapy may contribute to increased tumor growth through polarization of TIMs to an anti-inflammatory phenotype, a valuable observation given that many AMPK activators are being studied as cancer therapeutics. 


\section{TABLE OF CONTENTS}

\section{PAGE}

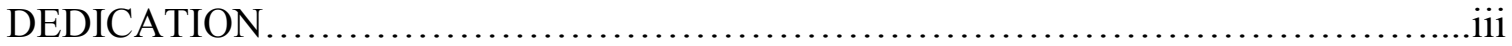

ACKNOWLEDGEMENTS.........................................................

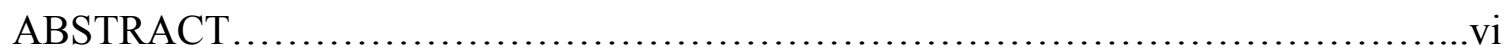

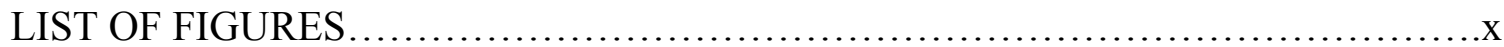

CHAPTER

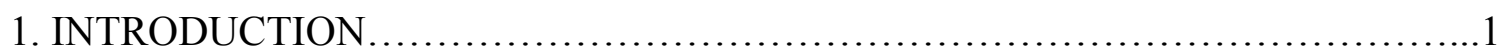

2. AMPK $\alpha 1$ DEFICIENCY AMPLIFIES PROINFLAMMATORY MYELOID APC ACTIVITY AND CD40 SIGNALING

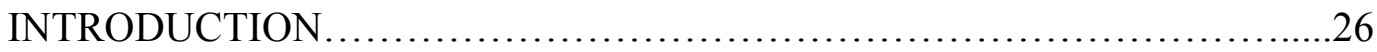

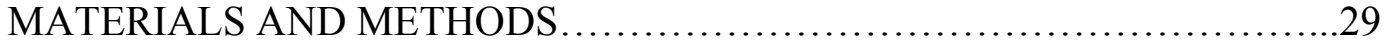

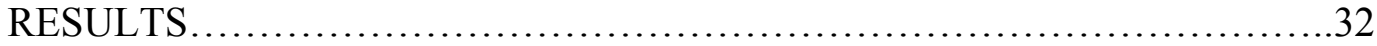

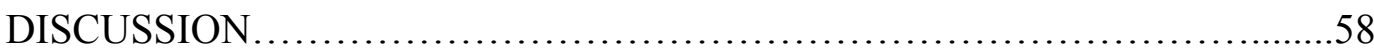

3. MACROPHAGE-EXPRESSED AMPK $\alpha 1$ REGULATES TUMOR GROWTH

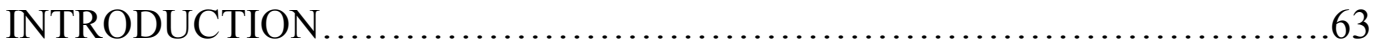

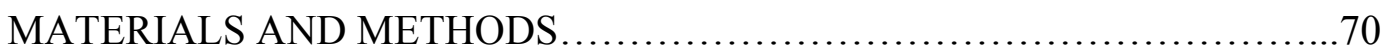

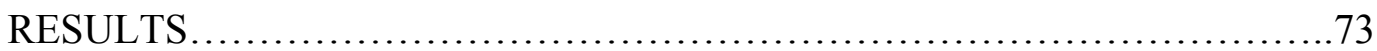

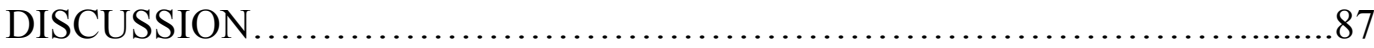

4. CONCLUSIONS AND FUTURE PERSPECTIVES ............................93

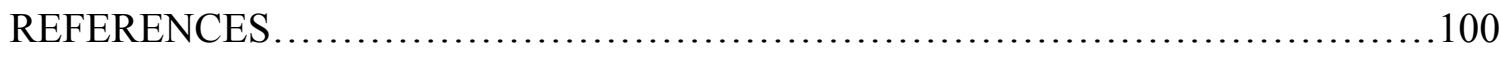

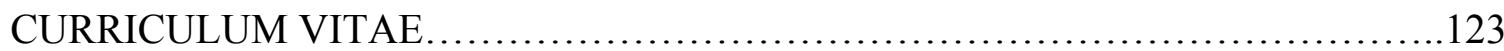




\section{LIST OF FIGURES}

$\begin{array}{ll}\text { FIGURE } & \text { PAGE }\end{array}$

1. AMPK turns off ATP-consuming pathways and turns on ATP-generating............23 pathways.

2. Macrophages have a wide variety of functions................................. 24

3. APC present antigen to naïve T cells.......................................... 25

4. The CD40:CD154 interaction induces proinflammatory activity in ...................36 macrophages and $\mathrm{T}$ cells

5. AMPK $\alpha 1$ modulates the inflammatory response of DCs and macrophages............37

6. Ag presentation by AMPK $\alpha 1-/-$ DCs and macrophages promotes.....................38 proinflammatory $\mathrm{T}$ cell responses

7. AMPKa1-/- macrophages, DCs, and T cells do not express AMPK $\alpha 1 \ldots \ldots \ldots \ldots \ldots . . . . .39$

8. AMPK $\alpha 1$ deficiency in both APC and T cells leads to Th1 responses................40

9. AMPK $\alpha 1$ deficiency in both APC and T cells leads to Th17 responses...............41

10. AMPK $\alpha 1$-deficient $\mathrm{T}$ cells do not display altered CD154 expression...............42

11. AMPK $\alpha 1$-deficient APC have increased expression of CD80 ..................44

12. AMPK $\alpha 1$-deficient APC have increased expression of CD $86 \ldots \ldots \ldots \ldots \ldots \ldots \ldots . \ldots 46$

13. AMPK $\alpha 1$-deficiency does not alter APC CD40 expression.......................48

14. AMPK $\alpha 1$-deficient APC do not have altered expression of MHC II................50

15. AMPK $\alpha 1$-deficiency does not alter APC phagocytosis of latex beads...............52

16. AMPK $\alpha 1$ regulates the inflammatory cytokine response of APC to................54

CD154-stimulation

17. CD154-stimulation of DCs and macrophages has no effect on phosphorylation......55 
of AMPK $\alpha$

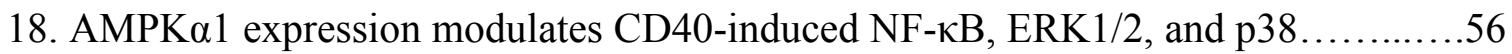
signaling in DCs

19. AMPK $\alpha 1$ expression modulates CD40-induced Akt - CREB - GSK3 $\beta$.

signaling in DCs

20. MacAMPKa1 KO mice have decreased rate of LLC tumor growth...................77

21. Tumors harvested from MacAMPK $\alpha 1 \mathrm{KO}$ mice weigh less than those from.........78 from control mice

22. Lungs from MacAMPK $\alpha 1 \mathrm{KO}$ mice have fewer metastases........................79

23. MacAMPK $\alpha 1 \mathrm{KO}$ and WT mice maintain weight throughout tumor growth and....80 metastasis

24. MacAMPK $\alpha 1 \mathrm{KO}$ mice have increased $\mathrm{CD} 19^{+}$and decreased $\mathrm{CD} 8^{+}$ immune cell infiltration of primary tumors

25. TIMs isolated from MacAMPK $\alpha 1 \mathrm{KO}$ mice have decreased expression of...........82 AMPK $\alpha$

26. TIMs isolated from MacAMPK $\alpha 1 \mathrm{KO}$ mice have increased expression of..........83 proinflammatory cytokines and MMP-12 than control mice

27. TIMs isolated from MacAMPK $\alpha 1 \mathrm{KO}$ mice have increased MMP-9 expression.......84

28. TIMs isolated from MacAMPK $\alpha 1 \mathrm{KO}$ mice have increased phosphorylation........85 of NF- $\mathrm{KB}$ p 65

29. TIMs isolated from MacAMPK $\alpha 1 \mathrm{KO}$ mice have decreased phosphorylation........86 of Akt and CREB

30. Both activation and inhibition of myeloid AMPK $\alpha 1$ may be useful..........98 therapeutic strategies 


\section{CHAPTER 1 INTRODUCTION}

In order to survive and grow, living organisms must maintain energy balance through regulation of consumption and generation of ATP. The AMP-activated protein kinase (AMPK) has been well-established as a regulator of energy homeostasis in eukaryotic cells. AMPK becomes activated by stresses causing ATP depletion and, once activated, works to turn off ATP-consuming anabolic pathways and turn on ATPproducing catabolic pathways (Fig. 1). In recent years, AMPK has been shown to have a counter-regulatory role in many inflammatory processes [1].

\section{A BRIEF HISTORY OF AMPK}

It is estimated that the ancestral form of AMPK emerged at least one billion years ago [2]. In the early 1970's, protein kinase activity associated with inactivation of acetylCoA carboxylase (ACC) [3] and 3-hydroxy-3-methyl-glutaryl-CoA reductase (HMGR) [4] were being investigated independently. Early studies of HMGR and ACC had shown

that the kinase activity leading to inactivation of both proteins was activated by AMP and in 1987, Carling et al., reported that HMGR and ACC were inactivated by the same protein kinase [5], now known as AMPK. The name AMP-activated protein kinase was first proposed in 1988 by Munday et al. [6], and in 1994, mammalian AMPK was successfully purified and sequenced $[7,8]$. 
Since these initial studies, interest in AMPK as a regulator of cellular energy has grown significantly. AMPK is ubiquitously expressed in eukaryotic cells and is thought to have a conserved function as a metabolic sensor in all eukaryotes, mammals, fungi, and plants. In addition to its role in metabolism, AMPK is now considered an important player in inflammation and associated pathologies, including cancer, neurogenerative disease, obesity, and aging [1].

\section{STRUCTURE AND REGULATION OF AMPK}

\section{Heterotrimeric structure}

AMPK is an obligate heterotrimer, made up of a catalytic $\alpha$ subunit and regulatory $\beta$ and $\gamma$ subunits (Fig. 1). The $\alpha$ and $\beta$ subunits each have two isoforms ( $\alpha 1$, $\alpha 2, \beta 1, \beta 2)$, while the $\gamma$ subunit has three $(\gamma 1, \gamma 2, \gamma 3)$. Each isoform is encoded by a separate gene. The subunit genes are named PRKA followed by a subunit identifier (A1, A2, B1, B2, G1, G2, G3); for example, the gene for the $\alpha 1$ subunit is PRKAA1. The subunit genes are distributed across five chromosomes $-\alpha 1$ on chromosome $5, \alpha 2$ and $\beta 2$ on chromosome 1, $\beta 1$ and $\gamma 1$ on chromosome 12, $\gamma 2$ on chromosome 7 , and $\gamma 3$ on chromosome 2 [9]. All 12 possible combinations of isoforms can form complexes, although $\alpha 1, \beta 1$, and $\gamma 1$ are the predominant isoforms in most cells [10].

AMPK subunits show differential tissue expression and activation. AMPK $\alpha 1$ is expressed highly in murine adipose tissue, moderately in liver, kidney, heart, and brain, and lowest in spleen and pancreas. AMPK $\alpha 2$ expression in mice is highest in skeletal muscle, then in heart, kidney and liver, and very low in lung, brain, adipose, pancreas, and spleen. The AMPK $\beta 1$ subunit is expressed in many tissues, comparable to $\alpha 1$ subunit 
expression, while $\beta 2$ is most highly expressed in skeletal muscle and heart tissue. The AMPK $\gamma 1$ isoform has very widespread expression, while the $\gamma 2$ isoform is expressed in a variety of tissues including brain, placenta, and skeletal muscle, and the $\gamma 3$ isoform is expressed rarely and mainly in skeletal muscle [9].

It has been well-established that AMPK is activated in response to increases in the intracellular AMP:ATP ratio. More recently, it was discovered that in addition to AMP, ADP directly binds to the $\gamma$ regulatory subunit and thereby induces a conformational change that promotes AMPK phosphorylation and protects against dephosphorylation [1]. The $\gamma$ subunit contains two Bateman domains, sequence motifs that serve as nucleotide binding sites in many mammals and bacterial proteins. In the $\gamma 1$ subunit, two Bateman domains assemble head to head to form a flattened disk with four clefts where nucleotides can bind. Initial studies on the $\gamma$ subunit indicated that only two molecules of AMP bind [11], however, it was recently discovered that three of the four clefts in mammalian AMPK $\gamma 1$ bind nucleotide [12]. One cleft does not bind nucleotide at all and another binds AMP very tightly and does not exc hange with ADP or ATP [12]. The other two sites bind AMP reversibly and competitively with ADP and ATP. Additionally, structural studies have shown that nucleotides bind such that the adenine moieties are deep within the binding cavity and the phosphate groups face the exterior and are partially exposed [13].

Allosteric Regulation of AMPK

AMPK is allosterically activated by $5^{\prime}$-AMP. This mechanism appears very specific, as only AMP and closely related AMP analogues can activate AMPK allosterically [1]. AMPK is not allosterically activated by ADP [1]. The presence of ATP 
antagonizes activation by AMP, although ATP is not a direct inhibitor [14]. It is apparent that the degree of activation by AMP varies and is dependent upon the identity of the $\gamma$ isoform present [15]. It is estimated that maximum allosteric activation achieves a 5-fold induction of AMPK activity, much less than the activation induced by phosphorylation of Thr172 [1].

\section{Regulation through phosphorylation/dephosphorylation}

AMPK activity is primarily regulated through reversible phosphorylation. In mammals, AMPK is only significantly active after phosphorylation of Thr172, located within the activation loop of the $\alpha$ subunit (Fig. 1) [16]. Phosphorylation of AMPK can be mediated by upstream kinases LKB1, CaMKK (calcium/calmodulin-dependent protein kinase kinase) $\alpha$ and $\beta$, or TAK1 (Transforming growth factor-beta (TGF $\beta$ )-activated kinase) [17]. Additionally, AMP and ADP promote phosphorylation of Thr172 and activation of AMPK [18].

LKB1 is a serine/threonine kinase that directly phosphorylates Thr172 of AMPK [19-21], and studies of tissue-specific deletion of LKB1 show that it mediates the majority of AMPK activation $[19,20]$. Although LKB1 phosphorylates only AMPKa1 and AMPK $\alpha 2$ in response to energy stress, it has also been shown to phosphorylate twelve other kinases including those in the MARK, SIK, BRSK, and NUAK families. All twelve of these kinases are related to AMPK and it is generally thought that there is crosstalk between AMPK and the AMPK related kinases [22].

It was believed that AMPK was only activated via an AMP-dependent mechanism until the discovery that CaMKKs, especially CAMKK $\beta$, also phosphorylate AMPK at Thr172 [23-25]. CaMKK $\beta$ phosphorylates AMPK in response to an increase in the 
intracellular $\mathrm{Ca}^{2+}$ concentration. Unlike LKB1, CaMKKs are tissue restricted and are mainly found in neurons, T cells and endothelial cells [26-28]. In addition to LKB1 and CaMKK, MAPKKK family member TAK1 is an upstream activator of AMPK. TAK1 has been found to phosphorylate and activate AMPK in cell-free assays [29], but the contexts where TAK1 may regulate AMPK phosphorylation of Thr172 in vivo and whether TAK1 phosphorylation of AMPK involves LKB1 are still being explored [30].

The Thr172 phosphorylation site serves as an on/off switch for AMPK activity. While phosphorylation induces AMPK activity, dephosphorylation of AMPK leads to nearly complete inactivation of AMPK and it has been reported that dephosphorylated AMPK has negligible catalytic activity [31]. Many mammalian serine/threonine phosphatases have been shown to effectively dephosphorylate Thr172 and inactivate AMPK. These include PP (phosphoprotein phosphatase) 1, PP2A, and PP2Ca phosphatases, although it is apparent that the phosphatases involved in the regulation of AMPK may be dependent on the cell type and/or stimulus to which the cell is responding [32]. AMP has long been known to protect against dephosphorylation of the Thr172 residue of AMPK. In 2011, it was shown that in addition to AMP, ADP effectively protects against dephosphorylation of Thr172 [33].

The level of phosphorylation of Thr172 is controlled by the balance of activities of upstream kinases and protein phosphatases. There is still much to be resolved, including many of the structural details revealing how AMP allosterically activates AMPK and, along with ADP, increases phosphorylation and protects against dephosphorylation of AMPK [34]. 


\section{AMPK ACTIVATORS}

Many physiological and pharmacological activators of AMPK have been reported. AMPK is activated by any ATP-depleting cellular stress, including nutrient deprivation, hypoxia, ischemia, oxidative stress and exercise [35, 36]. Additionally, AMPK can also be activated independently of cellular energy stress by adipose tissue hormones leptin and adiponectin. Leptin has been shown to activate AMPK $\alpha 2$ in skeletal muscle [37], and alternatively, inhibit AMPKa2 activity in the hypothalamus [38]. Adiponectin has been shown to activate AMPK in both peripheral tissues [39] and the hypothalamus [40]. Additionally, it is apparent that leptin and adiponectin regulation of AMPK in the hypothalamus mediates appetite [38]. It has also been shown that TCR stimulation results in activation of AMPK by CaMKK in T cells through a PI3Kindependent pathway [27].

Pharmacological AMPK activators include 5-aminoimidazole-4-carboxamide ribose (AICAR). AICAR is taken into the cell and converted to ZMP, an AMP analog that mimics the effects of AMP. As such, AICAR has the ability to activate any AMPsensitive protein, and has been shown to have AMPK-independent effects [41-43]. Metformin and thiazolidinediones (TZDs), both drugs used to treat type II diabetes, are known AMPK activators [9]. Metformin is an oral biguanide that inhibits gluconeogenic and lipogenic gene expression in the liver [44], and activates AMPK in an LKB1dependent manner [45]. It is thought that biguanides activate AMPK through mild inhibition of respiratory chain complex I, inhibiting mitochondrial respiration, and leading to a decrease in intracellular ATP levels [46]. The specific contribution of AMPK to the effect seen by metformin treatment, needs to be further elucidated, as one would 
expect that reduction in mitochondrial metabolism would activate a variety of stresssensing pathways [17]. TZDs are insulin sensitizers and work through upregulation of peroxisome proliferator-activated receptors (PPARs), a group of nuclear receptors [9]. PPAR $\gamma$ is most highly expressed in adipose tissue, but has also been shown to have a significant role in the maintenance of skeletal muscle insulin resistance [47] and contributes to hepatic steatosis in liver [48]. TZDs have been shown to activate AMPK in skeletal muscle cells through increasing the intracellular AMP:ATP ratio [49].

Additionally, a wide variety of plant products, termed xenobiotics, have been shown to activate AMPK. Resveratrol, a polyphenol found in the skin of red grapes, activates AMPK. Recently, low concentrations of resveratrol have been shown to lead to an accumulation of cAMP and activation of Epac1, a cAMP effector protein, which increases intracellular $\mathrm{Ca}^{2+}$ and activates AMPK via CaMKK $\beta$ [50]. In a type I diabetes mouse model, polyphenols were shown to activate AMPK and lower lipidemia and inhibit atherosclerosis disease progression [51]. Other xenobiotics that activate AMPK include egigallocatechin gallate found in green tea, capsaicin found in chili peppers, quercetin found in many fruits and vegetables, and curcumin found in tumeric. Generally, it is thought that these xenobiotics activate AMPK through inhibiting the respiratory chain or ATP synthase and may have evolved to deter insects and plant-eating animals or pathogens [34].

While metformin, TZDs, and plant-derived compounds are considered indirect AMPK activators and often work through alteration of the AMP:ATP ratio, there are also several direct AMPK activators. These include the aforementioned ZMP, along with 
A769661, PT-1, and OSU-53, and while it known that ZMP acts as an AMP mimetic, the mechanism for many direct activators remains elusive [1].

\section{AMPK REGULATES CARBOHYDRATE, LIPID, AND PROTEIN METABOLISM}

Once active, AMPK mediates many metabolic signaling events that turn off ATPconsuming pathways and turn on ATP-generating pathways (Fig. 1). AMPK plays a significant role in the metabolism of carbohydrates through regulation of several downstream effectors. AMPK impacts expression and trafficking of GLUT4, a transmembrane protein that regulates the uptake of glucose across the plasma membrane in response to certain stimuli, such as the presence of insulin and muscle activity [52-54]. Constitutive activation of AMPK $\alpha 1$ results in increased glucose uptake in skeletal muscle cells [55]. AMPK also phosphorylates the insulin receptor substrate 1 (IRS-1) (Ser789), the most upstream component of the insulin-signaling cascade [56]. Also, AMPK, along with CREB-regulated transcription coactivator 2 (CRTC2), regulates liver gluconeogenesis [57]. AMPK phosphorylates glycogen synthase (Ser7) and inhibits its activity $[58,59]$. Mice deficient for AMPKa2 display decreased phosphorylation (Ser7) of glycogen synthase in skeletal muscle basally and in response to AICAR treatment [59]. Additionally, AMPK coordinates many aspects of lipid metabolism and the coordination of fat and carbohydrate metabolism. AMPK has a regulatory role in fatty acid uptake [60] and once fatty acids are taken into the cell, AMPK plays a critical role in determining if they are directed towards oxidation or storage [9]. AMPK phosphorylates and inhibits acetyl-CoA carboxylase (ACC) 1 in lipogenic tissues and mediates 
suppression of fatty acid synthesis [2]. AMPK also suppresses fatty acid synthesis through inhibition of the transcription factor sterol regulatory element binding protein $1 \mathrm{c}$ (SREBP1c), which regulates many genes involved in lipogenesis, including fatty acid synthase (FAS) (Fig. 1) [61]. AMPK is also involved in regulation of cholesterol synthesis as it is directly phosphorylates (Ser872) and inhibits HMG-CoA reductase (HMGR) (Fig. 1), the rate-limiting enzyme for cholesterol synthesis [14, 62].

AMPK regulates protein synthesis through phosphorylation of eukaryote elongation factor 2 (eEF-2) kinase (Ser398) and results in inhibition of mRNA translation and peptide elongation [63]. Additionally, AMPK regulates protein synthesis through inhibiting the mammalian target of rapamycin complex (mTORC) 1 (Fig. 1). AMPK inhibition of protein synthesis has been demonstrated in skeletal muscle [64], liver [65], and cardiac muscle [66]. AMPK phosphorylates the tumor suppressor complex tuberous sclerosis complex (TSC) 2 (Ser1387), which activates the GTPase Rheb and leads to mTORC1 inhibition [67]. AMPK also inhibits mTORC1 activity through phosphorylation of raptor at Ser722 and Ser792, which makes it physically unavailable to the mTOR complex [68]. In addition to suppression of protein synthesis, the mTORC pathway has been shown to control many other aspects of metabolism, including regulation of glucose and lipid homeostasis, suggesting that many of the metabolic effects attributed to AMPK could be mediated by mTORC signaling [9].

\section{DYSREGULATION OF AMPK IN DISEASE}

Dysregulation of AMPK signaling is apparent in several diseases. AMPK regulates many pathways associated with the metabolic syndrome, a combination of 
medical disorders characterized by insulin resistance, type 2 diabetes, cardiovascular disease, fatty liver disease, and dysregulation of AMPK in obesity is now being investigated. AMPK activity is reduced in liver, heart, and skeletal muscle of rat and mouse genetic models of obesity [69-71]. AICAR activation of AMPK leads to increased glucose uptake and fatty acid oxidation in diabetic obese rodents [72] and humans [73], suggesting AMPK may be a valid therapeutic target for metabolic syndrome.

Alternatively, in a few studies of human obesity, AMPK expression and activity are not significantly decreased $[74,75]$. Future studies will further clarify the role of AMPK signaling in obesity and determine if AMPK activation is a valuable therapeutic strategy to treat metabolic syndrome.

AMPK has a critical role in regulation of ATP use in the heart and is thought to play a role in cardiovascular disease. Increased AMPK activity leads to increased glucose uptake [76] and fatty acid oxidation [77] in the heart, and it has been proposed that AMPK has a protective role against ischemia-reperfusion injury [9]. In myocardial ischemia, expression of AMPK $\alpha 1$ and $\alpha 2$ is elevated [77].

Studies thus far indicate that AMPK may play a role in aging. It has been well described that aging results in decreased ability to tolerate metabolic stress and increased AMPK signaling has been associated with longer lifespan in C. elegans [78]. The role of AMPK in the aging of higher organisms is not clear. Current studies show mixed results, as some reports indicate lower expression of AMPK in muscle with aging, while others report increases or no change in AMPK activity (reviewed in [9]). 


\section{AMPK AND CANCER}

LKB1, an upstream activator of AMPK, is a known tumor suppressor. Germline mutation in LKB1 results in Peutz-Jeghers syndrome (PJS), a rare hereditary disease characterized by a predisposition of benign and malignant neoplasms in various organs. PJS patients have a dramatically increased risk of cancer and are affected at relatively young ages. Although LKB1 mutations are relatively rare in most cancers, LKB1 somatic inactivation is seen in approximately $30-50 \%$ of sporadic lung adenocarcinomas and $19 \%$ of sporadic squamous cell carcinomas [79]. Additionally, it has been shown that LKB1 expression inversely correlates with tumor grade and stage in human endometrial cancers, indicating that decreased expression of LKB1 may contribute to endometrial cancer progression [80].

The role of AMPK in the regulation of LKB1 tumor suppressor signaling and its association with cancer incidence is being investigated. AICAR treatment of MDA-MB231 breast cancer cells decreases proliferation, markers for invasion, and colony formation [81]. In vivo, AICAR treatment of MDA-MB-231 tumors in nude mice attenuated tumor growth [81]. AICAR has also been found to decrease the proliferative capacity of acute lymphoblastic leukemia cells [82].

Much supporting evidence associating AMPK activity and decreased cancer incidence has been provided by studies with metformin. Diabetic patients treated with metformin have a nearly $30 \%$ reduction in deaths from cancer compared to those receiving other diabetic therapies [83]. Additionally, metformin treatment significantly decreased incidence, size, and increased mean latency in mammary adenocarcinomas of HER-2/neu-positive transgenic mice [84]. In a murine model of tobacco carcinogen- 
induced lung cancer, oral metformin treatment reduced tumor burden by $>50 \%$ [85].

These studies along with many more concerning breast, prostate, colorectal, pancreatic, and other malignancies have led to over two dozen clinical trials investigating metformin as a potential anti-cancer drug [86]. Although the anti-tumorigenic properties of metformin are often attributed to its activation of the LKB1 pathway and AMPK, it is known that this pathway is only one of many by which metformin exerts its effects [86, 87]. Thus, it is difficult to attribute the effects of metformin to AMPK activation alone. AMPK activity may suppress tumor growth through a variety of mechanisms. Tumor growth requires a great deal of energy and AMPK may reduce cancer cell growth through inhibition of anabolic pathways in times of limited energy [88].

Alternatively, there is also evidence that AMPK activity promotes tumor growth. Studies on prostate cancer tissues and cell lines suggest that AMPK inhibition may benefit prostate cancer patients. ACC phosphorylation and AMPK activity were increased in malignant prostate tissue compared to normal tissue cells [89]. Reduced expression of AMPK through siRNA led to decreased proliferation of prostate cancer cell lines and treatment of prostate cancer lines with a non-selective AMPK inhibitor induced higher levels of apoptosis $[89,90]$. It has been proposed that increased AMPK activity gives cancer cells a survival advantage, possibly through increasing glucose uptake and glycolysis, mitosis, and/or migration [1].

\section{AMPK AND INFLAMMATION}

Inflammation is crucial to maintaining health. Innate and adaptive immunity initiate inflammatory processes to offer protection from invading pathogens and repair 
tissue injuries. Although inflammation is crucial to protect and heal, it can be dangerous if activated in excess or chronically. Chronic inflammation has been shown to play a role in many diseases, including type II diabetes, atherosclerosis, and cancer $[1,91]$.

Inflammation and metabolism are closely linked. It is thought that these two systems coevolved, and in lower organisms such as Drosophila melanogaster both are regulated by one organ, the fat body [92]. Metabolic dysregulation is associated with many diseases known to have inflammatory dysregulation, including diabetes, atherosclerosis, and cancer [93]. Obesity is associated with chronic inflammation and increased risk of inflammatory disease, and alternatively, malnutrition is associated with immunosuppression [92]. There are also similarities between adipocytes and macrophages, as both cell types secrete cytokines and can be activated by pathogen components like LPS [92]. Additionally, pre-adipocytes can trans-differentiate into macrophages [92].

It is also apparent that the metabolism of immune cells is closely related to their inflammatory capacity. Inflammatory cells such as activated macrophages [94] and Th17 cells $[94,95]$ display high rates of glycolysis and lower rates of oxidative metabolism. Alternatively, anti-inflammatory macrophages [94] and regulatory T cells (Treg) [94, 95] have lower rates of glycolysis. It is also apparent that resting DCs generate ATP through oxidative phosphorylation and upon LPS stimulation, switch to glycolysis [96]. Much about this association is still unclear, but increased glycolysis may provide a quicker, albeit less efficient, source of energy for the cell to rapidly alter its functional phenotype from resting to inflammatory. Interestingly, the transition to glycolysis in activated cells mirrors the 'Warburg effect' previously observed in cancer cells [93]. 
AMPK has an established role in regulation of cellular energy metabolism, and there is a growing number of reports indicating AMPK has a prominent role in the regulation of inflammation. AMPK activation by AICAR has been shown to reduce the severity of murine acute and chronic colitis [97], experimental autoimmune encephalomyelitis (EAE) [98], and experimental autoimmune uveitis (EAU) [43]. Additionally, reports demonstrate that in vitro AICAR treatment inhibits the LPS-induced inflammatory response $[97,99]$. AMPK activation by AICAR has also been shown to inhibit inducible nitric oxide synthase (iNOS) synthesis in adipocytes, macrophages, and myocytes [100]. AMPK activation via metformin also decreases inflammation. In mild metabolic syndrome, metformin reduces systemic inflammation through decreasing the presence of C-reactive protein and IL-6 [101]. Metformin also reduces macrophage migration inhibitory factor (MIF) expression in obese people [102]. Metformin is thought to activate AMPK through decreasing intracellular ATP through inhibition of the mitochondrial respiratory chain [46], but as previously described, metformin has many AMPK-independent effects $[86,87]$ and much regarding its effects on systemic inflammation is unknown.

Many AMPK activators are also associated with reduced inflammation, including adiponectin [103], phytochemicals resveratrol and curcumin [104], as well as physical activity [105]. Additionally, IL-4, PPAR $\gamma$ agonist $15 \mathrm{dPJG}_{2}$, ciglitazone, and the green tea polyphenol epigallocatechin-3-gallate activate AMPK in macrophages (Suttles unpublished data).

Studies from our lab using macrophage cell lines expressing constitutively active (CA) and dominant negative forms (DN) of AMPKal indicated that AMPK promotes 
anti-inflammatory activity and suppresses proinflammatory activity in macrophages [106]. Macrophage cell lines expressing DN AMPK $\alpha 1$ produced higher levels of TNF $\alpha$ and IL-6 in response to LPS. Furthermore, we demonstrated that treatment of primary macrophages with anti-inflammatory stimuli such as IL-10 and TGF $\beta$ resulted in rapid phosphorylation of AMPK, whereas LPS stimulation resulted in rapid de-phosphorylation of AMPK [106]. Subsequent to this work, it was reported that AMPK counter-regulates lipid-induced inflammation through SIRT1 [107]. It has also been shown that AMPK $\beta 1$ reduces adipose tissue macrophage inflammation in obesity [108]. Additionally, AMPK $\alpha 1$ antagonizes TLR-induced DC maturation [96]. It was also recently shown that AMPK suppresses IFN $\gamma$-induced gene expression in astrocytes and microglia [109]. Studies on mTOR activity in macrophages have provided much insight into the role of AMPK in myeloid inflammation. AMPK, along with mTOR and SIRT1, has been shown to regulate autophagy in macrophages $[110,111]$. Impairment of autophagy in macrophages leads to inflammation and has been associated with progression of atherosclerosis [112].

AMPK has also been shown to play a role in T cell survival [113] and proliferation [114]. It has also been reported that AMPK $\alpha 1$ is required for $\mathrm{CD} 8^{+} \mathrm{T}$ cell memory [115]. In murine models of inflammatory disease, in vivo AICAR treatment reduced the production of proinflammatory Th cell cytokines [43, 97, 98]. Alternatively, studies by McIver et al., showed that AMPK $\alpha 1$ regulates T cell viability and metabolism and promotes CD44 expression and proinflammatory cytokine production through mTORC1 in $\mathrm{CD}^{+} \mathrm{T}$ cells, but not $\mathrm{CD} 4^{+} \mathrm{T}$ cells [116]. A study of $\mathrm{CD} 4^{+} \mathrm{T}$ cell subset differentiation reported that generation of Treg was accompanied by elevation of AMPK 
activity, associated with dependency on lipid oxidation for the Treg functional phenotype [37].

\section{MACROPHAGE AND DC FUNCTION AND PLASTICITY}

Macrophages and DCs are very heterogeneous and plastic cells. Both are part of the mononuclear phagocyte system and are generated from myeloid precursors in bone marrow. Newly formed monocytes leave the bone marrow, enter the blood, and populate different tissues and can differentiate into macrophages or DCs. Both macrophages and DCs have subpopulations resident to specific tissues, often given their own names such as microglial cells in the brain, Langerhans cells in the skin, and Kupffer cells in the liver [94]. It is currently not clear if all macrophages and DCs derive from a common progenitor and additionally, there is some controversy over whether the many varied subsets of macrophages and DCs arise from the same progenitor [117].

Macrophages are present in all tissues of the body and have an astonishing variety of functional and phenotypic characteristics (Fig. 2). The function and phenotype of a given macrophage population is thought to be dependent upon the presence of various factors in its environment, including cytokines, chemokines, adrenergic and cholinergic agonists, complement proteins, fatty acids, stress hormones, and immunoglobulins [118, 119]. Macrophages in different tissues display quite different functional patterns.

Stimulation by various factors alone or in combination is thought to regulate macrophage homing to various tissues and function. Macrophages engage in a wide spectrum of activities and many are in opposition to one another. These include proinflammatory and 
anti-inflammatory activities, immunogenic and tolerogenic activities, and tissuedestructive and tissue-restorative activities [120].

Many have tried to establish subsets of macrophages with distinct phenotypes. Macrophages are often characterized as classically activated (M1) or alternatively activated (M2). The M1/M2 nomenclature is derived from the $\mathrm{T}$ cell responses associated with these macrophage phenotypes. Classically activated macrophages are inflammatory and phagocytic and are associated with Th1 cytokines IFN $\gamma$, IL-12, TNF $\alpha$ and toll-like receptor (TLR) ligands [121]. Inflammatory macrophages have increased activity of STAT1 and NF- $\mathrm{BB}$ transcription factors that up-regulate proinflammatory genes such as nitric oxide and reactive oxygen species [121, 122]. Classical activation of macrophages is imperative to proper immune defense against viral and microbial pathogens and cancer, although proinflammatory activities must be tightly controlled. Dysregulation of macrophage-induced inflammation has been implicated in many autoimmune diseases, such as multiple sclerosis [123] and rheumatoid arthritis [124, 125].

Alternatively activated macrophages display a quite different functional pattern and are generally anti-inflammatory and wound healing (Fig. 2). Alternative activation is induced by Th2 cytokines IL-4 and IL-13 and leads to production of anti-inflammatory IL-10, TGF $\beta$, and arginase [126]. Alternatively activated macrophages have many physiologic and pathological roles and are involved in homeostasis, inflammation, repair, allergy, parasitic infections, and tumor progression [126, 127]. Wound healing responses are also associated with vascular endothelial growth factor (VEGF), MMPs, and epidermal growth factor (EGF) [128]. IL-4 and IL-13 signaling are also associated with increased expression of PPAR $\gamma$, a nuclear receptor involved in wound healing and lipid 
metabolism, and reports suggest that PPAR $\gamma$ expression may be involved in alternative activation of macrophages $[128,129]$. Although classical and alternative phenotyping of macrophages may be helpful in some cases, in others it is limited and does not appreciate the apparent heterogeneity of macrophages. It is evident that exposure of macrophages to various stimuli alone or in combination (IL-10, TGF $\beta, \operatorname{IgG}$, and many others) leads to functional phenotypes that are not necessarily entirely classical or alternative [130].

It is also apparent that the macrophage phenotype and response profile is not static. In 2003, it was reported that macrophage response to LPS changes over time, with vastly different gene expression early $(0-6 \mathrm{~h})$ and late (12-24 h) [131]. It is also clear that macrophages are continually sensing and responding to stimuli in their microenvironment. Macrophages may respond to cytokines they produced through earlier responses and shift their functional phenotype accordingly. In the context of injury, macrophages contribute early on to the generation of an inflammatory response (proinflammatory cytokine, antimicrobial oxidative radicals, and tissue-debriding proteinase production) and later once the wound is cleared of inflammatory debris, macrophages contribute to wound resolution $[122,130]$. Although it has not been formally established, it is likely that the early inflammatory macrophages and late wound resolving macrophages are the same population experiencing a progressive change in their functional phenotype through differential regulation by tissue-derived cytokines, hormones, and metabolites $[120,130,132]$. An alternative hypothesis is that the switch in macrophage roles reflects a sequential recruitment of first inflammatory then healing populations of macrophages [121]. More studies are needed to elucidate the mechanisms regulating macrophage injury response and resolution. 
Studies in our lab also demonstrated that macrophages revert back to their original phenotype after cytokine signaling ends. For example, in vitro or in vivo treatment of macrophages with cytokine changes their functional response to LPS. However, if the macrophages are washed after cytokine treatment and cultured for 1-2 days without cytokine, they respond to LPS stimulation identically to macrophages that had no cytokine stimulation [130]. Additionally, when immature DCs, bone marrow-derived macrophages, and peritoneal macrophages are removed from IL-4 and GM-CSF and placed in a neutral environment, they revert back to a basal macrophage phenotype [130, 133]. These studies and others indicate that cytokines induce a transient functional pattern rather than a stable macrophage subset.

Macrophage populations in various tissues throughout the body (i.e. lung, liver, peritoneum, brain) are usually considered to be separate lineages with distinct and unique functions $[118,119]$. Early studies indicated that many of these populations were derived from precursors that seeded organs during development. Since then, however, it has been shown that the slow turnover of tissue macrophage populations is maintained, at least in part, by infiltrating monocytes from the blood $[118,119]$. Although each of these populations displays a unique phenotype, usually described by high/low expression of various cell surface markers, it is apparent that there is still much heterogeneity within each population. Importantly, each population is also able to alter its phenotype in response to infection and/or inflammation $[118,119,134]$. These observations have led many to question how much of the phenotype of a macrophage population is a result of reversible adaptation to the tissue microenvironment and how much of the phenotype is due to irreversible differentiation [130]. 
DCs are highly specialized APC that efficiently activate T lymphocytes (Fig. 3). DCs arise from precursors in the blood and home to peripheral non-lymphoid tissues as immature DCs. Immature DCs sense and sample antigen in their environment through forming and retracting processes from the cell body, and are often present at sites where antigen exposure is more intense. These sites include those at the body surface and internal mucosae [135]. Immature DCs express MHC molecules, low levels of costimulatory molecules, and chemokine receptors. In the presence of pathogens and inflammation, immature DCs become activated and mature. Once mature, DCs increase expression of MHC molecules and chemokine receptors and have an increased ability to secrete cytokines and chemokines [136]. Up-regulation of chemokine receptors directs mature DC migration to lymphoid organs where they drive various effector $\mathrm{T}$ cell responses. Importantly, in absence of pathogenic and inflammatory signals, DCs promote tolerance through inhibition of $\mathrm{T}$ cell reactions, specifically through clonal deletion of inflammatory $\mathrm{T}$ cells and expansion of Tregs $[135,136]$.

Like macrophages, DCs are very heterogeneous and display plasticity. They do not exist as one distinct population, but as an assembly of many subpopulations. Subsets of DCs have been identified in lymphoid and non-lymphoid tissues. DCs are classified into two main subsets: conventional myeloid derived DCs and plasmacytoid DCs. Plasmacytoid DCs are crucial to antiviral immune responses and selectively express TLR7 and TLR9 and large amounts of Type I IFN in both mice and humans [135]. This dissertation discusses myeloid-derived DCs, a very heterogeneous group of cells expressing myeloid markers, specifically CD11c, CD13, CD33, CD11b, and MHC II in humans [137]. 
Being very heterogeneous, DCs within the same species and even in different regions of the same organ can vary in their surface expression of certain markers, phagocytic and endocytic ability, MHC and costimulatory molecule expression, and cytokine secretion. DCs can be stimulatory or regulatory in nature and there are many intermediate phenotypes. Stimulatory DCs are characterized by IL-12, TNF $\alpha$, IFN $\alpha$, and IL-6 cytokines and drive Th1, Th2 and Th17 responses [135]. Alternatively, regulatory DCs are characterized by IL-10, TGF $\beta$, indoleamine 2, 3-dioxygenase (IDO), and arginase and drive Treg responses [137]. The functional phenotype of DCs is determined by environmental stimuli, very similar to the determination of macrophage functional phenotype. Additionally, there seems to be some overlap between macrophages and myeloid DCs. In response to macrophage colony-stimulating factor (M-CSF), myeloid DCs from blood develop a macrophage morphology [138]. Diao et al. also reported that immunostimulatory DCs evolve into macrophage-like cells with a regulatory phenotype during cancer [139].

DCs play a critical role at the interface of innate and adaptive immunity and therefore it is not surprising that they are involved in the pathology of many diseases. While stimulatory DCs are important in pathogen clearance and tumor immunosurveillance, they have also been associated with autoimmunity. It has been shown that the tolerogenic function of DCs is compromised in many autoimmune diseases [137], including psoriasis [140], systemic lupus erthyematosus (SLE) [141], allergy [142], and inflammatory bowel disease [143]. Additionally, tolerogenic DCs can be exploited by tumors to maintain a tumor-promoting immunosuppressive environment and also by pathogens, leading to chronic infection [137]. 
Because macrophages and DCs display a wide variety of phenotypes and can be both immunostimulatory and immunosuppressive, much interest has been generated in the cellular mechanisms that determine their functional phenotype. Identifying and manipulating pathways that govern macrophage and DC functional phenotype is a promising therapeutic strategy. Specifically, through the presence or absence of various stimuli, stimulatory macrophages and DCs may be able to be transformed into regulatory cells and vice versa. Diseases that are characterized by macrophage and DC-driven chronic inflammation (i.e. autoimmunity) could be treated with therapeutics that drive a regulatory macrophage and DC functional phenotype. Alternatively, diseases that are characterized by macrophage and DC-driven immunosuppression, like cancer, could be treated through transforming these cells to a more immunostimulatory and anti-tumor phenotype [120].

Our lab is interested in the mechanisms that govern DC and macrophage behavior and through studies on fatty acid binding proteins, we became interested in AMPK as a mediator of macrophage and DC inflammatory activity. Knowing AMPK has regulatory roles in metabolism and inflammation, we wanted to investigate the role of AMPK in the regulation of antigen presentation activity and TIM activity. Herein, we demonstrate that AMPK $\alpha 1$ counter-regulates APC LPS and CD40-induced inflammatory activity and that deficiency in AMPK $\alpha 1$ in both APC and T cells promotes Th1 and Th17 responses. Additionally, we report that deficiency of myeloid AMPK $\alpha 1$ leads to reduced tumor growth and lung metastasis and leads to higher proinflammatory signaling in TIMs. 


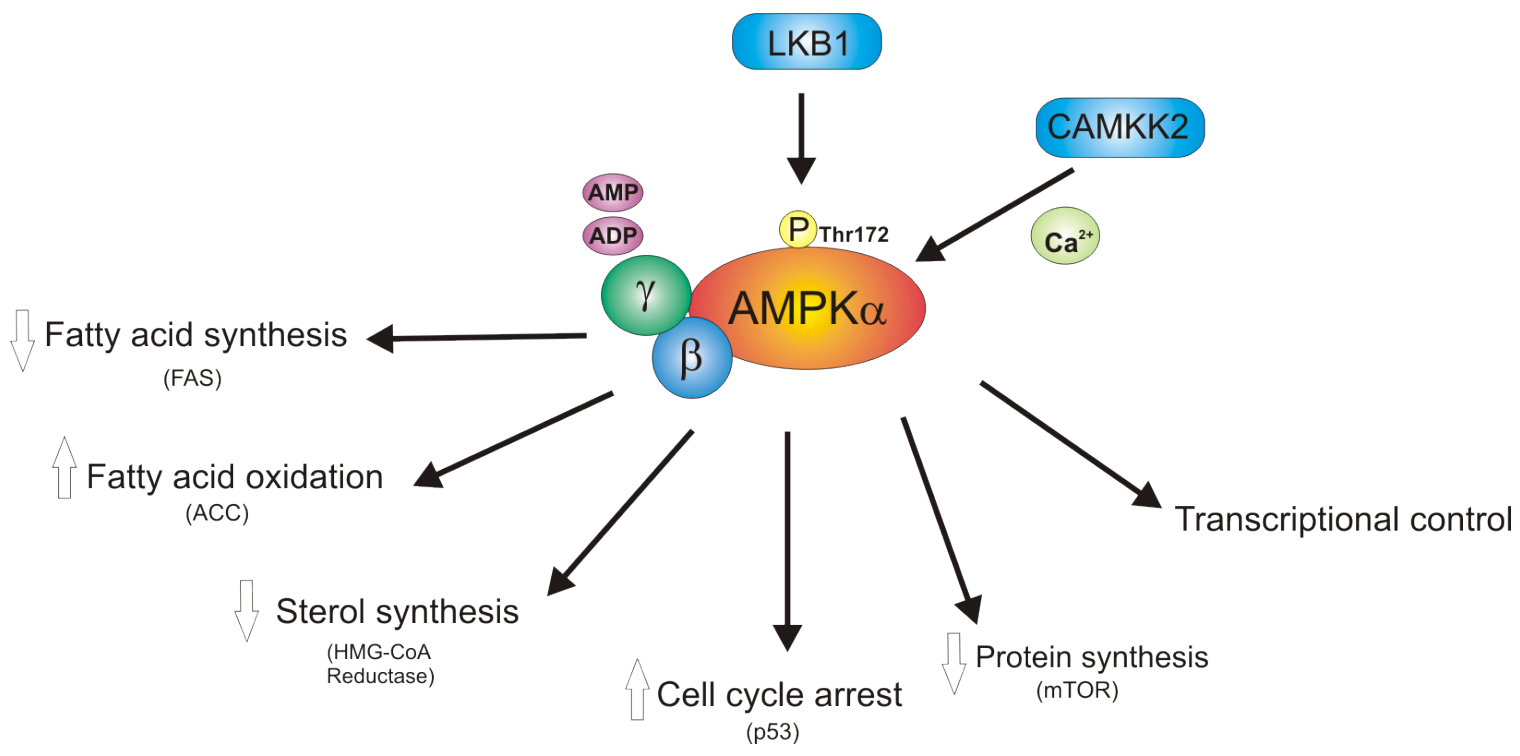

Figure 1. AMPK turns off ATP-consuming pathways and turns on ATP-generating

pathways. AMPK is a heterotrimeric serine/threonine kinase that is made up of a catalytic $\alpha$ subunit, $\beta$ scaffolding subunit, and $\gamma$ regulatory subunit. AMPK senses the cellular AMP+ADP:ATP ratio through binding of nucleotides to the $\gamma$ regulatory subunit and is allosterically activated by AMP. AMPK is activated by upstream kinases through phosphorylation of the $\alpha$ subunit at Thr172. Once active, AMPK turns off ATP consuming pathways such as those involved in the synthesis of fatty acids, sterols, and proteins and turns on ATP generating pathways, like those involved in fatty acid oxidation. 


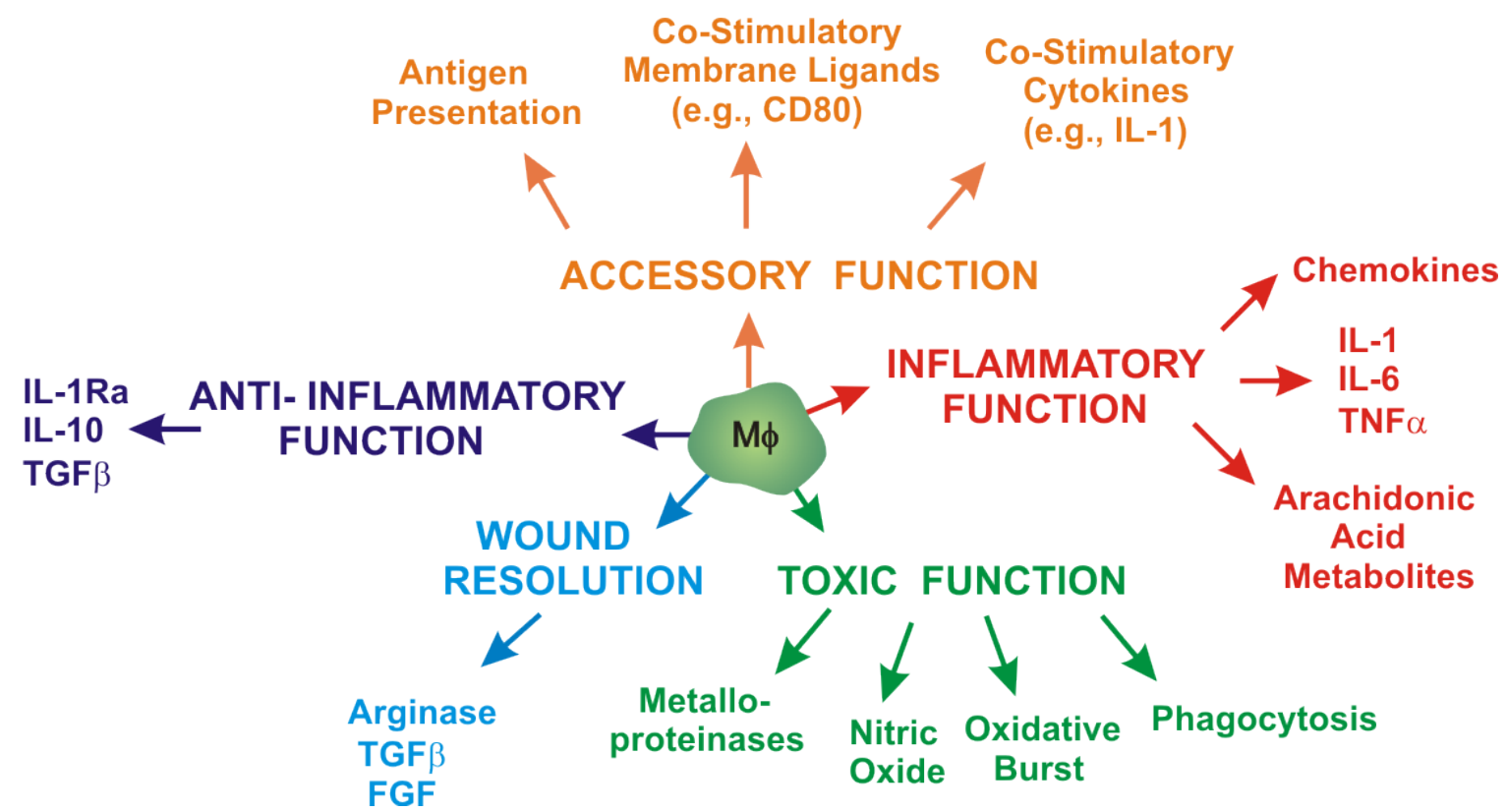

Figure 2. Macrophages have a wide variety of functions. Macrophages have the ability to perform a wide variety of activities, many in opposition to one another. Macrophages can exhibit proinflammatory activities such as secretion of proinflammatory cytokines, chemokines, and metabolites. Additionally, macrophages can secrete anti-inflammatory cytokines, like IL-10 and TGF $\beta$. Macrophages can also contribute to wound resolution and serve as accessory cells in antigen presentation. 


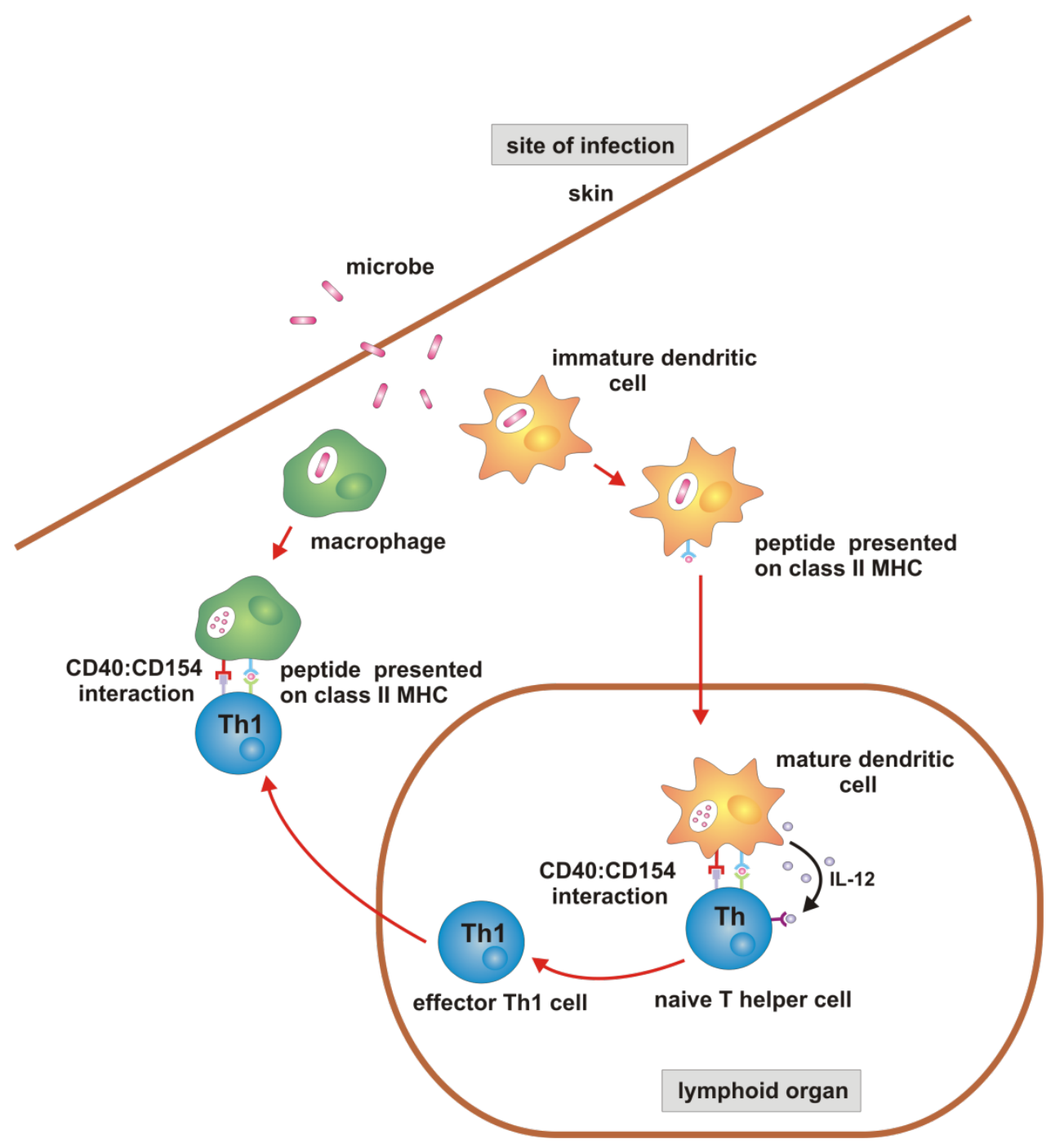

Figure 3. APC present antigen to naïve T cells. APC phagocytose antigen at the sites of infection, such as the skin, and then travel to lymphoid organs, where they display peptide to naïve T cells and stimulate them to become effector T cells. 


\section{CHAPTER 2}

\section{AMPKa1 DEFICIENCY AMPLIFIES PROINFLAMMATORY MYELOID APC ACTIVITY AND CD40 SIGNALING}

\section{INTRODUCTION}

APC are crucial to the development of specific immune responses that are appropriate to different types of pathogens. It is well-reported that APC direct the generation of inflammatory and tolerogenic immune responses. APC traffic through peripheral tissues, sampling antigens from their microenvironment [135]. In the steady state, much of the antigen sampled by APC is from apoptotic tissue cells during turnover and is critical in the maintenance of self-tolerance and does not activate APC or induce inflammation [144-146]. During infection, however, APC increase their MHC and costimulatory molecule expression and migrate from the periphery to secondary lymphoid organs where they display pathogenic antigens to naïve T cells and drive effector T cell responses (Fig. 3) [135]. Migration of APC from peripheral tissues to secondary lymphoid organs is initiated through changes in chemokine receptor and adhesion molecule expression on the APC [147].

Through presentation of antigen to naïve T cells, APC signal important information. Through pathogen-derived antigenic peptides bound to MHC, APC trigger the T-cell receptor and confer the molecular identity of the pathogen. Through CD80 and 
CD86, APC provide a costimulatory second signal and indicate the pathogenic nature of the antigen. Both the antigen-specific signal and costimulatory signals must be present to activate antigen specific naïve T cells into effector and memory cells [148]. Additionally, APC confer a "third signal" that contributes to the polarization of the T cell response. $\mathrm{APC}$ are capable of driving a wide variety of $\mathrm{T}$ cell responses. Those of $\mathrm{CD} 4^{+} \mathrm{T}$ helper (Th) are particularly varied and generally characterized by the cytokines they produce. $\mathrm{CD}^{+}$Th subsets include Th1, Th2, Th17, and Treg. The type of T cell response generated is dependent on a number of factors including the presence of pathogen associated molecular patterns and cytokines in the microenvironment, level of costimulation, and interactions with other immune cells [149-152]. When intracellular pathogens (i.e. bacteria, viruses, fungi) are present, APC produce IL-12 and type I IFN and drive $\mathrm{CD}^{+} \mathrm{T}$ cells to differentiate into Th1 cells that secrete IFN $\gamma$ (Fig. 4). Alternatively, the presence of extracellular pathogens such as helminths induces APC to drive Th2 responses characterized by secretion of IL-4, IL-5, and IL-13. Th17 responses are driven in the presence of IL-1 $\beta$, IL-6, IL-23, and TGF $\beta$ and are characterized by ROR $\gamma \mathrm{T}$, IL-17, IL-21, and IL-23 production. Naïve $\mathrm{CD} 4^{+} \mathrm{T}$ cells are polarized to a Treg phenotype when TGF $\beta$ and retinoic acid are present and result in the production of IL-10 and TGF $\beta$ [153]. Traditionally, Th subsets have been viewed as terminally differentiated cells with a defined phenotype, but in recent years it has become apparent that some $\mathrm{Th}$ subsets can display plasticity and phenotypic flexibility [154]. Specifically, Th17 and Treg subsets display phenotypic flexibility, while Th1 and Th2 subsets change their functional phenotype much less readily [155]. 
CD40 is a transmembrane glycoprotein surface receptor and a member of the tumor necrosis factor receptor (TNFR) family that is very important in antigen presentation. CD40 is expressed constitutively on both DCs and macrophages and is also expressed on monocytes, B cells, and endothelial cells [94, 156]. Binding of CD40 by its counter-receptor, CD154 (also known as TRAP, T-BAM, CD40 Ligand, or CD40L), has been shown to induce changes in DC that make them more effective APC, including increased expression of MHC II as well as costimulatory molecules CD80 and CD86 [157]. CD40 ligation has also been shown to condition DCs for effective cytotoxic T lymphocyte induction [158-160]. Additionally, CD40 signaling in DCs and macrophages has been shown to induce production of proinflammatory cytokines and chemokines [94, $156,157]$. CD154 is expressed by activated CD $4^{+} \mathrm{T}$ cells, on many other cell types, and in soluble form and the CD40:CD154 interaction mediates both APC and T cell responses (Fig. 4) [94, 156].

Given the reports by our lab and others demonstrating that AMPK is an important regulator of macrophage [106-109], DC [96], and T cell inflammatory responses [113116], we investigated the role of AMPK $\alpha 1$ in antigen presentation. Herein, we utilized AMPK $\alpha 1$ knockout mice to analyze the role of AMPK $\alpha 1$ in APC function and T cellAPC interactions, including the unexplored role of $\mathrm{AMPK} \alpha 1$ in CD40 signaling. Herein, we demonstrate that AMPK $\alpha 1$ polarizes APC to an anti-inflammatory phenotype and attenuates LPS and CD40-induced proinflammatory activity. Additionally, deficiency of AMPK $\alpha 1$ in both APC and T cells results in enhanced capacity for production of proinflammatory $\mathrm{T}$ cell responses. 


\section{MATERIALS AND METHODS}

Mice. Mice deficient for AMPK $\alpha 1$ were generated as described previously [161] and provided by Dr. Leona Rubin, University of Missouri, with permission of Dr. Benoit Viollet. AMPKa1-deficient and wild-type littermates are bred and maintained in the University of Louisville's Research Resources Facility. All animal care and experimental procedures were approved by the University of Louisville's Institutional Animal Care and Use Committee.

Reagents. LPS (Escherichia coli serotype O111:B4) was purchased from SigmaAldrich. CD40 was activated with FLAG-tagged multimeric CD154 (MegaCD40L ${ }^{\mathrm{TM}}$ ) purchased from Enzo Life Sciences. CD3 was activated with plate-bound LEAFTM antiCD3 antibody (clone 17A2) (Biolegend). Western blot detection of specific proteins used the following primary Abs: anti-phospho-AMPK $\alpha$ (Thr172), anti-AMPK $\alpha$, anti-phosphoERK1/2 (Thr202/Tyr204), anti-ERK1/2, anti-phospho-NF-кB p65 (Ser536), anti-NF-кB p65, anti-phospho-p38 MAPK (Thr180/Tyr182), anti-p38 MAPK, anti-phospho-GSK3 $\beta$ (Ser9), anti-GSK3 $\beta$, anti-phospho-CREB (Ser133), anti-CREB, anti-phospho-Akt (Ser473), anti-Akt (Cell Signaling Technology), anti- $\beta$-actin, and HRP-conjugated secondary Ab (Jackson ImmunoResearch Laboratories).

ELISA. Murine bone marrow-derived DCS and macrophages were generated as described previously [162]. Following stimulation in 96 well plates, supernatants were collected and assayed by ELISA for TNF $\alpha$, IL-6, IL-10, IFN $\gamma$ (BD Biosciences), and IL- 
17 (R\&D Systems) according to the manufacturer's instructions. Analysis was performed using an E-max precision micro plate reader (Molecular Devices).

Ag Presentation Assays. Murine bone marrow-derived DCs and macrophages were plated $\left(10^{5}\right.$ cells $/$ well in $100 \mu \mathrm{L}$ medium) with $100 \mu \mathrm{g} / \mathrm{mL}$ OVA peptide (Sigma Aldrich) for $4 \mathrm{~h}$. T cells isolated from spleens of OT-II mice (The Jackson Laboratory) using CD4 (L3T4) Microbeads (Miltenyi Biotec) were then added to culture. Supernatants were collected after $48 \mathrm{~h}$ and analyzed via ELISA.

Myelin oligodendrocyte glycoprotein peptide, $\mathrm{MOG}_{35-55}$, corresponding to the sequence MEVGWYRSPFSRVVHLYRNGK was purchased from Bio-Synthesis. Mice were injected in the flank with $100 \mu \mathrm{l}$ of an emulsion containing $150 \mu \mathrm{g}$ of $\mathrm{MOG}_{35-55}$ in CFA (Sigma-Aldrich) supplemented with $500 \mathrm{ng}$ of Mycobacterium tuberculosis H37Ra (Difco Laboratories). Fourteen days later, T cells were isolated from the spleens of immunized mice using Pan T Cell Isolation Kit II (Miltenyi Biotec). $2.5 \times 10^{5} \mathrm{~T}$ cells were added to murine bone marrow DCs and macrophages that had been pulsed with 50 $\mu \mathrm{g} / \mathrm{mL} \mathrm{MOG}_{35-55}$ peptide for $1 \mathrm{~h}$. Supernatants were collected and assayed by ELISA at $48 \mathrm{~h}$.

Flow cytometry. Single cell suspensions of bone marrow-derived DCs and macrophages were stained with fluorescently conjugated antibodies against murine CD11b, CD11c, CD80, CD86, CD40, and MHC II I-Ab (all from BD Biosciences) for 30 min at $4^{\circ} \mathrm{C}$, washed, and analyzed using a FACSCalibur flow cytometer and FlowJo software (Tree Star). $\mathrm{CD}^{+}{ }^{+} \mathrm{T}$ cells were isolated from spleens of wild-type mice using CD4 (L3T4) Microbeads (Miltenyi Biotec) and were stained with fluorescently 
conjugated antibodies against murine CD4 and CD154 (both from BD Biosciences) and analyzed using the same method.

Phagocytosis Assay. Murine bone marrow-derived DCs and macrophages were cultured for $24 \mathrm{~h}$ with IgG FITC-conjugated latex beads (Cayman Chemical). Cells were collected, stained with fluorescently conjugated antibodies against CD11c or CD11b (both from BD Biosciences) for $30 \mathrm{~min}$ at $4^{\circ} \mathrm{C}$, washed, and analyzed using a FACSCalibur flow cytometer and FlowJo software (Tree Star).

Western blot analysis. Murine bone marrow-derived DCs and macrophages, and splenic $\mathrm{CD}^{+}{ }^{+}$cells were lysed in buffer containing $125 \mathrm{mM}$ Tris (pH 6.8), 2\% SDS, 20\% glycerol, $200 \mathrm{uM}$ PMSF, protease inhibitor mixture (Promega), and phosphatase inhibitor mixture (ThermoFisher Scientific). Total protein content of the samples was assessed by BCA protein assay (ThermoFisher Scientific). Equal amounts of protein were separated on $10 \%$ Criterion gels (Bio-Rad) by SDS-PAGE. Proteins were transferred to nitrocellulose membranes using the Trans-blot Turbo Transfer System (Bio-Rad). Abbound proteins were detected using an ECL Western blotting analysis system (GE Healthcare), and the membranes were exposed to UltraCruz 5x7 Autoradiography Film (Santa Cruz Biotechnology) Densitometric analysis was performed using UN-SCAN-IT gel analysis software (Silk Scientific).

Statistical Analysis. Statistical significance between groups was evaluated by two way analysis of variance (ANOVA) followed by Bonferroni multiple comparison test using Graphpad Prism software (Graphpad), and a level of $\mathrm{p}<0.05$ was considered statistically significant. 


\section{RESULTS}

\section{AMPKa1 activity counter-regulates APC inflammatory activity}

The influence of AMPK $\alpha 1$ on APC inflammatory activity was evaluated using bone marrow-derived DCs and macrophages generated from AMPK $\alpha 1$-deficient mice. Cytokine production of AMPK $\alpha 1$-deficient bone marrow-derived DCs and macrophages in response to LPS stimulation was measured by ELISA. AMPK $\alpha 1$-deficient APC showed increased LPS-induced production of the proinflammatory cytokines IL-6 (Fig. 5 $A, D)$ and TNFa (Fig. $5 B, E)$. Alternatively, decreased production of the antiinflammatory cytokine IL-10 was displayed by AMPK $\alpha 1$-deficient APC stimulated with LPS (Fig. $5 C, F$ ). The results of these experiments reveal that AMPK $\alpha 1$ counterregulates LPS-induced inflammatory cytokine production in primary macrophages and DCs and support our previous work that utilized macrophage cell lines transfected with DN and CA forms of AMPK $\alpha 1$ [106].

\section{AMPKa1-deficient APC promote proinflammatory Th cell responses}

To determine the influence of AMPK $\alpha 1$ on T cell-APC interactions, bone marrow-derived DCs and macrophages generated from AMPK $\alpha 1$ knockout mice were pulsed with OVA and cocultured with OT-II T cells. Cell culture supernatants were assayed for cytokine content. AMPK $\alpha 1$-deficient APC induced significantly higher levels 
of T cell production of IFN $\gamma$ (Fig. $6 A, C$ ) and IL-17 (Fig. $6 B, D$ ) than wild-type APC, demonstrating that absence of AMPK $\alpha 1$ in APC leads to a promotion of Th1 and Th17 responses.

We also evaluated APC-T cell interactions using T cells isolated from mice immunized with $\mathrm{MOG}_{35-55}$ peptide. We verified that bone marrow-derived DCs and macrophages, along with $\mathrm{CD}^{+}$splenic $\mathrm{T}$ cells from AMPK $\alpha 1$-deficient mice did not express AMPK (Fig. 7). AMPK $\alpha 1$-deficient and AMPK $\alpha 1+/+$ APC were pulsed with $\mathrm{MOG}_{35-55}$ peptide and co-cultured with splenic $\mathrm{CD} 4^{+} \mathrm{T}$ cells harvested from AMPK $\alpha 1+/+$ and AMPK $\alpha 1-/-$ mice that had been immunized with $\mathrm{MOG}_{35-55} 14 \mathrm{~d}$ earlier. AMPKa1-deficient APC induced significantly higher levels of IFN $\gamma$ (Fig. $8 \mathrm{~A}, \mathrm{C}$ ) and IL17 (Fig. 9 A, C) secretion than AMPKa1+/+ APC.

Assays utilizing AMPKa1-deficient T cells provided evidence for the role of AMPK $\alpha 1$ in the regulation of effector T cell responses. In assays with AMPK $\alpha 1+/+$ APC, T cells isolated from AMPKa1-/- mice led to increased production of IFN $\gamma$ (Fig. 8 $B, D$ ) and IL-17 (Fig. $9 B, D$ ). AMPKa1-deficiency in both cell types may promote Th1 and Th17 responses. When both APC and T cells were deficient in AMPK $\alpha 1$ the most profound influence on production of IFN $\gamma($ Fig. $8 B, D$ ) and IL-17 (Fig. $9 B, D$ ) was observed. T cells were isolated from total body AMPK $\alpha 1-/-$ mice, and it is important to consider the effect of T cell priming by AMPKa1-/- APCs in immunized mice before they were isolated and used in our recall assay. This is addressed further in the Chapter 1 discussion. Additionally, we observed no difference in CD154 expression of AMPKa1deficient $\mathrm{T}$ cells compared to wild-type (Fig. 10). 


\section{APC deficiency of AMPKa1 leads to increased expression of CD80 and CD86}

To further explore the role of AMPK $\alpha 1$ in antigen presentation, the impact of AMPK $\alpha 1$-deficiency on expression of antigen presentation machinery was evaluated. LPS-stimulated AMPK $\alpha 1$-deficient DCs had significantly higher expression of costimulatory molecules CD80 (Fig. $11 A-E$ ) and CD86 (Fig. $12 A-E$ ) compared to DCs generated from control mice. AMPK $\alpha 1$-deficiency in LPS-stimulated macrophages resulted in similar increases of CD80 (Fig. $11 A-E$ ) and CD86 (Fig. $12 A-E$ ), but did not reach statistical significance. We did not see a significant difference in CD40 (Fig. 13) or MHC II (Fig. 14) expression on AMPKa1-deficient bone marrow-derived DCs or macrophages compared to those generated from control mice, nor did we see differences in phagocytosis of latex beads (Fig. 15).

\section{AMPKa1 regulates APC response to CD154 stimulation}

The CD40:CD154 interaction is critical to productive APC-T cell interactions [94, 156]. With the demonstration that AMPK $\alpha 1$ influences antigen presentation and the development of effector T cell responses, we investigated the response of myeloid APC to CD154 stimulation. AMPKal-deficient bone marrow-derived DCs and macrophages were generated and evaluated for their cytokine production in response to stimulation with a soluble, multimeric CD154. AMPK $\alpha 1$-deficient APC displayed increased production of the proinflammatory cytokine IL-6 in response to CD154 stimulation (Fig. $16 \mathrm{~A}, \mathrm{C}$ ) and alternatively, decreased production of the anti-inflammatory cytokine IL-10 (Fig. $16 B, D$ ). In contrast to previous observations by our laboratory and others that proinflammatory stimuli result in decreased phosphorylation of AMPK $\alpha 1[96,106,107$, 
163], stimulation of macrophages and DCs with CD154 at a concentration that effectively induced a proinflammatory response $(1.0 \mu \mathrm{g} / \mathrm{mL})$ had no effect on phosphorylation of AMPK $\alpha 1$ (Fig. 17).

We considered a number of downstream targets of AMPK as possible mediators of the anti-inflammatory activity we observed. CD154-mediated TRAF signaling activates the NF-KB and MAPK pathways, including p38 and ERK1/2 kinases $[109,164-$ 168]. We evaluated CD154-induced NF-אB activation through phosphorylation of $\mathrm{p} 65$. As shown in Fig. 18A, CD154 induced p65 phosphorylation in AMPKa1-deficient DCs to a much greater degree than in DCs generated from wild-type mice. Phosphorylation of the MAPKs ERK1/2 and p38, which have been implicated in the production of proinflammatory cytokines in response to CD40 activation [109, 166, 168], was also evaluated. AMPKa1-deficient DCs showed much higher phosphorylation of ERK1/2 and p38 in response to CD154 stimulation (Fig. $18 B, C$ )

AMPK $\alpha 1$ is known as a modulator of signaling events downstream of the PI3KAkt pathway [169] and in previous studies of macrophage function we found that deficiency of AMPK $\alpha 1$ resulted in decreased Akt activity in response to LPS-stimulation [106]. In the unphosphorylated state GSK3 $\beta$ is active and prevents IL-10 expression via its inactivation of the transcription factor CREB. Akt can phosphorylate and inactivate GSK3 $\beta$ (Ser9) such that it can no longer prevent CREB-dependent IL-10 production $[170,171]$. We evaluated phosphorylation of Akt, CREB, and GSK3 $\beta$ in AMPK $\alpha 1-$ deficient DCs. As shown in Fig. 19 A-C, DCs lacking AMPKal expression displayed decreased phosphorylation of Akt, CREB, and GSK3 $\beta$ when stimulated with CD154 as compared to DCs generated from wild-type mice. 


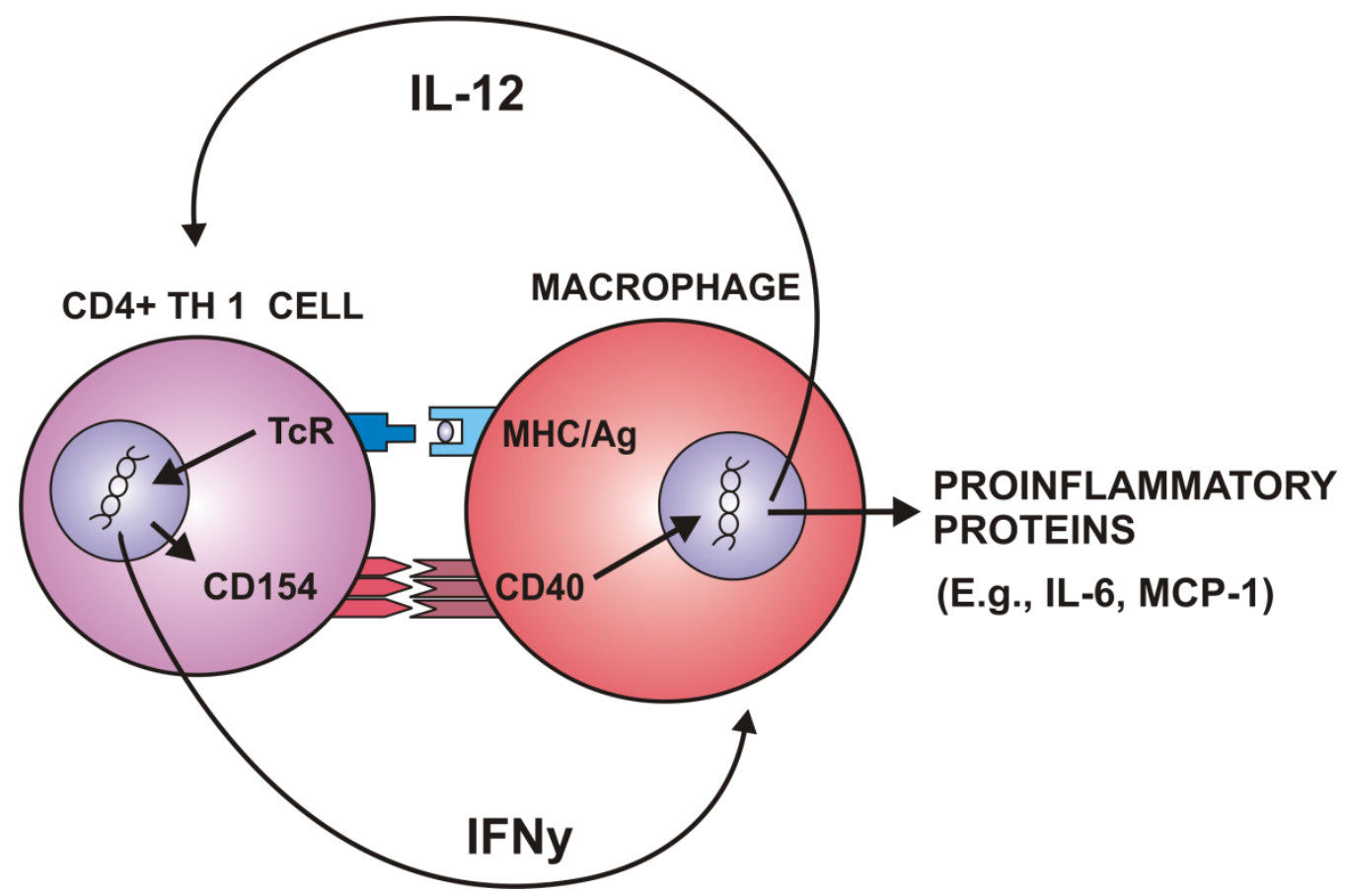

Figure 4. The CD40:CD154 interaction induces proinflammatory activity in macrophages and $\mathbf{T}$ cells. Binding of CD40, expressed on macrophages, to its counterreceptor, CD154, on T cells results in macrophage production of proinflammatory proteins and cytokines, such as IL-12, IL-6, and monocyte chemoattractant protein (MCP) -1. Production of IL-12 results in the development of Th1 effector T cells. Additionally, the CD40:CD154 engagement results in T cell IFN $\gamma$ production, which further influences macrophage activity. 

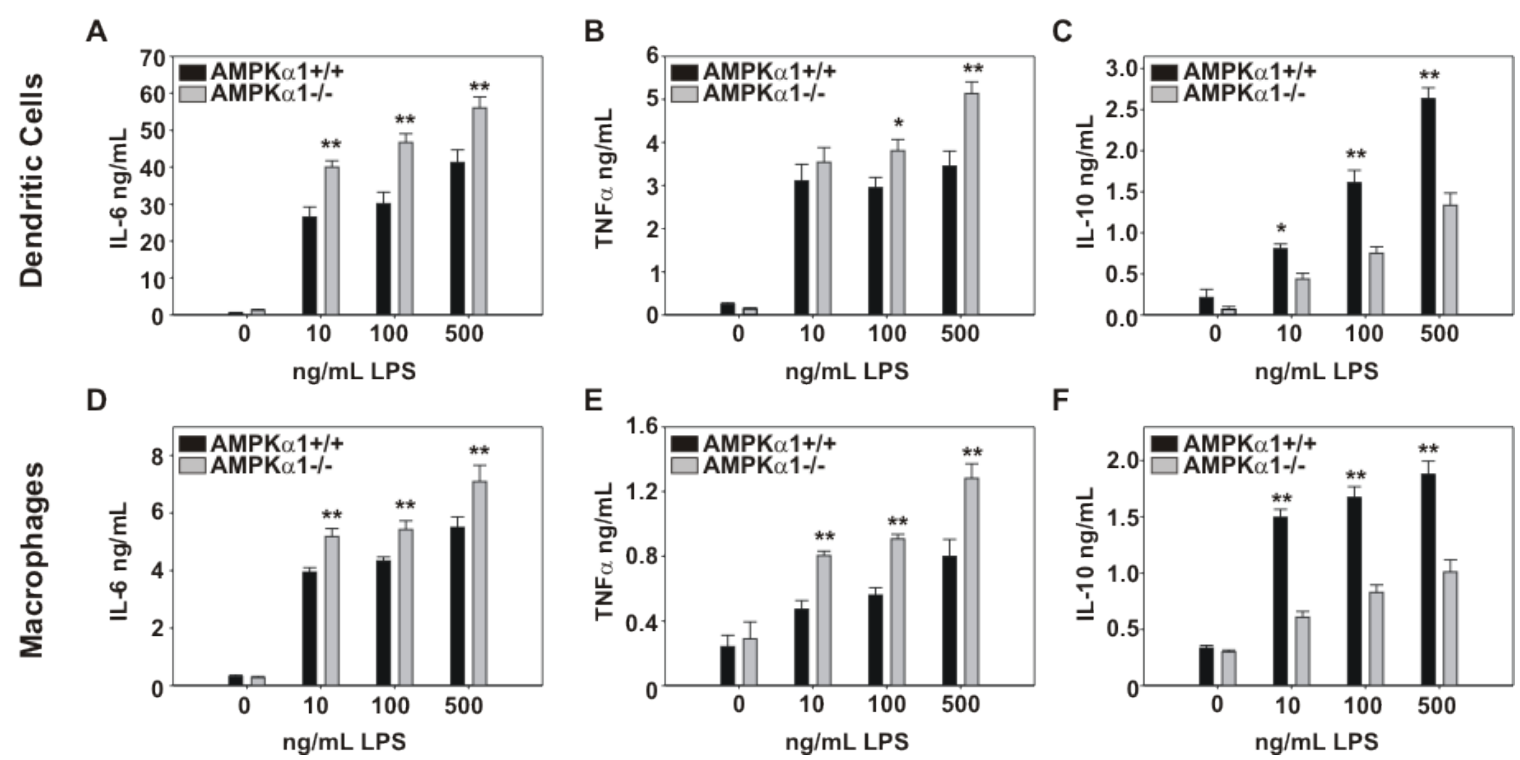

Figure 5. AMPKa1 modulates the inflammatory response of DCs and macrophages.

Bone marrow-derived DCs $(A-C)$ and macrophages $(D-F)$ were generated from

AMPK $\alpha 1-/-$ and AMPK $\alpha 1+/+$ mice and stimulated with LPS at the concentrations shown for $18 \mathrm{~h}$ or left unstimulated. IL-6, TNF $\alpha$, and IL-10 levels were detected by ELISA. Data are shown as mean \pm SEM and are combined results of three independent experiments (*, $\mathrm{p}<0.05 ; * *, \mathrm{p}<0.01)$. 


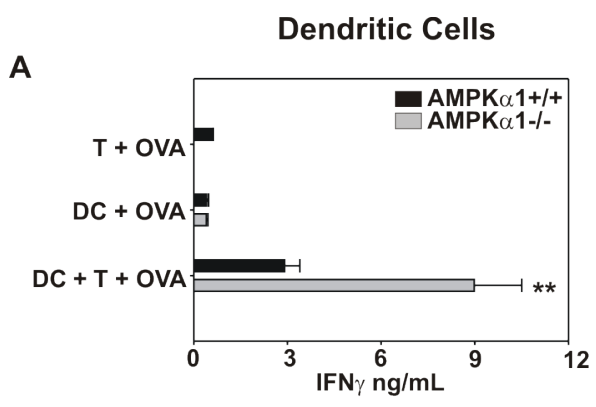

B

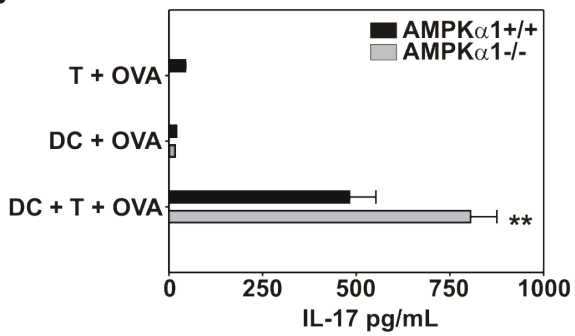

C

Macrophages

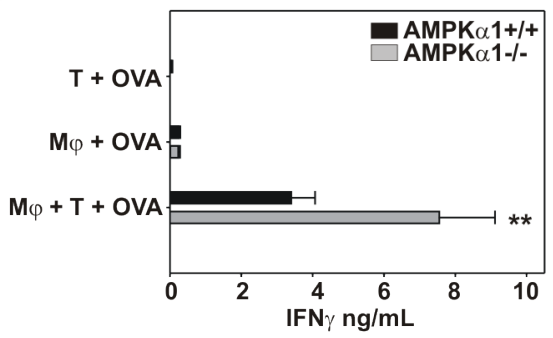

D

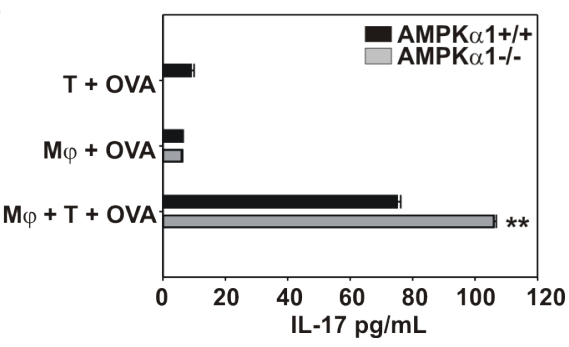

Figure 6. Ag presentation by AMPKa1-/- DCs and macrophages promotes

proinflammatory $\mathbf{T}$ cell responses. AMPK $\alpha 1+/+$ and AMPK $\alpha 1-/-$ bone marrow-derived DCs $(A-B)$ and macrophages $(C-D)$ were pulsed with OVA and coincubated with OT-II $\mathrm{CD}^{+} \mathrm{T}$ cells for $18 \mathrm{~h}$. IFN $\gamma$ and IL-17 levels were detected by ELISA. Data are shown as mean \pm SEM and are combined results of three independent experiments $(* *, p<0.01)$. 


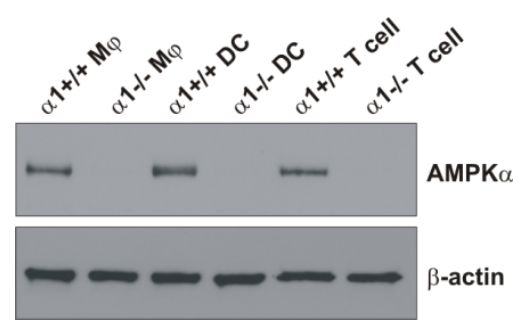

Figure 7. AMPKa1-/- macrophages, DCs, and T cells do not express AMPKa. Bone marrow-derived macrophages and DCs were generated from AMPK $\alpha 1+/+$ and AMPK $\alpha 1$ /- mice. T cells were isolated from spleens of AMPK $\alpha 1+/+$ and AMPK $\alpha 1-/-$ mice. After cell lysis, Western blot was performed with Abs against AMPK $\alpha$ and $\beta$-actin. 

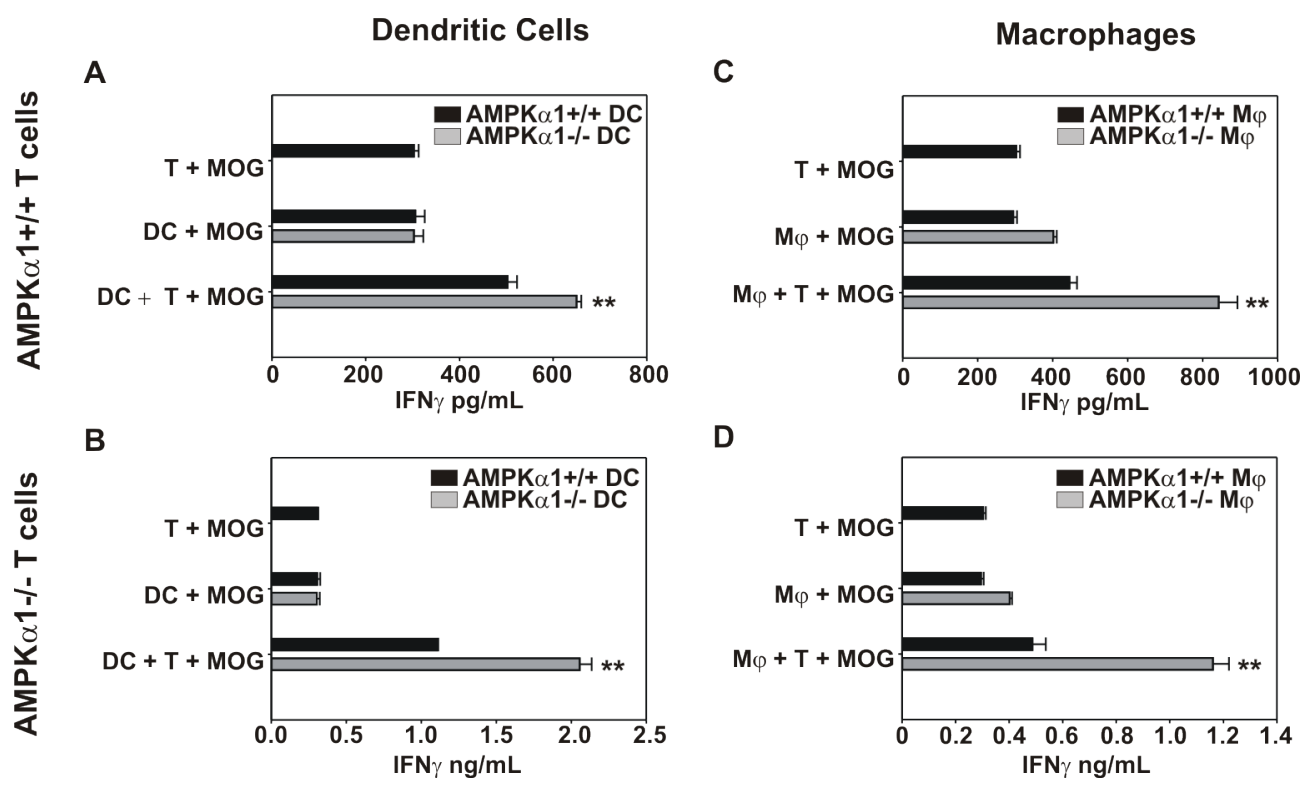

D

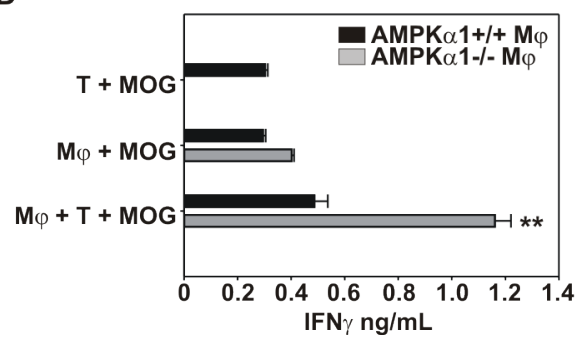

Figure 8. AMPKa1 deficiency in both APC and T cells leads to Th1 responses. Bone marrow-derived DCs and macrophages were generated from AMPK $\alpha 1$-deficient and AMPK $\alpha 1+/+$ mice. DCs $(A-B)$ and macrophages $(C-D)$ were pulsed with $\mathrm{MOG}_{35-55}$ before coculture with $\mathrm{T}$ cells from $\mathrm{MOG}_{35-55}$-immunized AMPK $\alpha 1+/+(A, C)$ or AMPK $\alpha 1-/-(B, D)$ mice. Levels of IFN $\gamma$ were detected by ELISA. Data shown are mean $\pm \mathrm{SD}$ and are representative of three independent experiments with similar results $(* *, \mathrm{p}$ $<0.01)$. 

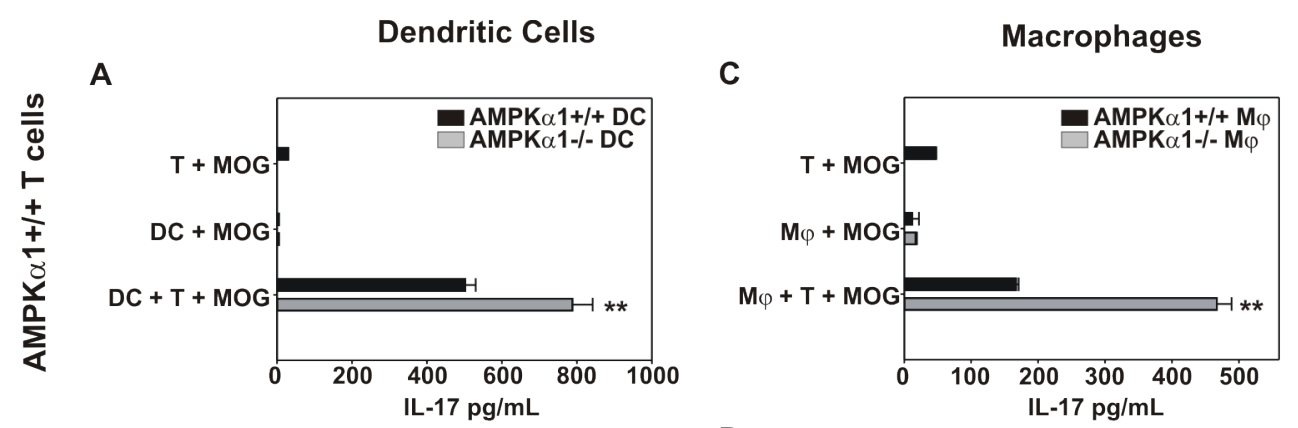

B

D
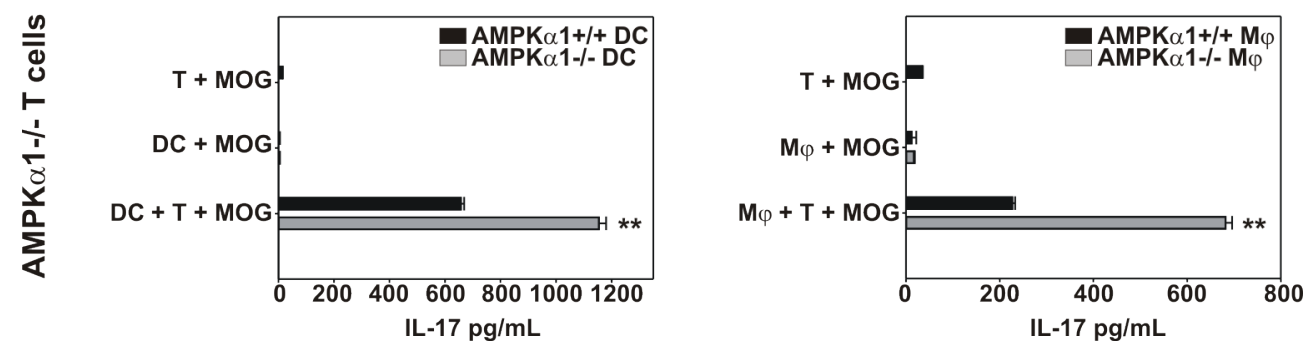

Figure 9. AMPKa1 deficiency in both APC and T cells leads to Th17 responses.

Bone marrow-derived DCs and macrophages were generated from AMPK $\alpha 1$-deficient and AMPK $\alpha 1+/+$ mice. DCs $(A-B)$ and macrophages $(C-D)$ were pulsed with $\mathrm{MOG}_{35-55}$ before coculture with $\mathrm{T}$ cells from $\mathrm{MOG}_{35-55}$-immunized AMPK $\alpha 1+/+(A, C)$ or AMPK $\alpha 1-/-(B, D)$ mice. Levels of IL-17 were detected by ELISA. Data shown are mean \pm SD and are representative of three independent experiments with similar results $(*, \mathrm{p}<0.05 ; * *, \mathrm{p}<0.01)$. 

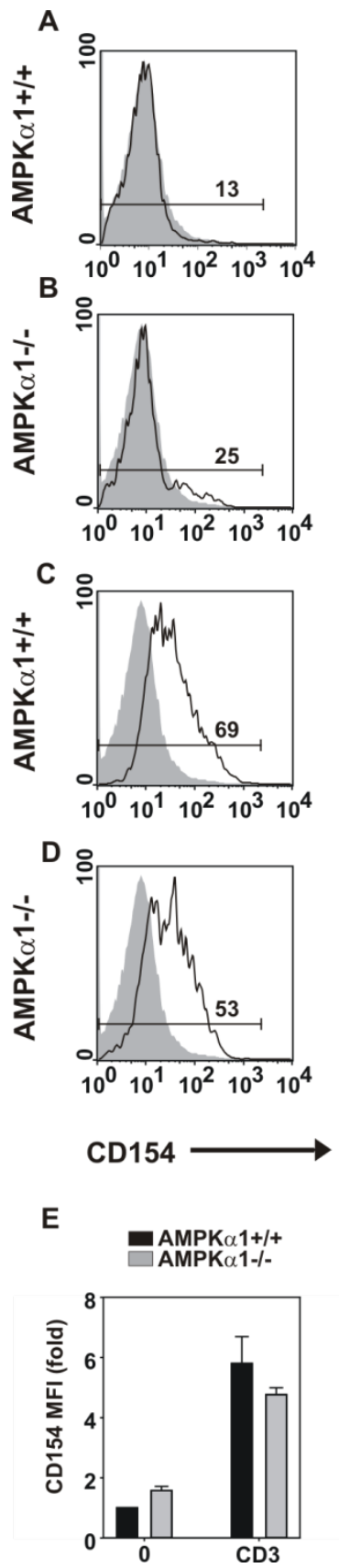

Figure 10. AMPKa1-deficient T cells do not display altered CD154 expression.

Surface expression of CD154 on AMPK $\alpha 1+/+$ and AMPK $\alpha 1-/-$ splenic T cells was analyzed via flow cytometry. CD154 expression of unstimulated cells $(A-B)$ and cells stimulated with plate-bound anti-CD3 antibody $(2.5 \mu \mathrm{g} / \mathrm{mL})$ for $18 \mathrm{~h}(C-D)$ was 
evaluated. Histograms show fluorescence of CD154 expression (black line) of $\mathrm{CD}^{+} \mathrm{T}$ cells and unstained cells (solid grey peak). Mean fluorescence intensity (MFI) of populations in brackets is stated numerically. Data shown in $A-D$ are representative of three independent experiments with similar results. Bar graphs $(E)$ describe fold change in MFI of CD154 compared to unstimulated wild-type cells and values are mean \pm SEM and are the combined results of three independent experiments. 

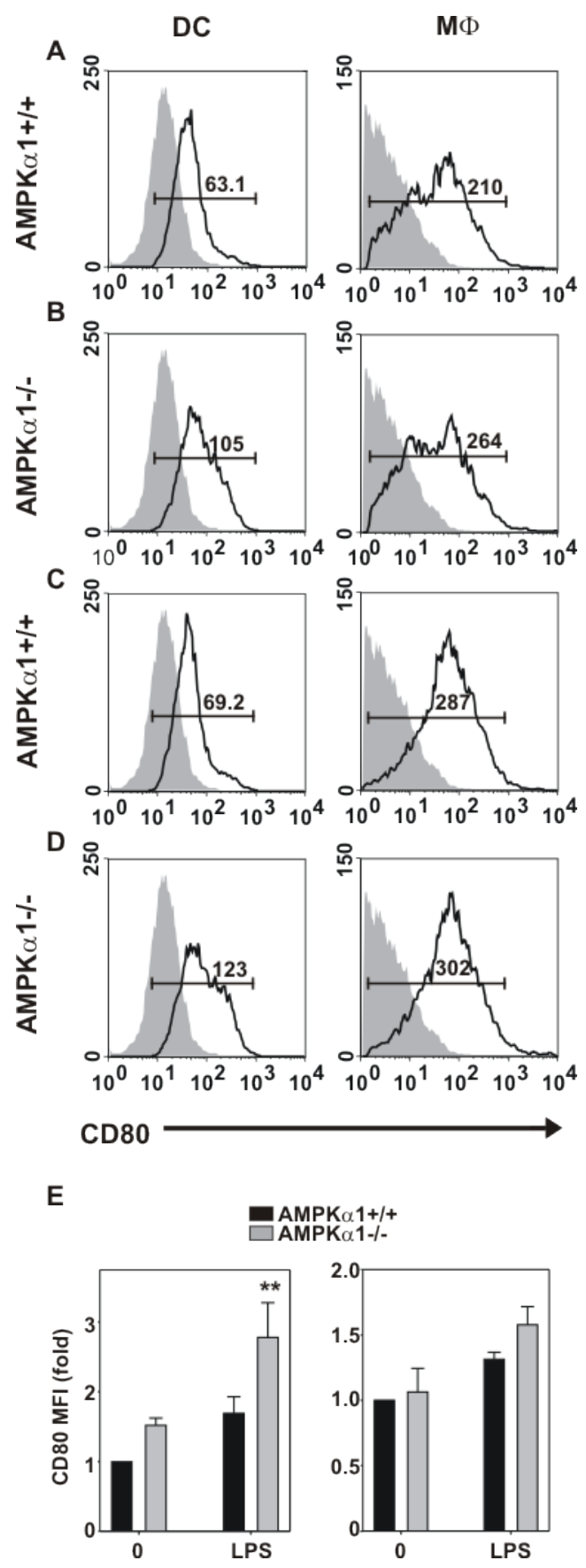

Figure 11. AMPKa1-deficient APC have increased expression of CD80. Surface expression of CD80 on AMPK $\alpha 1+/+$ and AMPK $\alpha 1-/-$ bone marrow-derived DCs and macrophages was analyzed via flow cytometry. Costimulatory molecule expression of unstimulated cells $(A, B)$ and cells stimulated with LPS $(100 \mathrm{ng} / \mathrm{mL})$ for $18 \mathrm{~h}(C, D)$ was 
evaluated. Histograms show fluorescence of CD80 expression (black line) of CD11c+ (for DCs) or CD11b+ (for macrophages) cells and unstained cells (solid grey peak). Mean fluorescence intensity (MFI) of populations in brackets is stated numerically. Data shown in $A-D$ are representative of three independent experiments with similar results. Bar graphs $(E)$ describe fold change in MFI of CD80 compared to unstimulated wild-type cells and values are mean \pm SEM and are the combined results of three independent experiments $(* *, p<0.01)$. 

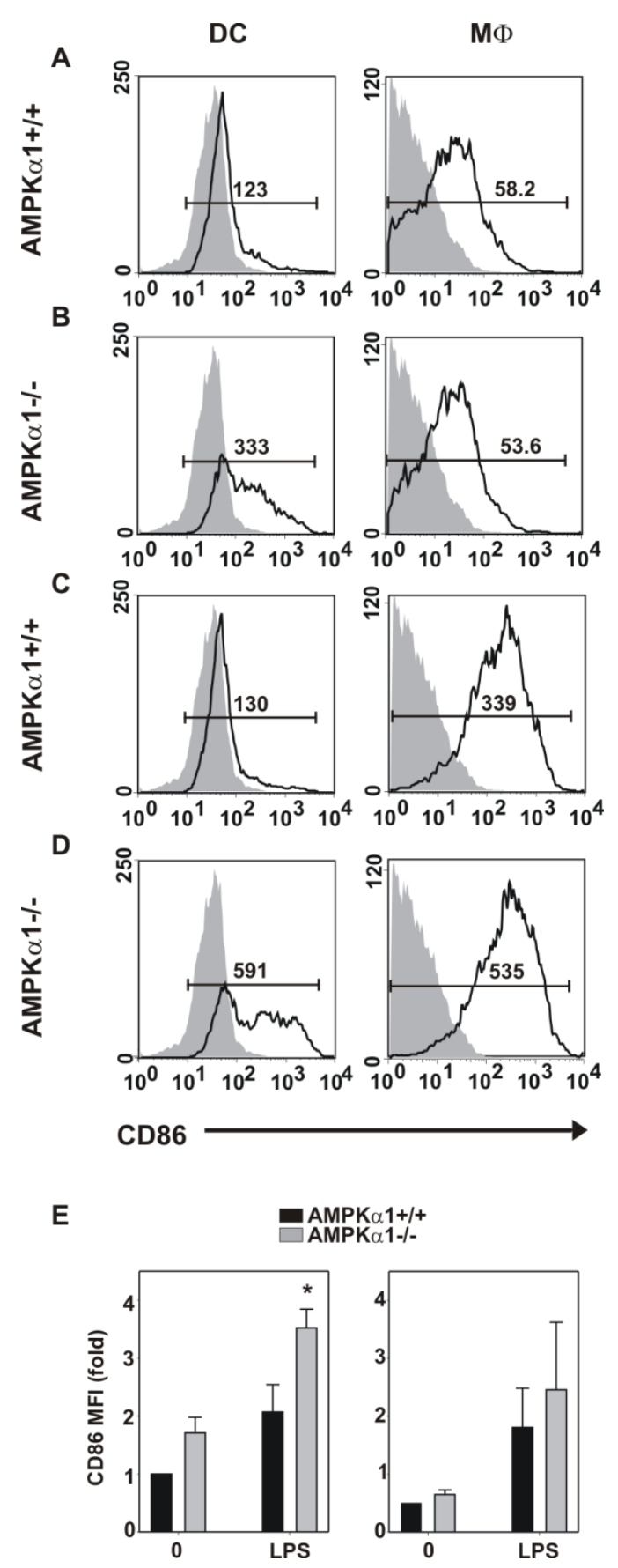

Figure 12. AMPKa1-deficient APC have increased expression of CD86. Surface expression of CD86 on AMPK $\alpha 1+/+$ and AMPK $\alpha 1-/-$ bone marrow-derived DCs and macrophages was analyzed via flow cytometry. CD86 expression of unstimulated cells $(A, B)$ and cells stimulated with LPS $(100 \mathrm{ng} / \mathrm{mL})$ for $18 \mathrm{~h}(C, D)$ was evaluated. 
Histograms show fluorescence of costimulatory molecule expression (black line) of $\mathrm{CD} 11 \mathrm{c}+($ for DCs) or CD11b+ (for macrophages) cells and unstained cells (solid grey peak). Mean fluorescence intensity (MFI) of populations in brackets is stated numerically. Data shown in $A-D$ are representative of three independent experiments with similar results. Bar graphs $(E)$ describe fold change in MFI of CD86 compared to unstimulated wild-type cells and values are mean \pm SEM and are the combined results of three independent experiments $(*, \mathrm{p}<0.05)$. 

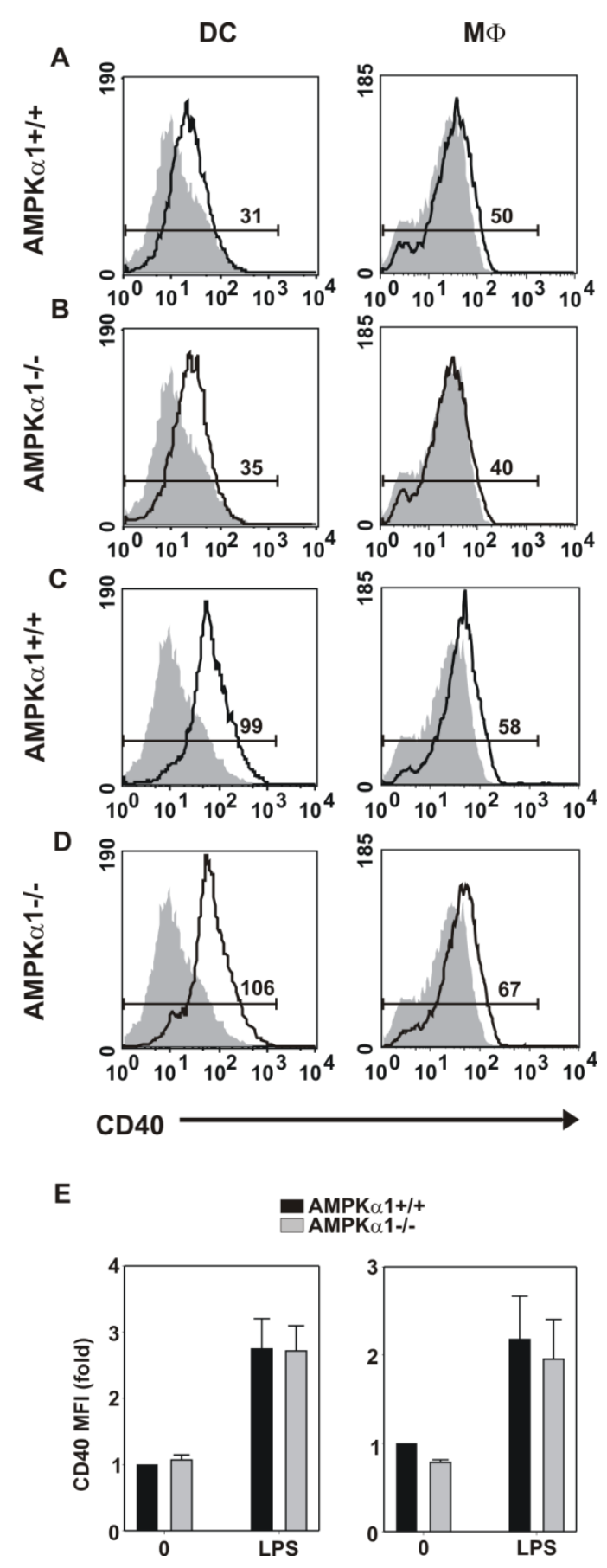

Figure 13. AMPKa1-deficiency does not alter APC CD40 expression. Surface expression of CD40 on AMPK $\alpha 1+/+$ and AMPK $\alpha 1-/-$ bone marrow-derived DCs and macrophages was analyzed via flow cytometry. CD40 expression of unstimulated cells 
$(A-B)$ and cells stimulated with LPS $(100 \mathrm{ng} / \mathrm{mL})$ for $18 \mathrm{~h}(C-D)$ was evaluated. Histograms show fluorescence of CD40 expression (black line) of CD11c+ (for DCs) or $\mathrm{CD} 1 \mathrm{~b}+$ (for macrophages) cells and unstained cells (solid grey peak). Mean

fluorescence intensity (MFI) of populations in brackets is stated numerically. Data shown in $A-D$ are representative of three independent experiments with similar results. Bar graphs $(E)$ describe fold change in MFI of CD40 compared to unstimulated wild-type cells and values are mean \pm SEM and are the combined results of three independent experiments. 

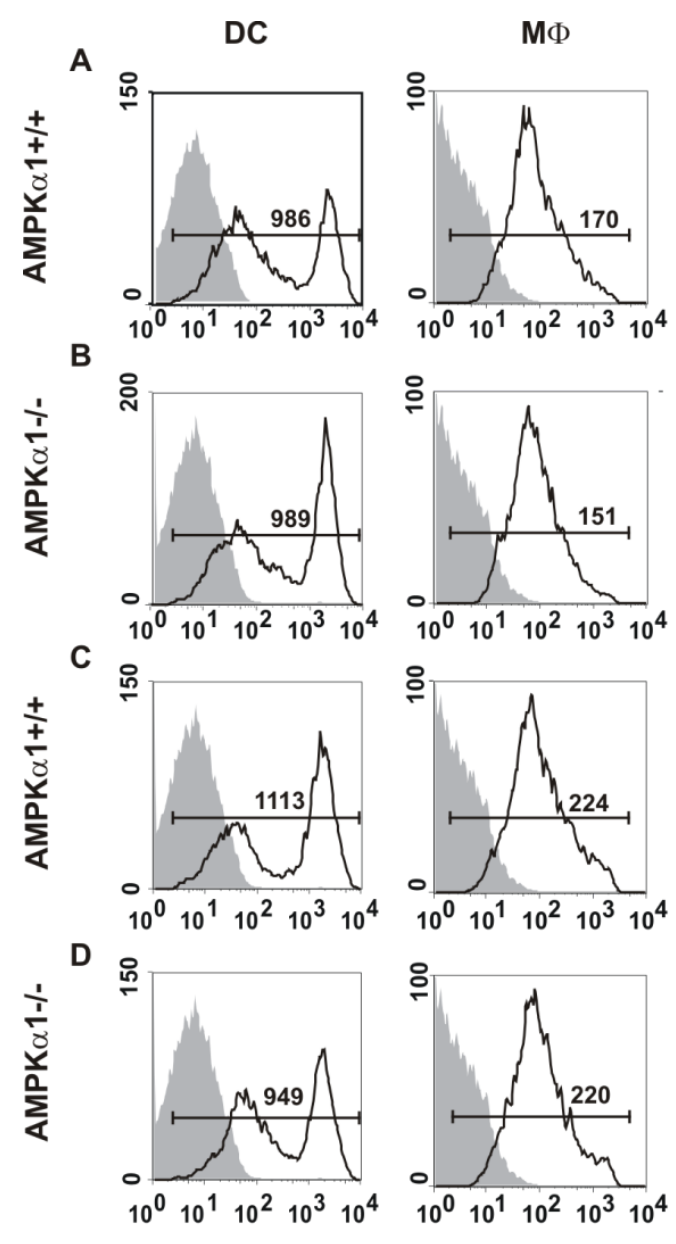

MHC II

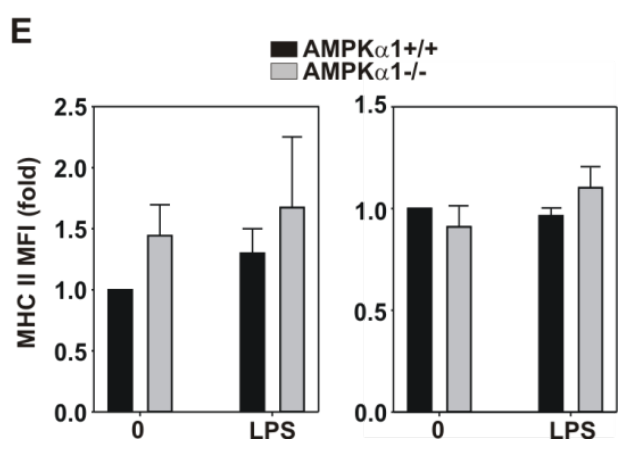

Figure 14. AMPKa1-deficient APC do not have altered expression of MHC II.

Surface expression of MHC II on AMPK $\alpha 1+/+$ and AMPK $\alpha 1-/-$ bone marrow-derived DCs and macrophages was analyzed via flow cytometry. MHC II expression of unstimulated cells $(A-B)$ and cells stimulated with LPS $(100 \mathrm{ng} / \mathrm{mL})$ for $18 \mathrm{~h}(C-D)$ was 
evaluated. Histograms show fluorescence of MHC II expression (black line) of CD11c+ (for DCs) or CD11b+ (for macrophages) cells and unstained cells (solid grey peak). Mean fluorescence intensity (MFI) of populations in brackets is stated numerically. Data shown in $A-D$ are representative of three independent experiments with similar results. Bar graphs $(E)$ describe fold change in MFI of MHC II compared to unstimulated wild-type cells and values are mean \pm SEM and are the combined results of three independent experiments. 

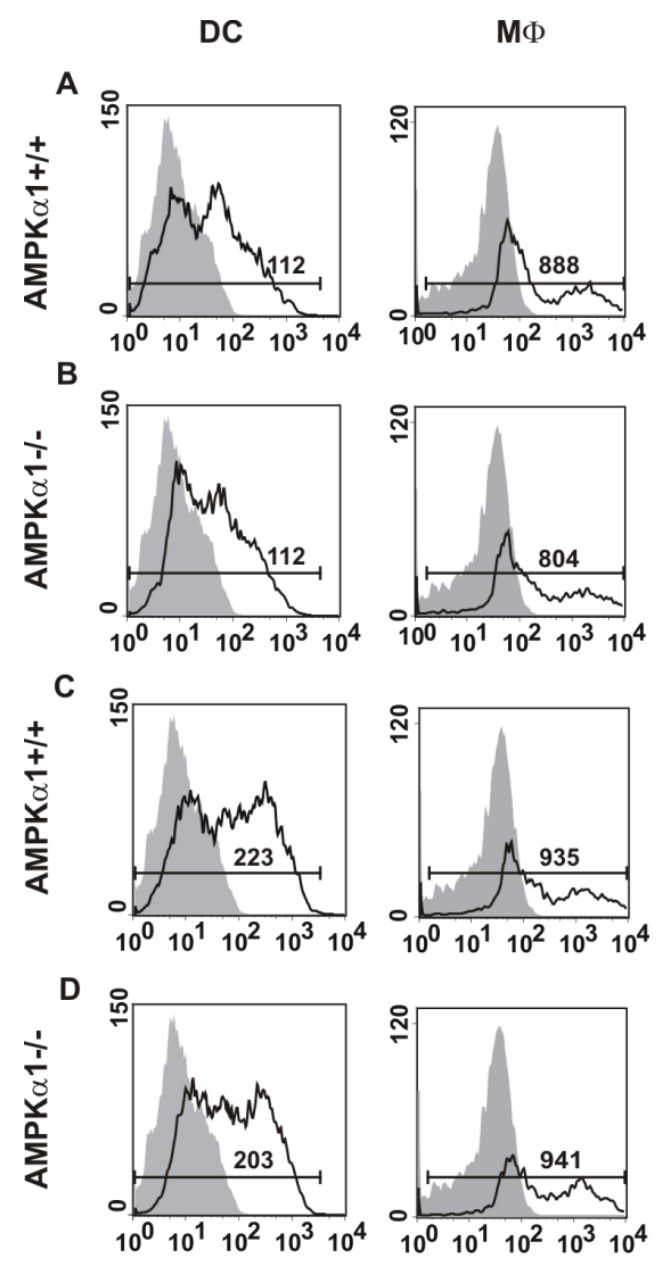

$$
\text { FITC }
$$

E

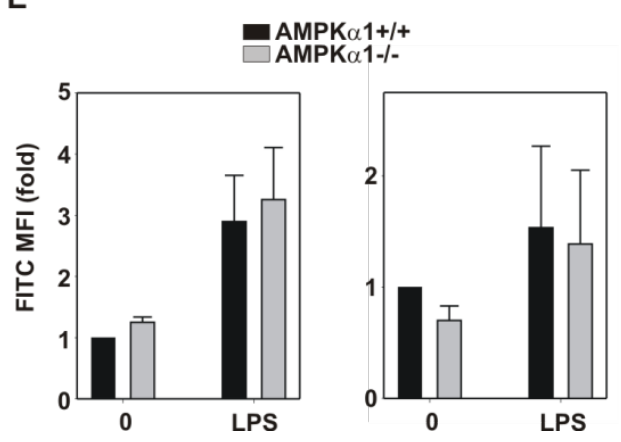

Figure 15. AMPKa1-deficiency does not alter APC phagocytosis of latex beads. AMPK $\alpha 1+/+$ and AMPK $\alpha 1-/-$ bone marrow-derived DC and macrophage phagocytosis of latex beads was analyzed via flow cytometry. FITC+ latex bead fluorescence of 
unstimulated cells $(A-B)$ and cells stimulated with LPS $(100 \mathrm{ng} / \mathrm{mL})$ for $18 \mathrm{~h}(C-D)$ was evaluated. Histograms show fluorescence of FITC expression (black line) of CD11c+ (for $\mathrm{DCs}$ ) or $\mathrm{CD} 11 \mathrm{~b}+$ (for macrophages) cells and unstained cells (solid grey peak). Mean fluorescence intensity (MFI) of populations in brackets is stated numerically. Data shown in $A$-D are representative of three independent experiments with similar results. Bar graphs $(E)$ describe fold change in MFI of FITC compared to unstimulated wild-type cells and values are mean \pm SEM and are the combined results of three independent experiments. 

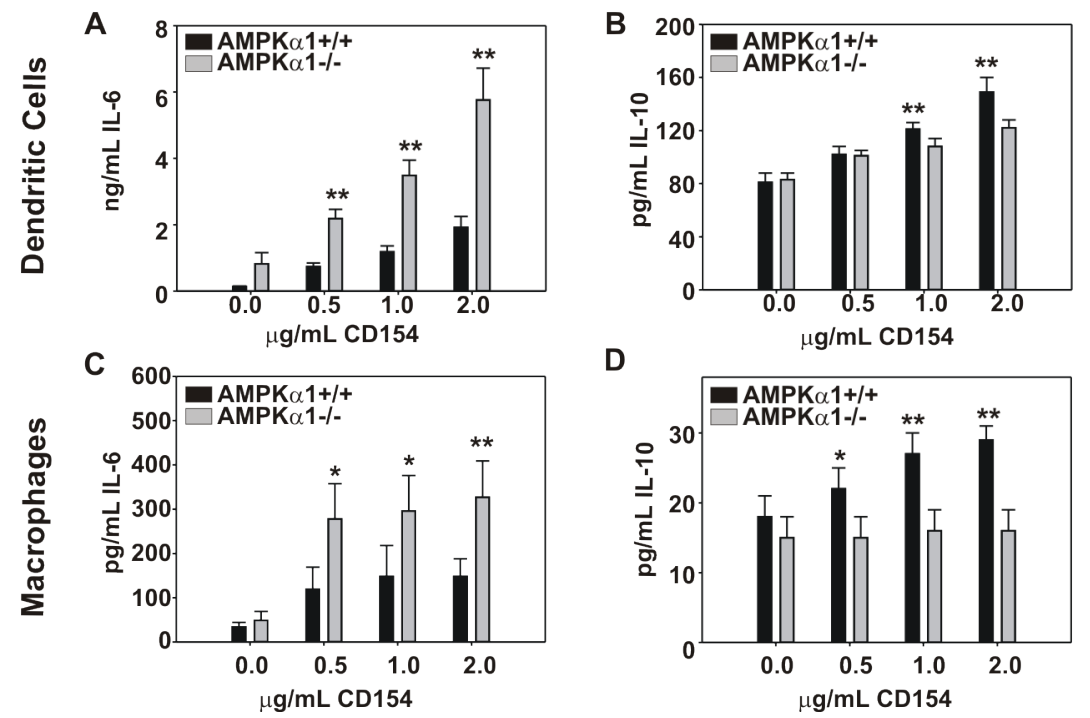

Figure 16. AMPKa1 regulates the inflammatory cytokine response of APC to

CD154 stimulation. Bone marrow-derived DCs $(A-B)$ and macrophages $(C-D)$ were generated from AMPK $\alpha 1-/-$ and AMPK $\alpha 1+/+$ mice and stimulated with CD154 at the concentrations shown for $18 \mathrm{~h}$ or left unstimulated. IL- 6 and IL-10 cytokine levels were detected by ELISA. Data shown are mean \pm SEM and are the combined results of three independent experiments $(*, \mathrm{p}<0.05 ; * *, \mathrm{p}<0.01)$. 
A

CD40L $\quad 0 \quad 10^{\prime} 30^{\prime}, 1 \mathrm{~h} \quad 3 \mathrm{~h} \quad 6 \mathrm{~h} \quad 18 \mathrm{~h}$

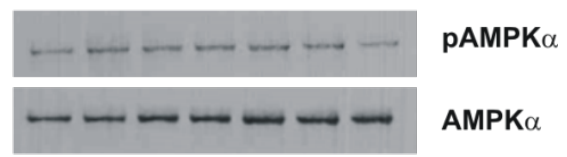

B

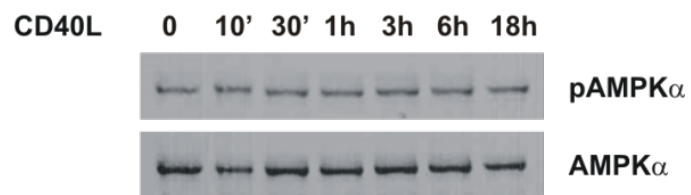

Figure 17. CD154 stimulation of DCs and macrophages has no effect on phosphorylation of AMPKa. Bone marrow-derived DCs $(A)$ and macrophages $(B)$ generated from AMPK $\alpha 1+/+$ mice were stimulated with $1.0 \mu \mathrm{g} / \mathrm{mL}$ CD40L for the timepoints indicated. After cell lysis, Western blot was performed using Abs against pAMPK (Thr172) and total AMPK. Data shown are representative of four independent experiments with similar results. 


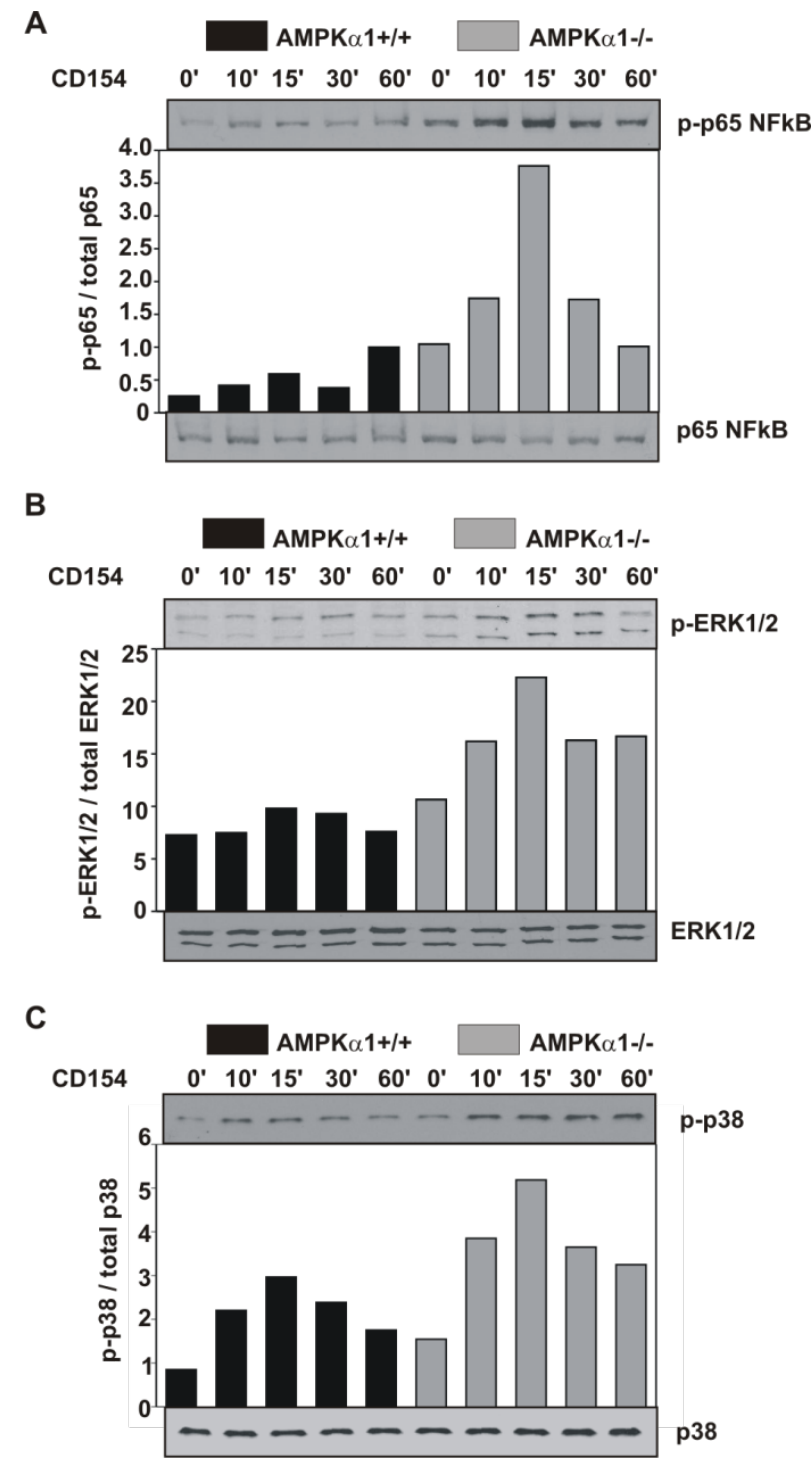

Figure 18. AMPKa1 expression modulates CD40-induced NF- $\mathrm{B}$, ERK1/2, and p38 signaling in DCs. Bone marrow-derived DCs were generated from AMPK $\alpha 1-/-$ and AMPK $\alpha 1+/+$ mice and stimulated with $1.0 \mu \mathrm{g} / \mathrm{mL}$ CD 154 for the time points indicated. After cell lysis, Western blot was performed using Abs against p-NF-кB p65 (Ser536) and total NF-אB p65 $(A)$, p-ERK1/2 (Thr202/Tyr204) and total ERK1/2 (B), and p-p38 MAPK (Thr180/Tyr182) and p38 MAPK (C). Bands were analyzed by densitometry and displayed as bar histograms. Data shown are representative of three $(B, C)$ and four $(A)$ independent experiments with similar results. 


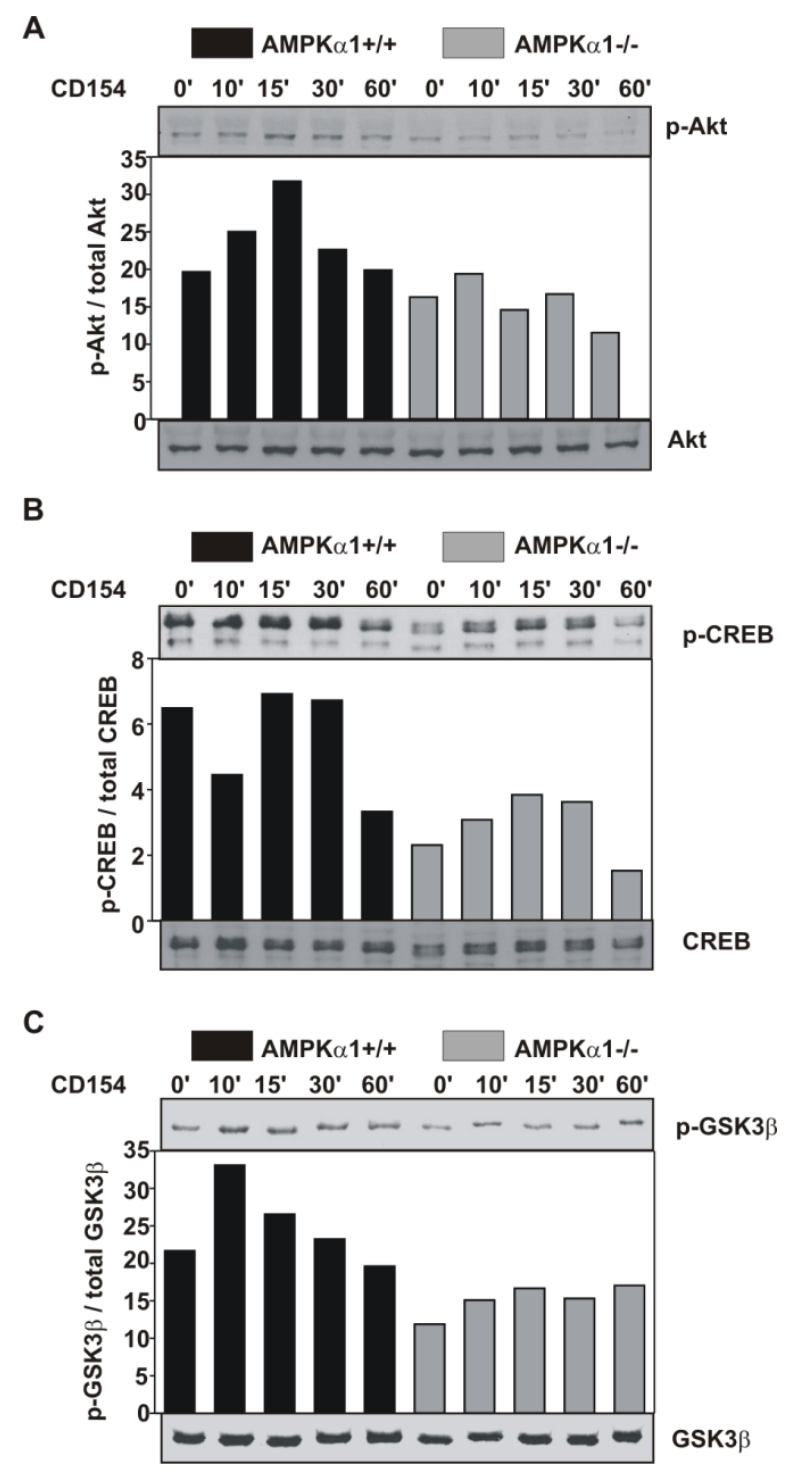

Figure 19. AMPKa1 expression modulates CD40-induced Akt- CREB- GSK3ß signaling in DCs. Bone marrow-derived DCs were generated from AMPK $\alpha 1-/-$ and AMPK $\alpha 1+/+$ mice and stimulated with $1.0 \mu \mathrm{g} / \mathrm{mL}$ CD154 for the time points indicated. After cell lysis, Western blot was performed using Abs against p-Akt (Ser473) and total $\operatorname{Akt}(A), \mathrm{p}-\operatorname{CREB}(\operatorname{Ser} 133)$ and total CREB $(B)$, and p-GSK3 $\beta$ (Ser9) and total GSK3 $\beta$ (C). Bands were analyzed by densitometry and displayed as bar histograms. Data shown are representative of three $(A, \mathrm{C})$ and four $(B)$ independent experiments with similar results. 


\section{DISCUSSION}

AMPK has been recognized recently as a counter-regulator of inflammatory pathways including those induced by TLR and IFN $\gamma$ stimulation $[96,106,163]$ and fatty acids $[107,108]$. Our previous work utilizing macrophage cell lines transfected with CA and DN forms of AMPK $\alpha 1$, as well as AMPK $\alpha 1$ siRNA knock down, revealed AMPK $\alpha 1$ 's role as a negative regulator of TLR-mediated inflammatory activity [106]. In this report, use of primary myeloid APC generated from AMPK $\alpha 1$-deficient mice confirms the function of AMPK $\alpha 1$ in the suppression of TLR-mediated induction of proinflammatory cytokine production and the enhancement of anti-inflammatory IL-10 production (Fig. 5) and establishes AMPKa1 as a regulator of APC activity and CD40 signal transduction (Figs. 18-19). These data suggest that the influence of AMPK activators on development of autoimmune disease in mice $[43,98]$ could be largely due to AMPK $\alpha 1$ 's regulatory role in the outcome of CD154:CD40 interactions during initial APC events as well as during T cell activation of myeloid cells at the sites of inflammation.

We investigated a number of downstream effectors of AMPK $\alpha 1$ to determine the mechanism by which AMPK $\alpha 1$ exerts its anti-inflammatory influence on CD40 signaling including the Akt-GSK3 $\beta$ pathway known to be suppressive of TLR-mediated inflammatory signaling $[170,171]$. Previous reports on the association of AMPK and Akt activation have shown mixed results, with some suggesting that AMPK activation is 
positively correlated with Akt activation and others reporting an association of AMPK activity with decreased Akt activity (reviewed in Ref. [169]). We have previously shown a positive association of AMPK $\alpha 1$ and Akt in macrophages stimulated with LPS [106]. Likewise, in the present study, AMPKa1-deficient DCs responded to CD154 stimulation with decreased Akt activity, enhanced GSK3 $\beta$ activity, and decreased CREB activation (Fig. $19 D-F)$.

Akt must be phosphorylated at two sites to become active: Thr308 by phosphoinositide-dependent kinase I (PDK1) $[172,173]$ and Ser473 by the mTOR complex (mTORC) 2 [174]. When cellular energy becomes low, AMPK phosphorylates and activates TSC2, an inhibitor of mTOR [67] and alternatively Akt can phosphorylate and inactivate TSC2, thereby activating mTORC1 $[175,176]$. mTORC1 regulates mRNA translation in part through phosphorylation and activation of S6K1 [177], which has been shown to phosphorylate and inactivate GSK3 $\beta$ [178]. This fits with our data showing that decreased AMPK activity is associated with decreased Akt phosphorylation (Ser473) and decreased phosphorylation (Ser9) of GSK3 $\beta$ in CD154-stimulated DCs (Fig. 19 A, C).

GSK3 $\beta$ is a negative regulator of the transcription factor CREB, and phosphorylation and inactivation of GSK3 $\beta$ enhances CREB activity [170,171]. It is thought that inhibition of GSK3 $\beta$ allows CREB to compete for the nuclear coactivator protein CREB-binding protein, which is required for NF- $\mathrm{KB}$ activity. This results in reduced NF- $\mathrm{KB}$ activation and enhanced expression of CREB-activated IL-10 synthesis [171]. Accordingly, we observe decreased CREB phosphorylation (Fig. 19B) and increased phosphorylation of p-65 NF-אB (Fig. 18A) in AMPKa1-deficient DCs stimulated with CD154. AMPKa1-deficient DCs and macrophages also have increased 


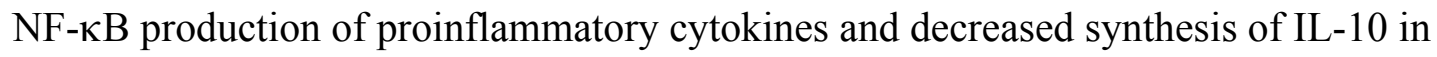
response to TLR- and CD154-stimulation (Fig. 5 and 16).

Our studies herein indicate that deficiency of AMPK has no effect on the phagocytosis of latex beads (Fig. 16). This result is in contrast to a previous report showing activation of AMPK via AICAR and metformin increases macrophage phagocytosis of apoptotic cells and bacteria [179]. As previously described, AICAR and metformin have AMPK-independent effects and thus it is possible the observed increase in phagocytic activity was independent of AMPK.

We also found that absence of AMPK in APC led to increased expression of CD80 and CD86 (Fig. 11-12). It has been previously reported that treatment of DCs with AICAR and LPS results in an AMPK $\alpha 1$-independent decrease in expression of CD80, CD86, CD40, and MHC II I-Ab [43]. Although AICAR has many AMPKa1-independent effects, our results demonstrate that AMPK $\alpha 1$ activity is involved in the regulation of CD80 and CD86 expression (Fig. 11-12). The increased presence of CD80 and CD86 costimulatory molecules in AMPK $\alpha 1$-deficient APC is associated with a robust induction of Th1 and Th17 responses (Fig. 6, 8-9).

In addition to AMPK $\alpha 1$ expression by APC, we demonstrate a role for T cellexpressed AMPK $\alpha 1$ in the development of Th immune responses (Fig. 8-9). Previous reports on the role of $\mathrm{AMPK}$ in $\mathrm{CD}^{+} \mathrm{T}$ cells show mixed results. One study implicated AMPK $\alpha 1$ in the regulation of inflammatory cytokine production by $\mathrm{CD} 8^{+} \mathrm{T}$ cells, but not $\mathrm{CD}^{+} \mathrm{T}$ cells [116]. A requirement for AMPK activity for Treg function has been reported [37]. It has also been shown that in vivo AICAR treatment in a murine model of EAU resulted in decreased $\mathrm{CD}^{+} \mathrm{Th} 1$ and $\mathrm{Th} 17 \mathrm{~T}$ cell responses [43]. Our results fit with 
the latter studies, wherein absence of AMPK $\alpha 1$ in $\mathrm{CD}^{+} \mathrm{T}$ cells leads to development of proinflammatory $\mathrm{T}$ cell responses (Figs. 11-12).

It is very important to note that in our studies of T-cell expressed AMPK $\alpha 1, \mathrm{~T}$ cells were isolated from $\mathrm{MOG}_{35-55}$-immunized total body AMPK $\alpha 1-/-$ mice and restimulated with AMPK $\alpha 1+/+$ and AMPK $\alpha 1-/-$ bone marrow-derived APCs pulsed with $\mathrm{MOG}^{35-55}$ peptide. Because the T cells were taken from total body AMPKa1-/- knockout mice, they may have been primed by AMPKa1-/- DCs before we isolated them from the spleen and utilized them in our recall assay. It is therefore difficult to determine from this experiment the extent to which T cell AMPKa1-deficiency led to higher production of proinflammatory cytokines compared to the potential effect of priming by an AMPK $\alpha 1-$ deficient APC.

Excessive proinflammatory $\mathrm{T}$ cell responses are associated with autoimmune disease, including rheumatoid arthritis, and therapeutic strategies include targeting factors that can dampen these $\mathrm{T}$ cell responses. Our results indicate that AMPK $\alpha 1$ is one such potential target, as AMPK $\alpha 1$ expression in APC leads to reduced IFN $\gamma$ and IL-17 T cell production in antigen presentation assays (Figs. 6, 8-9). Additionally, there are several therapeutic strategies that may benefit from inhibition of AMPK and activation of a proinflammatory DC response. Tolerogenic DCs are an obstacle to the success of DC vaccine immunotherapy and inhibition of AMPK may increase DC proinflammatory activity and result in a more effective vaccine. Although this has not yet been tested to our knowledge, AMPK inhibition in myeloid cells may lead to a greater immune response against pathogenic microbes, parasites, etc. Additionally, an immunosuppressive 
environment perpetuates cancer pathology and inhibition of AMPK $\alpha 1$ to activate a proinflammatory immune response may be a valuable anti-cancer therapeutic strategy. 


\section{CHAPTER 3}

\section{MACROPHAGE-EXPRESSED AMPKa1 REGULATES TUMOR GROWTH}

\section{INTRODUCTION}

More men and women die from cancer of the lung than that of any other tissue [180]. Nearly $80 \%$ of lung malignancies are non-small cell lung cancers (NSCLC), which have a grim prognosis. Only $15 \%$ of patients survive five years beyond diagnosis with NSCLC. It is widely accepted that chronic cigarette smoke is the largest contributor to lung cancer development, however it is not the only factor involved, as many chronic smokers do not develop cancer and, alternatively, lung cancer arises in nonsmokers, although rarely [181]. Being such a common and deadly disease, there is much interest in the development of new therapeutics for lung cancer.

Inflammatory processes have been shown to be highly involved in cancer development and progression. Chronic inflammation has been identified as a significant player in the development of many cancers and treatment with anti-inflammatory drugs has been shown to reduce cancer risk [182]. In conditions of chronic inflammation, it is evident that persistent recruitment of immune cells leads to higher production of reactive nitrogen and oxygen species, creates a mutagenic environment, and induces transformation of proximal epithelial cells. Additionally, chronic inflammation creates an 
environment rich in growth factors and cytokines that may induce premalignant cell proliferation and survival [183]. Many inflammatory pathways are suspected to contribute to lung cancer development. NF- $\mathrm{B}$ signaling, in particular, is thought to play a major role [184]. There is some degree of immune cell infiltration in all tumors, with some tumors displaying minimal infiltration and others much heavier [185]. Although some reports indicate that infiltrating immune cells can be involved in eradication of tumors, it is apparent that many infiltrating cells are supportive of tumor growth and metastasis [186]. TIMs, in particular, have been shown to be involved in tumorsupporting immune activities.

\section{TUMOR-INFILTRATING MACROPHAGES}

Monocytes are actively recruited to tumors from the bloodstream through the expression of various chemokines by malignant and stromal cells in tumors [186]. These include macrophage colony stimulating factor (M-CSF), MCP-1, CCL2, CCL3, CCL4, CCL5, CCL8, and VEGF [187]. VEGF is a major chemoattractant for monocytes and macrophages, and it is evident that more macrophages are found in VEGF-positive human breast carcinomas than those negative for VEGF [188, 189]. CXCL12 has also been shown to attract monocytes and macrophages to tumors, and has been linked to their recruitment to hypoxic areas of tumors [190].

The accumulation of macrophages and monocytes in tumors has been longassociated with poor prognosis in many cancers. Over $80 \%$ of studies published correlate a high density of TIMs with grim prognosis [191]. These include cancers of the breast, prostate, endometrium, bladder, kidney, and esophagus, along with squamous cell 
carcinoma and follicular lymphoma [186]. Alternatively, there are some cancers where high numbers of TIMs correlate with a favorable prognosis, including stomach, colorectal, and melanoma [186]. It was originally thought that infiltrating immune cells were involved in the generation of an anti-tumor response, and indeed, macrophages from healthy or inflamed tissues display an ability to lyse malignant cells, present tumor antigens, and produce proinflammatory cytokines stimulating anti-tumor T cell and NK cell activities [186]. Although macrophages are capable of generating anti-tumor immunity, those isolated from tumors both in human and animal models, do not display these activities. Instead, TIMs display an "alternative" functional phenotype associated with enhanced anti-inflammatory cytokine expression, promotion of angiogenesis, and poor antigen presentation capability [192]. In response to an immunosuppressive tumor microenvironment, TIMs are subverted by the tumor and have been shown to promote tumor angiogenesis, invasion, metastasis, and generalized immunosuppression in the tumor microenvironement $[120,186]$. Even within the tumor, macrophages display significant heterogeneity, and functional phenotypes are generally attributed to the discrete microenvironments of different areas of the tumor [120].

Macrophages are recruited to hypoxic and necrotic areas of the tumor and it is apparent that conditions there immobilize them, leading to significant accumulation of macrophages in these regions. TIMs near blood vessels are involved in tumor cell invasion and metastasis. TIMs produce a number of pro-angiogenic cytokines, such as TNF $\alpha$ and IL-8, growth factors like VEGF and basic fibroblast growth factor (bFGF), and enzymes including MMP-2, MMP-7, MMP-9, MMP-12, and COX-2 [193]. These 
angiogenic factors are likely responsible for the correlation observed between increased TIM accumulation and high vascular grade of many cancers $[194,195]$.

It has been demonstrated that macrophages assist tumor cell migration away from the main body of the tumor and extravasation into blood vessels [120]. The coordination of tumor cell and macrophage activities seems to be dependent upon EGF and CSF-1 signaling, respectively, as inhibition of either pathway blocks mobilization of both cell types [196, 197]. Macrophages induce tumor cell migration through expression of chemoattractants like EGF. In response to triggering of the EGFR, tumor cells secrete CSF-1, attracting macrophages and inducing them to secrete EGF [183]. An EGF/CSF-1 paracrine loop is thought to have a major role in metastasis, supported by clinical reports indicating CSF-1 expression in tumor cells and EGF expression in macrophages are both indicators of poor prognosis $[198,199]$. Studies of human breast and bone cancer have also indicated that CSF-1 expression is associated with increased metastasis [200].

In addition to coordination of tumor cell escape from the primary tumor, macrophages aid in the establishment of metastases at distant sites. In a breast cancer mouse model, systemic depletion of macrophages resulted in reduced lung metastasis [201]. It is also evident that alveolar macrophage and endothelial cell expression of MMP-9 and VEGF is necessary for the colonization and growth of tumor cells in the lung [202]. Studies indicating that macrophages at metastatic sites support tumor formation are supported by clinical evidence that high counts of macrophages in regional lymph node metastases are associated with decreased patient survival [203].

Macrophages have also been implicated in the establishment and maintenance of the immunosuppressive tumor microenvironment. Several reports indicate that tumor- 
derived cytokines, growth factors, proteases, and chemokines influence macrophage phenotype and function within the tumor [204-206]. Tumor-derived factors such as IL-4, IL-6, IL-10, and TGF $\beta$ inhibit cytotoxic activity of macrophages in the tumor [204, 207]. Several of these mediators have also been shown to reduce macrophage MHC II expression and are thought to inhibit presentation of tumor-associated antigens to $\mathrm{T}$ cells, and anti-tumor immunity [204]. TIMs display suppressed IL-12 production, a cytokine involved in NK and T cell cytotoxic responses [208]. Hypoxia within the tumor likely contributes to immunosuppressive macrophage activity, as it impairs the development of immune cells from their precursors and the anti-tumor functions of any immune cells that are formed [204, 209]. Additionally, hypoxia suppresses macrophage phagocytosis of dead and dying cells and expression of the costimulatory molecule CD80, further suppressing anti-tumor activities [204, 209, 210]. Generally, TIMs are strongly polarized towards anti-inflammation by tumor-derived factors and play a large role in the subversion of many kinds of anti-tumor immunity.

Peritumor and distal macrophages produce prostaglandin $\mathrm{E}_{2}, \mathrm{TGF} \beta$, and IL-10 [204] and are thought to spread immunosuppression from the site of the tumor and provoke systemic immune suppression. Macrophages in various tissues display an immunosuppressive phenotype regardless of the presence or absence of metastases [204, 211]. Although the mechanism by which the primary tumor induces immunosuppression in distal macrophages has not been elucidated, it has been shown that tumors release microvesicles expressing various ligands and cytokines. These microvesicles are suspected to not only generate an immunosuppressive functional phenotype in 
macrophages, but also downregulate NK cell activity, prevent maturation of myeloid DCs and the generation of anti-tumor $\mathrm{T}$ cell immune responses [212].

In addition to macrophages, immature myeloid cells called myeloid-derived suppressor cells (MDSC) accumulate in the tumor and play an important role in immunosuppression. In mice, MDSC are $\mathrm{Gr}^{+} \mathrm{CD} 11 \mathrm{~b}^{+}$and are subtyped as granulocytic MDSC (G-MDSC) characterized by a CD $11 b^{+} \mathrm{Gr} 1{ }^{\text {hi }} \mathrm{Ly} 6 \mathrm{G}^{+} \mathrm{Ly} 6 \mathrm{C}^{\text {low/med }} \mathrm{CD} 49 \mathrm{~d}-$ phenotype and monocytic MDSC (M-MDSC) characterized by a CD11 b $\mathrm{Gr}^{+}{ }^{\mathrm{mid}}$ Ly6GLy $6 \mathrm{C}^{\text {hi }} \mathrm{CD} 49 \mathrm{~d}^{+}$phenotype. It has been observed that tumor expansion of MDSC is mostly restricted to G-MDSC in the majority of tumor models [213]. MDSC suppress T cell responses through a variety of mechanisms, including production of reactive oxygen species [213]. MDSC also promote activation and expansion of Treg [214], downregulate macrophage IL-12 production [215], and induce antigen specific tolerance of $\mathrm{CD} 8^{+}$[216] and possibly $\left.\mathrm{CD}^{+}{ }^{+} 217\right] \mathrm{T}$ cell responses .

The strong immunosuppression established through MDSC and TIMs is a major obstacle in the development of cancer therapeutic strategies [218]. It has been shown that macrophages from healthy and inflamed tissues can generate potent anti-tumor responses, and remarkably, several reports have demonstrated that TIMs can be induced to display anti-tumor cytotoxic activities [219-223]. Studies indicate that increasing the presence of IL-12 [219, 223], induction of CD40 signaling [221, 222], and depletion of IL-10 [220] may be effective ways of altering immunosuppressive TIMs to generate cytotoxic activities. Reprogramming macrophages to reduce or eliminate their support for tumor angiogenesis, invasion, and metastasis and enhance their support for anti-tumor NK and T cell cytotoxic adaptive responses is a promising therapeutic strategy [120]. 
Previous studies from our lab [106] along with those described herein (Chapter 2) indicate that AMPK $\alpha 1$ is a counter-regulator of myeloid inflammatory activity. LPS and CD40 stimulation of AMPK $\alpha 1$-deficient macrophages results in increased proinflammatory cytokine production and decreased production of the anti-inflammatory cytokine IL-10 [Figs. 5 and 16 and Ref. [106]. Additionally, it is apparent that absence of AMPK $\alpha 1$ in both macrophages and DCs results in promotion of Th1 and Th17 responses (Figs. 6, 8-9) and increased expression of costimulatory molecules CD80 and CD86 (Figs. 11-12). Having demonstrated that absence of AMPK $\alpha 1$ results in a proinflammatory myeloid functional phenotype, we wanted to investigate the role of macrophage-expressed AMPK $\alpha 1$ on tumor-macrophage interactions and macrophage polarization in the tumor microenvironment. Herein, we utilize an AMPK $\alpha 1$ Cre-lox transgenic mouse model to determine the effect of myeloid-expressed AMPK $\alpha 1$ on LLC tumor growth and metastasis. We found that decreased AMPK $\alpha 1$ expression amplified TIM proinflammatory activity and resulted in decreased tumor growth and metastasis. 


\section{MATERIALS AND METHODS}

Mice. AMPK $\alpha 1$ flox/flox LysM-Cre+ (MacAMPK $\alpha 1$ KO) mice were generated through crossing LoxP AMPK $\alpha 1$ mice, provided by Benoit Viollet, with LysM-Cre mice (The Jackson Laboratory). AMPKalflox/flox LysM-Cre+ (MacAMPK $\alpha 1 \mathrm{KO})$ and AMPK $\alpha 1$ flox/- LysM-Cre- (WT) mice are bred and maintained at the University of Louisville Research Resources Facility. All animal care and experimental procedures used in this study were approved by the University of Louisville's Institutional Animal Care and Use Committee.

Tumor model. LLC tumor tissues were generated as previously described [224] and provided by Dr. Chi-Ping Day at the National Cancer Institute (Bethesda, Maryland). Tumor tissues were thawed, gently dissociated with a scalpel, and cultured in vitro to produce a viable cell line. Tumors were then maintained by in vivo passage with limited intermittent culture in vitro. Tumor cells $\left(2 \times 10^{5}\right)$ were injected subcutaneously into the right flank of MacAMPK $\alpha 1 \mathrm{KO}$ and WT mice. Five to seven mice were used in each group. Tumors were measured every 2-3 days with calipers at two bisecting diameters and an approximate volume was calculated by the formula (long side $\mathrm{x}$ short $\operatorname{side}^{2}$ ) $\mathrm{x} 6 / \pi$. Mice were sacrificed after 18 days.

To prepare single cell suspensions, resected tumors were digested using a tumor dissociation kit (Miltenyi Biotec) and MACS tissue dissociator (Miltenyi Biotec). The resulting cell suspensions were filtered through $70 \mu \mathrm{m}$ cell strainers (BD Biosciences) and 
washed with 5\% FBS in RMPI 1640. Tumor-infiltrating CD11 $\mathrm{b}^{+}$cells were isolated by positive selection with anti-CD11b (Mac-1) magnetic beads (Miltenyi Biotec). A purity of $>95 \% \mathrm{CD} 11 \mathrm{~b}^{+}$cells was confirmed by flow cytometry.

Flow Cytometric Analysis. Single cell suspensions were stained with fluorescently conjucated antibodies against murine CD4, CD8, CD19, CD11c, CD11b, F4/80, and NK1.1 (all from BD Biosciences) for 30 minutes at $4^{\circ} \mathrm{C}$, washed, and analyzed using a FACSCalibur flow cytometer and FlowJo software (Tree Star Inc.). A sample of 10,000 cells was isolated from each tumor and the number of positively stained cells in the sample was determined and expressed as a percentage. The calculated percentage was multiplied by the total number of tumor cells to determine the number of positively stained cells in the tumor.

Quantitative Real-time RT-PCR analysis. mRNA was isolated from $10^{6}$ purified TIMs and converted to cDNA using MACS One-Step cDNA Columns (Miltenyi Biotec). Real-time RT-PCR was performed with a DNA-Opticon 3 Monitor (Bio-Rad) using SYBR Green (Qiagen). IL-6, TNF $\alpha$, IL-23, and MMP-12 expression was analyzed by Quantitect Primer Assays (Qiagen). Results were normalized to $\beta$-actin. Relative expression of RNA transcripts was quantified using the Relative Expression Software Tool, REST.

Western blot analysis. $10^{6}$ macrophages were lysed in buffer containing $125 \mathrm{mM}$ Tris (pH 6.8), 2\% SDS, 20\% glycerol, $200 \mathrm{uM} \mathrm{PMSF,} \mathrm{protease} \mathrm{inhibitor} \mathrm{mixture}$ (Promega), and phosphatase inhibitor mixture (ThermoFisher Scientific). Total protein content of the samples was assessed by BCA protein assay (ThermoFisher Scientific). Equal amounts of protein were separated on $10 \%$ Criterion gels (Bio-Rad) by SDS- 
PAGE. Proteins were transferred to nitrocellulose membranes using the Trans-blot Turbo Transfer System (Bio-Rad). Ab-bound proteins were detected using an ECL Western blotting analysis system (GE Healthcare), and the membranes were exposed to UltraCruz 5x7 Autoradiography Film (Santa Cruz Biotechnology). Densitometric analysis was performed using UN-SCAN-IT gel analysis software (Silk Scientific).

Statistical Analysis. Statistical significance between groups was evaluated as indicated by unpaired $t$ test or two way analysis of variance (ANOVA) followed by Bonferroni multiple comparison test using Graphpad Prism software (Graphpad, La Jolla, $\mathrm{CA}$ ), and a level of $\mathrm{p}<0.05$ was considered statistically significant. 


\section{RESULTS}

\section{Deficiency of myeloid cell-expressed AMPKa1 results in decreased rate of tumor growth and metastasis.}

To determine the role of myeloid cell-expressed AMPK $\alpha 1$ in tumor growth, we utilized an AMPKa1 Cre-lox transgenic mouse model. Previous studies demonstrated the predominant expression of LysM in the myeloid lineage [225], and AMPK $\alpha 1$ flox/flox LysM-Cre+ (MacAMPKa1 KO) mice have myeloid-specific deficiency in AMPK $\alpha 1$. MacAMPK $\alpha 1 \mathrm{KO}$ and WT mice were subcutaneously injected in the flank with LLC tumor cells. Caliper measurements of tumor volume (Fig. 20) indicated that MacAMPK $\alpha 1 \mathrm{KO}$ mice had reduced tumor growth compared to WT mice through 18 days post-injection. Tumors harvested at day 18 from MacAMPK $\alpha 1 \mathrm{KO}$ mice weighed less than those from WT mice (Fig. 21). We also wanted to evaluate the role of myeloid cell-expressed AMPK $\alpha 1$ on lung metastasis. MacAMPK $\alpha 1$ KO mice had a lower number of lung metastases (Fig. 22).

As decreases in body weight can indicate muscle wasting and severe illness, we periodically weighed mice throughout the experiment. Both MacAMPK $\alpha 1 \mathrm{KO}$ 
and WT mice maintained weight throughout the course of tumor growth, indicating that tumor burden did not result in muscle wasting (Fig. 23).

\section{MacAMPKa1 KO mice have increased $\mathrm{CD}^{+}{ }^{+}$and decreased $\mathrm{CD8}^{+}$immune cell infiltration of primary tumors}

It has been well-established that immune cells infiltrate tumors, including macrophages, natural killer $(\mathrm{NK})$ cells, $\mathrm{CD}^{+}$and $\mathrm{CD}^{+} \mathrm{T}$ cells, B cells, and DCs. We wanted to determine the degree of infiltration of various immune cells into primary tumors of MacAMPK $\alpha 1 \mathrm{KO}$ and WT mice. We evaluated immune cell infiltration as a percentage of a sample of 10,000 tumor cells (Fig. 24A) and the number of infiltrating immune cells in the total tumor (Fig. 24B).

The percentage of infiltrating cells expressing $\mathrm{CD} 19^{+}$, a B cell marker, was significantly increased in tumors from MacAMPK $\alpha 1 \mathrm{KO}$ mice compared to WT (Fig. $24 A$ ). The number of infiltrating $\mathrm{CD} 19^{+} \mathrm{B}$ cells in the tumor was also increased in tumors from MacAMPKa1 KO mice compared to WT, but the difference was not significant (Fig. 24B). Additionally, the number of infiltrating $\mathrm{CD}^{+} \mathrm{T}$ cells was significantly decreased in tumors from MacAMPK $\alpha 1 \mathrm{KO}$ mice, compared to those from WT mice (Fig. 24B). The percentage of $\mathrm{CD}^{+} \mathrm{T}$ cells in tumors from MacAMPK $\alpha 1 \mathrm{KO}$ mice was decreased compared to tumors from WT mice, but the difference was not significant (Fig. 24A). Expression of NK cell (Ly6G/NK1.1), $\mathrm{CD}^{+}{ }^{+}$T cell, macrophage (F4/80/CD11b), and DC (CD11c) markers of single cell suspensions from MacAMPK 11 KO primary tumors was similar to those from WT tumors (Fig. 24), indicating that deficiency of 
AMPK $\alpha 1$ in myeloid cells does not impact the infiltration of these immune cell populations in the tumor.

\section{TIMs from MacAMPKa1 KO mice have increased expression of proinflammatory mediators}

The immunosuppressive tumor microenvironment has been associated with increased tumor growth and invasion, and macrophages drive this pathology [120]. As deficiency in AMPK $\alpha 1$ has been shown to lead to proinflammatory activity in macrophages [106, 107, 163], we wanted to characterize TIMs in tumors of MacAMPK $\alpha 1$ KO mice. We first verfied that TIMs isolated from MacAMPK $\alpha 1$ KO mice had dramatically reduced expression of phosphorylated and total AMPK compared to control mice (Fig. 25).

TIMs isolated from MacAMPK $\alpha 1 \mathrm{KO}$ mice had higher mRNA expression of proinflammatory cytokines IL-6, TNFa, and IL-23 compared to WT mice (Fig. 26). Additionally, MacAMPK $\alpha 1$ KO mice had significantly higher expression of MMP-12 mRNA (Fig. 26) and MMP-9 protein (Fig. 27), indicating that TIMs from MacAMPK $\alpha 1$ KO mice have higher expression of proinflammatory mediators.

We considered a number of downstream targets of AMPK $\alpha 1$ as possible mediators of the anti-inflammatory activity we observed. As we had previously observed an association of AMPK activity and decreased phosphorylation of p65 NF- $\mathrm{KB}$ (Fig. 18), we evaluated TIM NF-אB activation through phosphorylation of p65. As shown in Fig. 28, p65 phosphorylation was significantly higher in TIMs from MacAMPK $\alpha 1$ KO mice compared to those from WT mice. Additionally, TIMs from MacAMPK $\alpha 1 \mathrm{KO}$ mice had 
significantly decreased expression of p-Akt (Fig. 29A) and p-CREB (Fig. 29B). These data demonstrate that TIMs isolated from MacAMPK $\alpha 1 \mathrm{KO}$ mice have higher proinflammatory activity compared to those isolated from WT mice, a factor that may contribute to the reduced tumor growth (Figs. 20-21) and lung metastasis (Fig. 22) observed in MacAMPK $\alpha 1$ KO mice. 


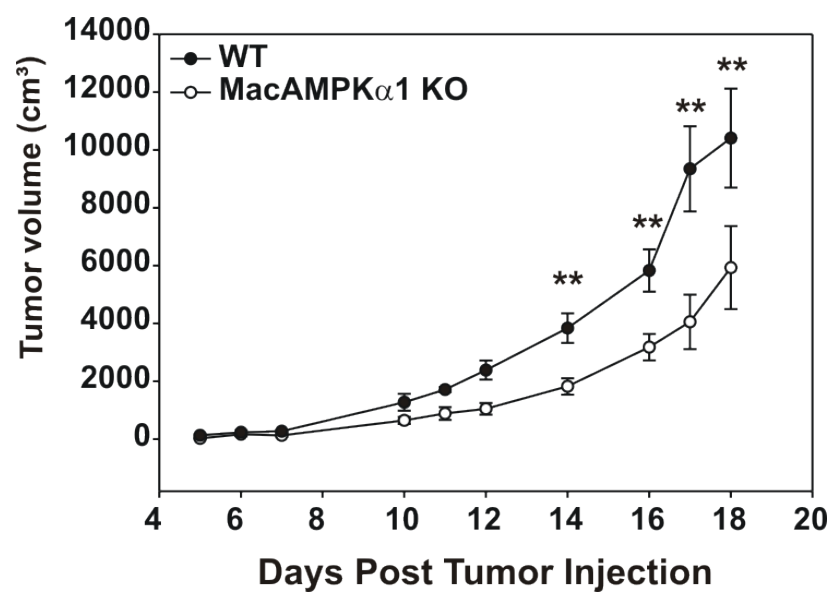

Figure 20. MacAMPKa1 KO mice have decreased rate of LLC tumor growth.

MacAMPK $\alpha 1 \mathrm{KO}$ and WT mice were injected subcutaneously with LLC tumor cells $(2 \mathrm{x}$ $10^{5}$ ) and growth was measured every 2-3 days for 18 days using caliper measurements.

Tumor volume was calculated using the formula (long side $\mathrm{x}$ short $\operatorname{side}^{2}$ ) $\mathrm{x} 6 / \pi$. Data are mean $\pm \mathrm{SEM}$ of results combined from two independent experiments, with 5-7 mice per group in each experiment $(* *, p<0.01)$. 


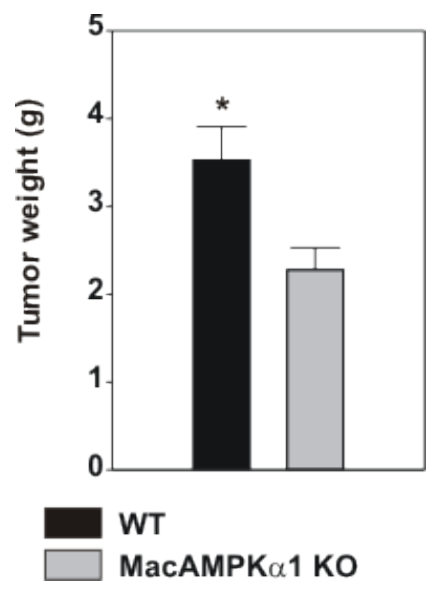

Figure 21. Tumors harvested from MacAMPKa1 KO mice weigh less than those from WT mice. MacAMPK $\alpha 1 \mathrm{KO}$ and WT mice were injected subcutaneously with LLC tumor cells $\left(2 \times 10^{5}\right)$ and tumors were harvested 18 days later and weighed. Data are mean $\pm \mathrm{SEM}$ of results combined from two independent experiments, with 5-7 mice per group in each experiment $(*, p<0.05)$. 
A

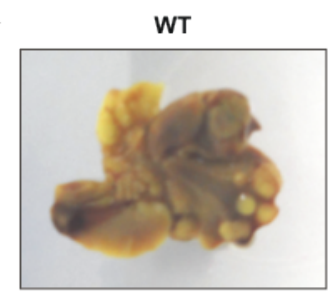

B

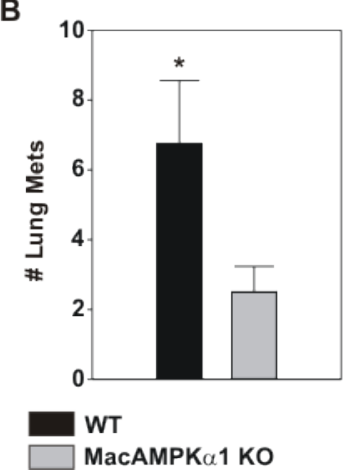

MacAMPK $\alpha 1$ Ko

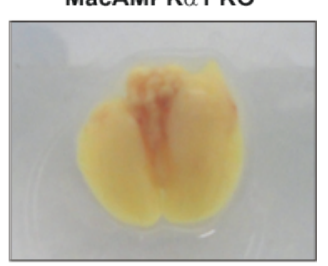

. 
A

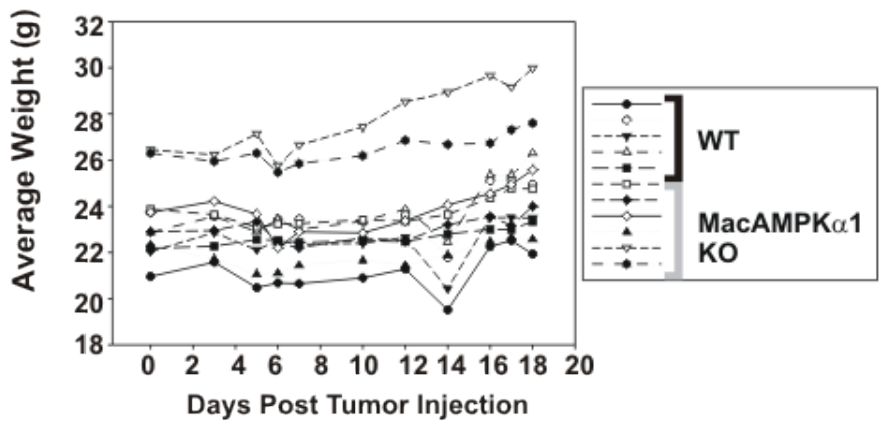

B

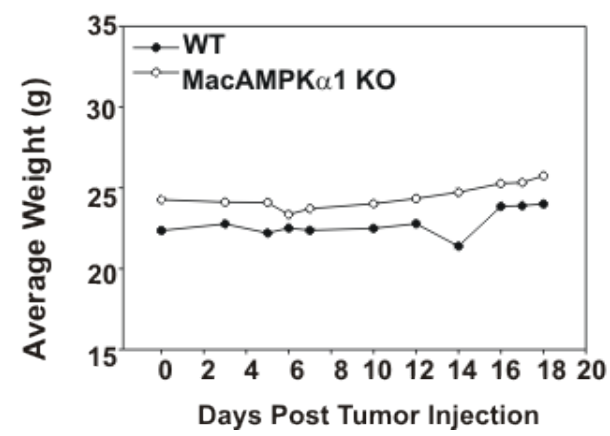

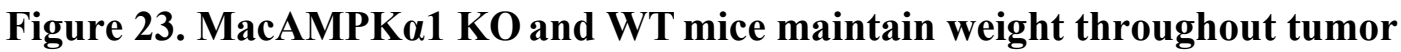
growth and metastasis. All mice were injected subcutaneously with LLC tumor cells (2 $\mathrm{x} 10^{5}$ ) on day 0 and the weight of each mouse was taken every 2-3 days until day $18(A)$. Average weights of each strain were calculated over time $(B)$. Data are representative of three separate experiments with similar results and five to seven mice in each group. 
A

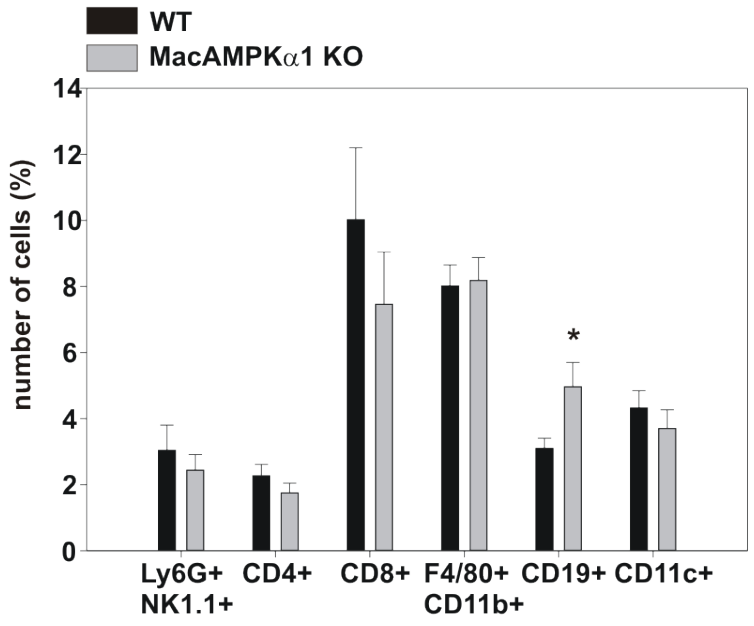

B

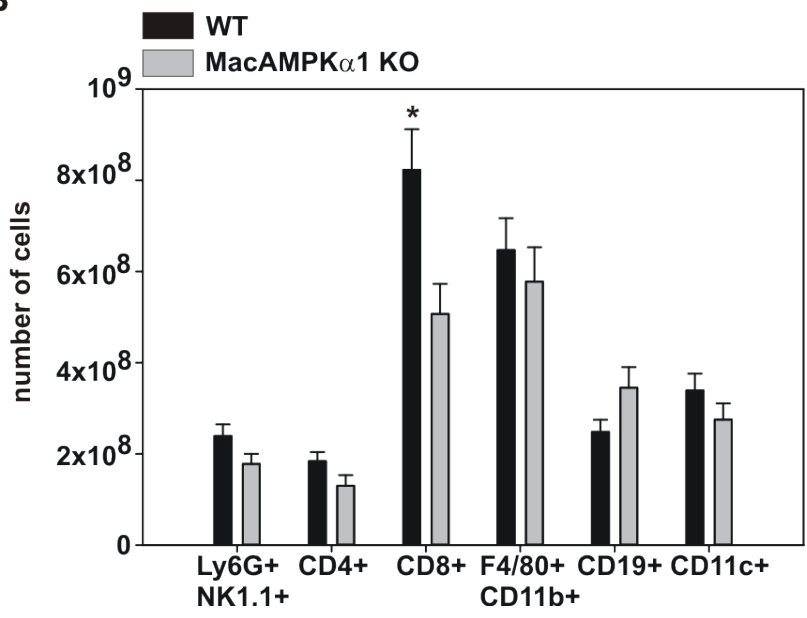

Figure 24. MacAMPKa1 KO mice have increased $\mathrm{CD19}^{+}$and decreased $\mathrm{CD8}^{+}$ immune cell infiltration of primary tumors. Single cell suspensions of primary tumors isolated from MacAMPKa1 KO and WT mice were generated and expression of various immune cell markers was evaluated via flow cytometry. The number of positively stained cells in a sample of 10,000 tumor cells was determined and is expressed as a percentage $(A)$. The number of positively stained cells in the total tumor was determined and is expressed as cell number $(B)$. Data are expressed as mean \pm SEM and are the combined results of two independent experiments with 5-7 mice per group $\left(^{*}, \mathrm{p}<0.05\right)$. 


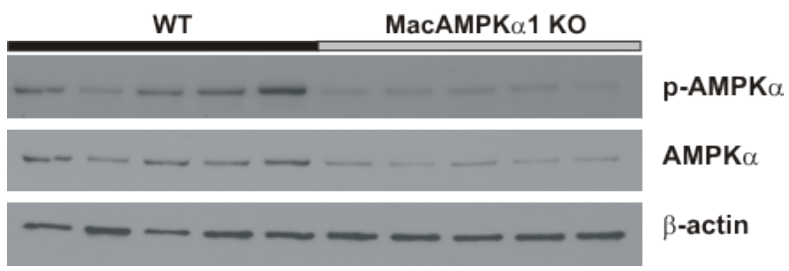

Figure 25. TIMs isolated from MacAMPKa1 KO mice have decreased expression of AMPKa. TIMs were isolated from primary tumors of MacAMPK $\alpha 1 \mathrm{KO}$ and WT mice. After cell lysis, Western blot was performed using Abs against p-AMPKa (Thr172), total AMPK $\alpha$, and $\beta$-actin. Data shown are representative of two experiments of five mice per group, and each band is protein expression from one mouse. 


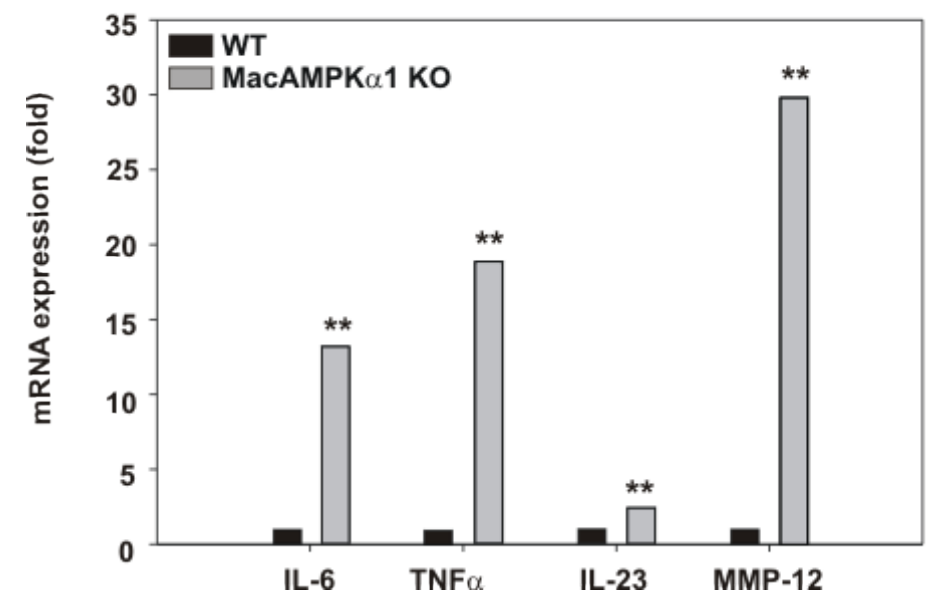

Figure 26. TIMs isolated from MacAMPKa1 KO mice have higher expression of proinflammatory cytokines and MMP-12 than WT mice. TIMs were isolated from primary tumor cell suspensions and mRNA expression was evaluated via RT-PCR and is expressed as fold difference compared to TIMs isolated from WT mice. Data expressed are from individual mice and are representative of two experiments with similar results and five or mice in each group $(* *, p<0.01)$. 

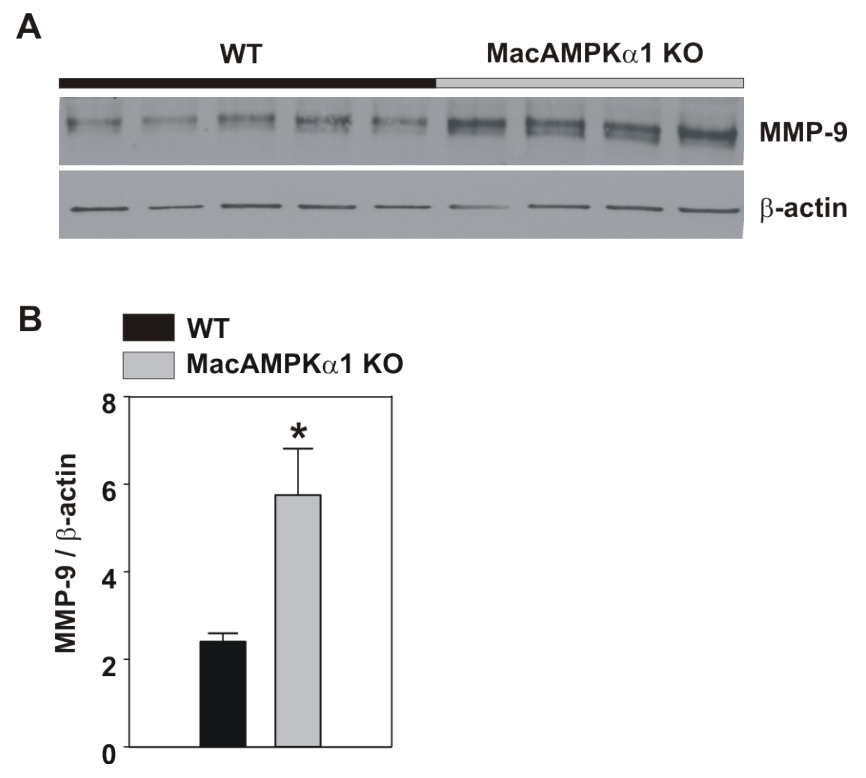

Figure 27. TIMs isolated from MacAMPKa1 KO mice have increased MMP-9 expression. TIMs were isolated from primary tumors of MacAMPK $\alpha 1 \mathrm{KO}$ and WT mice. After cell lysis, Western blot was performed using Abs against MMP-9 and $\beta$-actin. Each band is TIM protein expression from one mouse $(A)$. Densitometric analysis was performed and the average MMP-9 / $\beta$-actin protein expression for MacAMPK $\alpha 1$ and WT TIMs was determined $(B)$. Data shown are representative of two experiments of four to five mice per group $(*, p<0.05)$. 

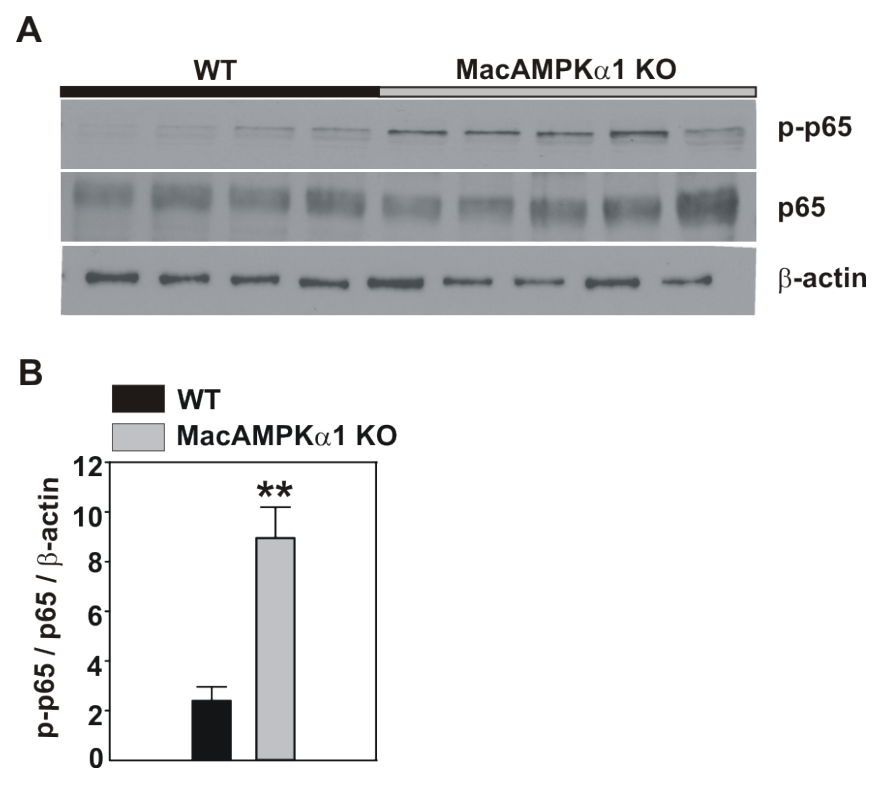

Figure 28. TIMs isolated from MacAMPKa1 KO mice have increased phosphorylation of NF-kB p65. TIMs were isolated from primary tumors of MacAMPKa1 KO and WT mice. After cell lysis, Western blot was performed using Abs

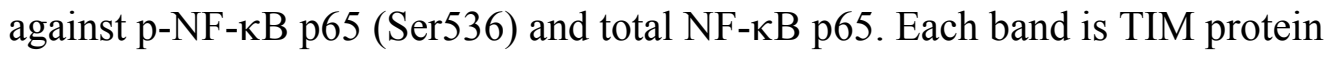
expression from one mouse $(A)$. Densitometric analysis was performed and the average p-p65 / p65 / $\beta$-actin protein expression for MacAMPK $\alpha 1$ and WT TIMs was determined (B). Data shown are representative of two experiments of four to five mice per group (**, $\mathrm{p}<0.01)$ 
A

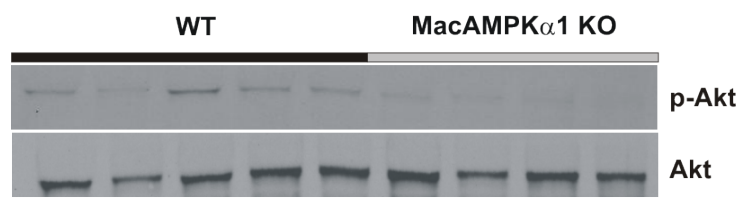

B
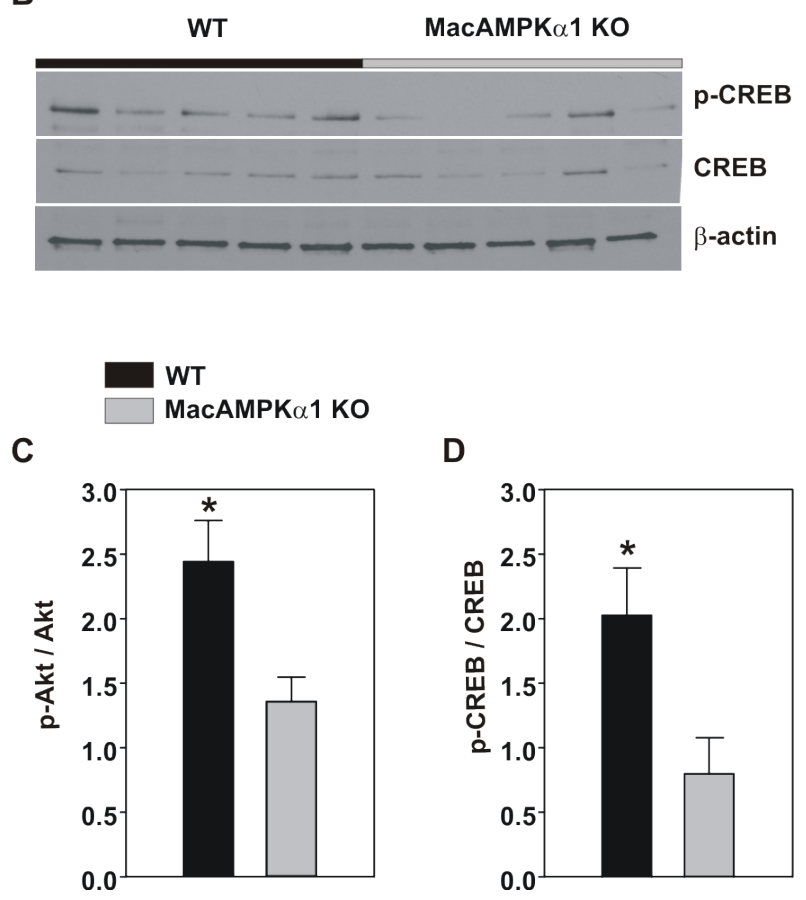

Figure 29. TIMs isolated from MacAMPKa1 KO mice have decreased

phosphorylation of Akt and CREB. TIMs were isolated from primary tumors of MacAMPK $\alpha 1 \mathrm{KO}$ and WT mice. After cell lysis, Western blot was performed using Abs against p-Akt (Ser473) and total Akt $(A)$, p-CREB (Ser133) and total CREB $(B)$, and $\beta$ actin. Each band is TIM protein expression from one mouse $(A-B)$. Densitometric analysis was performed and the average p-Akt / Akt $(C)$ and p-CREB / CREB $(D)$ protein expression for MacAMPK $\alpha 1$ and WT TIMs was determined. Data shown are representative of two experiments of four to five mice per group $\left(^{*}, \mathrm{p}<0.05\right)$. 


\section{DISCUSSION}

Macrophages display remarkable plasticity and can exhibit a number of functional phenotypes [120, 226]. TIMs are often found in high number in tumors [227] and usually indicate a poor prognosis [191]. TIMs often exhibit an anti-inflammatory, pro-tumor phenotype that is shaped by mediators found within the tumor microenvironment and TIMs are considered a major obstacle to the development of cancer therapeutics [120]. Despite the significant effects of macrophage polarization on tumor biology, the molecular and transcriptional mediators that control the pro-tumor phenotype of TIMs remain largely unknown.

Activation of AMPK has been a therapeutic strategy for the treatment of cancer for some time. Interest in AMPK activation for tumor therapy began with the discovery that LKB1, a known tumor suppressor, is an upstream kinase required for AMPK activation [20]. AMPK activation for cancer therapy is supported by the observation that diabetic patients treated with metformin have a decreased lifetime cancer risk [83]. Studies in tumor mouse models utilizing AICAR and metformin have shown an association of AMPK activation and decreased tumor growth [81, 84, 85]. It has been reported that AMPK activation is not beneficial in all cancers, however, including some oncogene-driven melanomas [228] and prostate cancers [89, 90], suggesting that the role of AMPK in cancer development is more complicated than originally thought. Very little is known about the contribution of immune cell-expressed AMPK $\alpha 1$ to tumor growth and 
metastasis. Our studies herein demonstrate that AMPK $\alpha 1$ activity in myeloid cells contributes to the anti-inflammatory phenotype of TIMs and is associated with increased tumor growth. We are not aware of any other study evaluating the role of AMPK $\alpha 1$ in TIM promotion of tumor growth.

Mice deficient in myeloid-expressed AMPK $\alpha 1$ had significantly decreased tumor growth from days 14-18 post tumor injection (Fig. 20) and TIMs isolated from these mice displayed significantly higher proinflammatory cytokine mRNA compared to control mice (Fig. 26). In many cancers, TIMs exhibit deficient expression of NF- $\mathrm{kB}$ leading to impaired iNOS expression and nitric oxide production [229, 230]. Additionally, it has been observed that TIMs have very high nuclear localization of the NF-kB inhibitory p50 homodimer [231] and defective NF- $\mathrm{KB}$ activation in response to LPS and TNF $\alpha$ stimulation [232]. We observed drastically higher NF-kB p65 activity in TIMs isolated from MacAMPK $\alpha 1$ KO mice (Fig. 28), indicating that AMPK $\alpha 1$ inhibition alters TIM gene transcription. Additionally, AMPKa1-deficient TIMs displayed decreased activation of Akt and CREB (Fig. 29). These data fit with our previous observations that AMPK $\alpha 1$ activation is positively correlated with activation of Akt and increased phosphorylation of CREB (Fig. 19, [106]). Enhanced CREB activity allows CREB to compete for the nuclear coactivator CREB-binding protein and leads to reduced activation of NF-kB.

Our studies of LLC tumor growth address tumor growth until 18 days postinjection, when mice were sacrificed. We did not measure tumor growth beyond 18 days, and thus it is possible that tumors in MacAMPK $\alpha 1 \mathrm{KO}$ mice had delayed growth, and may eventually catch up to the tumor growth observed in WT mice. Additionally, we did 
not complete survival studies and it is unknown if MacAMPK $\alpha 1 \mathrm{KO}$ mice have increased survival associated with LLC tumor growth compared to WT.

Mice with AMPK $\alpha 1$-deficient macrophages had reduced lung metastasis compared to control mice (Fig. 22). Macrophages are important in the development of lung metastasis, and have been shown to condition pre-metastatic tissue for the seeding of metastatic cancer cells [120]. In some tumor models, infiltrating myeloid cells form clusters in pre-metastatic tissue, forming what has been termed a "pre-metastatic niche" $[233,234]$. Our studies show that deficiency of macrophage-expressed AMPK $\alpha 1$ results in decreased lung metastasis. However, the functional phenotype of AMPK $\alpha 1$-deficient macrophages in the lung is unknown. Furthermore, the role of macrophage-expressed AMPKal on formation of the pre-metastatic niche still needs to be investigated.

Our studies indicate no difference in immune cell infiltration of NK, $\mathrm{CD} 4^{+}, \mathrm{CD}^{+}$, macrophages, and CD11 ${ }^{+}$cells in tumors from MacAMPK $\alpha 1 \mathrm{KO}$ and WT mice (Fig. 24). Our results did indicate that there was higher infiltration of $\mathrm{CD}_{1} 9^{+}$cells in tumors of mice deficient of myeloid AMPKa1. Studies suggest that B cells can contribute to the immunosuppressive phenotype exhibited by TIMs $[235,236]$. B1 cells have been shown to polarize peritoneal macrophages to an anti-inflammatory phenotype via IL-10 expression [235]. Additionally, B cells have been shown to foster angiogenic and protumor TIM activities through FcR $\gamma$-mediated activation [236]. Much is still unknown regarding the roles of various B cell populations on determination of TIM phenotype. Additionally, how deficiency of myeloid-AMPK $\alpha 1$ leads to enhanced B cell recruitment to the tumor still needs to be investigated. One possible explanation is that the tumor recruits B cells in an attempt to establish a pro-tumor immunosuppressive environment 
and combat the higher pro-inflammatory phenotype exhibited by AMPK $\alpha 1$-deficient TIMs.

Functional studies are also required to determine if AMPK $\alpha 1$ activity in TIMs affects the role of B cells in the tumor, as well as the roles of other infiltrating immune subsets. It is unknown if TIM-expressed AMPK $\alpha 1$ regulates infiltration of Th subsets and Treg, which are known to foster the immunosuppressive environment in tumors [237]. We observed increased $\mathrm{CD}^{+} \mathrm{T}$ cell infiltration in WT tumors compared to MacAMPK $\alpha 1$ KO tumors (Fig. 24) and it is unknown how AMPK $\alpha 1$ TIM expression contributes to this accumulation and how these cells are functionally contributing to tumor growth.

It is important to note that because our TIM isolation included positive selection of $\mathrm{CD} 11 \mathrm{~b}^{+}$tumor-infiltrating cells, we expect to have tumor-infiltrating MDSC in our “TIM" population. As we saw increased proinflammatory activity in tumor-infiltrating $\mathrm{CD}_{1} 1 \mathrm{~b}^{+}$cells, our studies suggest that MDSC may have a more proinflammatory phenotype in MacAMPK $\alpha 1 \mathrm{KO}$ tumors. A more specific isolation is needed in order to distinguish the MDSC functional phenotype from that of CD11 ${ }^{+}$TIMs in MacAMPK $\alpha 1$ KO tumors compared to WT tumors. Additionally, MDSC have a critical role in the establishment of the immunosuppressive tumor microenvironment and future studies will address the effect of myeloid-AMPK $\alpha 1$ deficiency on recruitment of MDSC to the tumor and their functional phenotype within the tumor.

The immunosuppressive tumor microenvironment is considered a major obstacle to the success of cancer therapies. Herein, we demonstrate that AMPK $\alpha 1$ depletion in TIMs critically affects their anti-inflammatory phenotype and their efficiency in promoting LLC tumor growth. Our results indicate the therapeutic potential of AMPK $\alpha 1$ 
inhibition as a way to curtail the pro-tumor functions of TIMs and reduce tumor progression. Furthermore, these data suggest that efforts to treat cancer through activation of AMPK $\alpha 1$ may detrimentally contribute to TIM immunosuppressive phenotype and tumor growth.

AMPK activation has been associated with both reduced risk of cancer development and tumor regression [1]. Many AMPK activators, including metformin [83], green tea [239], and resveratrol [240] have been shown to reduce cancer risk. The association of AMPK activation with reduced risk of specific cancers in various populations is still being investigated. It has been shown that metformin leads to reduced risk of breast cancer in female diabetic patients [241]. Chronic inflammation has been associated with increased cancer incidence, and it is possible that AMPK is inhibiting cancer development through decreasing inflammation [1]. Activation of AMPK has been shown to also reduce tumor growth, an effect attributed to AMPK inhibition of anabolic signaling pathways responsible for cell growth [88]. In conditions of limited energy supply, as is often in the tumor microenvironment, AMPK is activated and inhibits mTOR activity [67, 242] and lipid synthesis [243, 244], leading to decreased cancer cell growth. In addition to AMPK's role in the metabolism of cancer cells, it also likely has an important role in the regulation of metabolism and inflammation of other cells present in the tumor. Our results herein demonstrate that AMPK $\alpha 1$ activity in macrophages contributes to TIM anti-inflammatory activity and tumor growth. These results suggest that AMPK $\alpha 1$ 's role in the tumor may be complicated, and that its activation may enhance pro-tumor activities in some cells and anti-tumor activities in others. Perhaps this is not surprising, as the cellular metabolism of transformed cells may be different 
than infiltrating immune cells and, accordingly, AMPK regulation of inflammatory and metabolic pathways may result in differential regulation of these cell types.

It is likely that AMPK plays different roles in the stages of tumor development and progression, reflecting the complicated nature of the relationship between metabolism, inflammation, and cancer. AMPK activation may be beneficial in the prevention of cancer pathologies associated with chronic inflammation, while in later stages of cancer progression, it may detrimentally contribute to TIM anti-inflammatory activity and LLC tumor growth. AMPK inhibition in TIMS may be a valuable therapeutic strategy to overcome the strong immunosuppression these cells generate. The use of nanoparticle technology may be of potential use to inhibit AMPK in macrophages, specifically through utilization of the mannose receptor for macrophage specificity and an AMPK inhibitor, such as compound C. Much remains to be investigated, but our studies demonstrate that it will important to consider the effect of AMPKal activation in TIMs when developing cancer therapies. 


\section{CONCLUSIONS AND FUTURE PERSPECTIVES}

DCs and macrophages are heterogeneous cells that are involved in both protective and pathological immune responses. Understanding the mechanisms that govern their behavior is critical to the understanding and development of effective therapies to treat many diseases, including autoimmunity and cancer. AMPK has been recognized recently as a counter-regulator of inflammatory pathways including those induced by TLR and IFN $\gamma$ stimulation $[96,106,163]$ and fatty acids $[107,108]$. Through studies on macrophage cell lines expressing CA and DN forms of AMPK $\alpha 1$, our lab previously reported that AMPKa1 inhibits TLR-mediated inflammatory activity [106]. Herein, we have used AMPK $\alpha 1$-deficient primary cells to evaluate the role of AMPK $\alpha 1$ in APC-T cell interactions. Our studies show that deficiency of AMPK $\alpha 1$ results in enhanced APC inflammatory activity in response to LPS and CD154 stimulation (Fig. 5 and Fig. 16) and contributes to the development of proinflammatory Th1 and Th17 responses (Fig 8-10). Additionally, we evaluated the role of myeloid cell-expressed AMPK $\alpha 1$ in TIM antiinflammatory activity and its contribution to tumor growth. We demonstrate that inhibition of AMPK $\alpha 1$ in TIMs enhances their proinflammatory activity (Fig. 26-29) and results in decreased tumor growth and lung metastasis (Fig. 20-22). Together, our studies of $\mathrm{AMPK} \alpha 1$ in antigen presentation and on $\mathrm{AMPK} \alpha 1$ in tumor-macrophage interactions demonstrate that AMPK is a potent counter-regulator of myeloid inflammatory activity 
and its activation induces changes in many aspects of myeloid function. These changes are mediated through differential regulation of NF- $\mathrm{KB}$ and Akt - GSK3 $\beta$ - CREB pathways.

Our results demonstrate a counter-regulatory role for AMPK $\alpha 1$ in the regulation of myeloid cell and $\mathrm{T}$ cell proinflammatory activity. Much is still unknown regarding the role of AMPK $\alpha 1$ in the regulation of immunity. AMPK $\alpha 1$ may have regulatory roles regarding the inflammatory activity of other immune cells in addition to macrophages and $\mathrm{T}$ cells, and this still needs to be investigated. Additionally, a recent report showed that AMPK $\beta 1$ leads to an $85 \%$ reduction in AMPK activity and counter-regulates macrophage proinflammatory activity and insulin resistance [108]. Much is still unknown regarding the role of AMPK $\beta 1$ in the regulation of macrophage inflammation and the role of AMPK $\beta 1$ in antigen presentation activities still needs to be investigated.

Our studies and others have identified AMPK $\alpha 1$ is a counter-regulator of macrophage and DC inflammatory activity and both activation and inhibition of AMPK may be valuable therapeutic strategies for inflammatory diseases (Fig. 30). Excessive Th1 and Th17 responses are associated with autoimmune disease and research strategies include identifying targets that can attenuate these $\mathrm{T}$ cell responses. Our results indicate that AMPK $\alpha 1$ is one such potential target, as AMPK $\alpha 1$ expression in both APC and T cells leads to reduced IFN $\gamma$ and IL-17 T cell production in antigen presentation assays (Figs. 6, 8-9, 30). Indeed, it has been shown that AMPK activation ameliorates experimental mouse models of autoimmunity, including EAE [98] and EAU [43]. Chronic inflammation has been long associated with increased risk for several cancers, including lung, and activation of AMPK may reduce systemic inflammation and risk for 
these cancers (Fig. 30). Importantly, the effectiveness of AMPK activation on the prevention of cancer development may be dependent on the type of cancer and the timing of treatment or stage of cancer development. There are several readily available pharmacological and dietary activators of AMPK, as discussed in Chapter 1.

The therapeutic use of inhibitors of AMPK $\alpha 1$ activity also may be worthwhile, as there are many diseases where an immunosuppressive environment perpetuates pathology, such as cancer (Fig. 30). Our studies on TIMs from MacAMPK $\alpha 1$ KO mice indicate that in cancer, inhibition of AMPK $\alpha 1$ activates a proinflammatory immune response in TIMs that leads to reduced tumor growth. Inhibition of AMPK $\alpha 1$ in TIMs may be a valuable therapeutic strategy to combat immunosuppressive TIMs that contribute to tumor growth (Fig. 30). Inhibition of AMPK $\alpha 1$ in DCs may also be a valuble strategy to combat the tolerogenic phenotype known to be an obstacle to DC vaccine immunotherapy. It is also possible that inhibition of AMPK $\alpha 1$ may also lead to a more potent anti-microbial and/or anti-parasite immune response, although this has not been tested (Fig. 30).

This study is the first to identify AMPK $\alpha 1$ as a mediator of TIM antiinflammatory activity. TIMs isolated from MacAMPK $\alpha 1 \mathrm{KO}$ mice had increased phosphorylation of p65 NF-kB (Fig. 28) and expressed higher levels of IL-6 and TNF $\alpha$ mRNA (Fig. 26). Higher expression of proinflammatory markers in TIMs was associated with decreased tumor growth. TIMs have a critical role in the development of the immunosuppressive, pro-tumor environment and identifying mediators of TIM antiinflammatory activity, such as AMPK, is critical for the development of cancer immunotherapies. Additionally, the extent of myeloid AMPK $\alpha 1$ 's influence on the pro- 
and anti-tumor functions of other immune cell populations within the tumor, including cytotoxic T cells, Treg, and MDSC still needs to be investigated. It is unknown if AMPK $\alpha 1$ also plays a counter-regulatory role in the inflammatory activity of tumor infiltrating T cells. Our laboratory has mice deficient in CD4 cell-expressed AMPK $\alpha 1$ that could be utilized to determine the role of $\mathrm{AMPK} \alpha 1$ in $\mathrm{CD}^{+}$cells in tumor growth and metastasis.

The anti-inflammatory effect of AMPK on leukocyte behavior has been associated with the involvement of AMPK in cellular metabolism. Recent reports suggest that AMPK represses the metabolic switch from oxidative phosphorylation to glycolysis that occurs when cells become inflammatory. As described in two recent reviews from the lab of Graham Hardie [93, 245], resting and naïve immune cells generally use oxidative phosphorylation to generate ATP and when stimulated with proinflammatory stimuli (cytokines, TLRs, antigen presentation), switch to aerobic glycolysis for generation of ATP [94-96]. It has been observed that treatment with a glycolytic inhibitor causes proinflammatory Th17 cells to exhibit qualities more like anti-inflammatory Tregs, suggesting that metabolic cues are involved in the regulation of the glycolytic switch [94]. It is thought that increased rates of glycolysis provide a swift, yet inefficient, source of energy for the cell to become more inflammatory. AMPK activation through AICAR antagonizes the LPS-induced switch to glycolysis in DCs [96]. Additionally, T cells isolated from AMPK $\alpha 1-/-$ mice display elevated levels of glycolysis [116]. AMPK inhibits protein synthesis through TORC1 $[67,68]$, and it has been proposed that AMPK mediates the glycolytic switch through repressing expression of the transcription factor hypoxia-inducible factor-1 $\alpha$ (HIF $1 \alpha)$ through TORC1 inhibition [245]. HIF1 $\alpha$ expression 
drives the production of glycolytic enzymes and its inhibition could then repress the glycolytic switch [245].

Our findings regarding AMPKal's role in regulation of myeloid inflammatory activity raise many questions regarding the role of AMPK $\alpha 1$ in regulation of the glycolytic switch. AMPK $\alpha 1$ antagonizes CD154-induced proinflammatory signaling and cytokine production and it is unknown if $\mathrm{CD} 154$ stimulation is associated with a transition from oxidative to glycolytic metabolism. Additionally, AMPK $\alpha 1$ 's ability to suppress the switch to glycolysis in response to CD154 still needs to be investigated. Our studies show that AMPK $\alpha 1$ regulates the anti-inflammatory activity in TIMs and it is unknown if AMPK $\alpha 1$ represses glycolytic activity in TIMs and thereby contributes to their anti-inflammatory phenotype. The metabolic switch to glycolysis was first observed in proliferating cancer cells and was termed the 'Warburg effect,' and the potential ability of AMPK $\alpha 1$ to induce an anti-Warburg effect in cancer is one argument for using AMPK activators to treat cancer patients [245].

As we learn more about the metabolic profile of tumor-infiltrating immune cell subsets, it will be important to consider the impact AMPK $\alpha 1$ activation may have on their inflammatory phenotype and role in the tumor microenvironment. It is also important to consider that aside from its regulatory role in cell metabolism, AMPK $\alpha 1$ activity modulates numerous signaling pathways that influence cell behavior and gene transcription. Given its clear role in the regulation of both metabolism and inflammation, AMPK $\alpha 1$ has great potential as a target for the treatment of many diseases. 

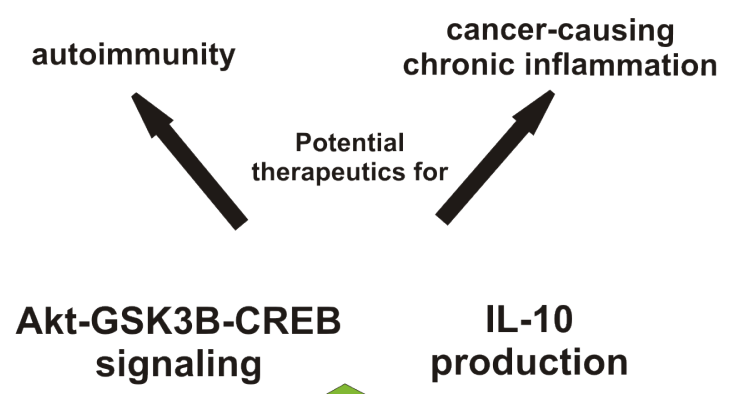

signaling production

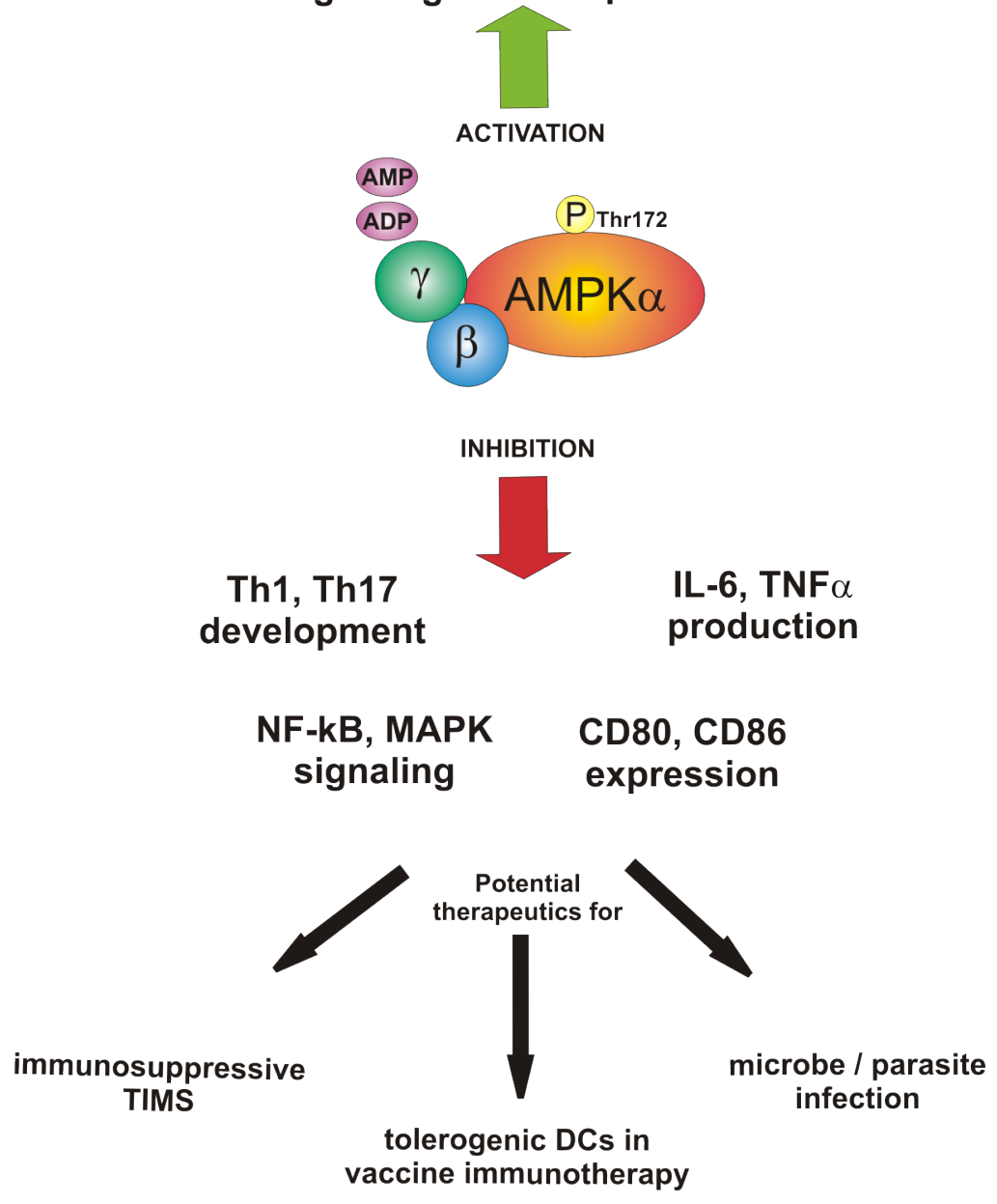

Figure 30. Both activation and inhibition of myeloid AMPKa1 may be useful

therapeutic strategies. Activation of AMPK $\alpha 1$ in myeloid cells leads to decreased proinflammatory activity including increased Akt - GSK3 $\beta$ - CREB signaling and IL-10 production. AMPK $\alpha 1$ activation may be a useful therapeutic strategy for the treatment of diseases exacerbated by inflammation, such as autoimmune disease cancer-causing 
chronic inflammation. Inhibition of AMPKal activity in myeloid cells leads to increased proinflammatory activity including increased Th1 and Th17 T cell responses, NF-kB and MAPK signaling, costimulatory molecule expression, and IL-6 and TNF- $\alpha$ cytokine production. AMPKa1 inhibition may be a useful therapeutic strategy to increase the inflammatory activity of immunosuppressive TIMs and tolerogenic DC in vaccine immunotherapy. Additionally, AMPK $\alpha 1$ inhibition may lead to a more potent antimicrobial and anti-parasite immune response. 


\section{REFERENCES}

1. Carling, D., Thornton, C., Woods, A., Sanders, M. J. (2012) AMP-activated protein kinase: new regulation, new roles? Biochem J. 445, 11-27.

2. Hardie, D. G. and Carling, D. (1997) The AMP-activated protein kinase--fuel gauge of the mammalian cell? Eur J Biochem. 246, 259-73.

3. Carlson, C. A. and Kim, K. H. (1974) Regulation of hepatic acetyl coenzyme A carboxylase by phosphorylation and dephosphorylation. Arch Biochem Biophys. $164,478-89$.

4. Beg, Z. H., Allmann, D. W., Gibson, D. M. (1973) Modulation of 3-hydroxy-3methylglutaryl coenzyme A reductase activity with cAMP and wth protein fractions of rat liver cytosol. Biochem Biophys Res Commun. 54, 1362-9.

5. Carling, D., Zammit, V. A., Hardie, D. G. (1987) A common bicyclic protein kinase cascade inactivates the regulatory enzymes of fatty acid and cholesterol biosynthesis. FEBS Lett. 223, 217-22.

6. Munday, M. R., Campbell, D. G., Carling, D., Hardie, D. G. (1988) Identification by amino acid sequencing of three major regulatory phosphorylation sites on rat acetyl-CoA carboxylase. Eur J Biochem. 175, 331-8.

7. Carling, D., Aguan, K., Woods, A., Verhoeven, A. J., Beri, R. K., Brennan, C. H., Sidebottom, C., Davison, M. D., Scott, J. (1994) Mammalian AMP-activated protein kinase is homologous to yeast and plant protein kinases involved in the regulation of carbon metabolism. J Biol Chem. 269, 11442-8.

8. Mitchelhill, K. I., Stapleton, D., Gao, G., House, C., Michell, B., Katsis, F., Witters, L. A., Kemp, B. E. (1994) Mammalian AMP-activated protein kinase shares structural and functional homology with the catalytic domain of yeast Snf1 protein kinase. J Biol Chem. 269, 2361-4.

9. Steinberg, G. R. and Kemp, B. E. (2009) AMPK in Health and Disease. Physiol Rev. 89, 1025-78.

10. Woods, A., Salt, I., Scott, J., Hardie, D. G., Carling, D. (1996) The alpha1 and alpha2 isoforms of the AMP-activated protein kinase have similar activities in rat liver but exhibit differences in substrate specificity in vitro. FEBS Lett. 397, 34751. 
11. Scott, J. W., Hawley, S. A., Green, K. A., Anis, M., Stewart, G., Scullion, G. A., Norman, D. G., Hardie, D. G. (2004) CBS domains form energy-sensing modules whose binding of adenosine ligands is disrupted by disease mutations. J Clin Invest. 113, 274-84.

12. Xiao, B., Heath, R., Saiu, P., Leiper, F. C., Leone, P., Jing, C., Walker, P. A., Haire, L., Eccleston, J. F., Davis, C. T., Martin, S. R., Carling, D., Gamblin, S. J. (2007) Structural basis for AMP binding to mammalian AMP-activated protein kinase. Nature. 449, 496-500. Epub 2007 Sep 12.

13. Hardie, D. G. (2011) AMP-activated protein kinase: a cellular energy sensor with a key role in metabolic disorders and in cancer. Biochem Soc Trans. 39, 1-13.

14. Corton, J. M., Gillespie, J. G., Hawley, S. A., Hardie, D. G. (1995) 5aminoimidazole-4-carboxamide ribonucleoside. A specific method for activating AMP-activated protein kinase in intact cells? Eur J Biochem. 229, 558-65.

15. Cheung, P. C., Salt, I. P., Davies, S. P., Hardie, D. G., Carling, D. (2000) Characterization of AMP-activated protein kinase gamma-subunit isoforms and their role in AMP binding. Biochem J. 346, 659-69.

16. Hawley, S. A., Davison, M., Woods, A., Davies, S. P., Beri, R. K., Carling, D., Hardie, D. G. (1996) Characterization of the AMP-activated protein kinase kinase from rat liver and identification of threonine 172 as the major site at which it phosphorylates AMP-activated protein kinase. J Biol Chem. 271, 27879-87.

17. Mihaylova, M. M. and Shaw, R. J. (2011) The AMPK signalling pathway coordinates cell growth, autophagy and metabolism. Nat Cell Biol. 13, 1016-23. doi: $10.1038 / \mathrm{ncb} 2329$.

18. Oakhill, J. S., Chen, Z. P., Scott, J. W., Steel, R., Castelli, L. A., Ling, N., Macaulay, S. L., Kemp, B. E. (2010) beta-Subunit myristoylation is the gatekeeper for initiating metabolic stress sensing by AMP-activated protein kinase (AMPK). Proc Natl Acad Sci U S A. 107, 19237-41. Epub 2010 Oct 25.

19. Woods, A., Johnstone, S. R., Dickerson, K., Leiper, F. C., Fryer, L. G., Neumann, D., Schlattner, U., Wallimann, T., Carlson, M., Carling, D. (2003) LKB1 is the upstream kinase in the AMP-activated protein kinase cascade. Curr Biol. 13, 2004-8.

20. Hawley, S. A., Boudeau, J., Reid, J. L., Mustard, K. J., Udd, L., Makela, T. P., Alessi, D. R., Hardie, D. G. (2003) Complexes between the LKB1 tumor suppressor, STRAD alpha/beta and MO25 alpha/beta are upstream kinases in the AMP-activated protein kinase cascade. J Biol 2, 28. Epub 2003 Sep 24.

21. Shaw, R. J., Kosmatka, M., Bardeesy, N., Hurley, R. L., Witters, L. A., DePinho, R. A., Cantley, L. C. (2004) The tumor suppressor LKB1 kinase directly activates 
AMP-activated kinase and regulates apoptosis in response to energy stress. Proc Natl Acad Sci U S A. 101, 3329-35. Epub 2004 Feb 25.

22. Alessi, D. R., Sakamoto, K., Bayascas, J. R. (2006) LKB1-dependent signaling pathways. Annu Rev Biochem 75, 137-63.

23. Hawley, S. A., Pan, D. A., Mustard, K. J., Ross, L., Bain, J., Edelman, A. M., Frenguelli, B. G., Hardie, D. G. (2005) Calmodulin-dependent protein kinase kinase-beta is an alternative upstream kinase for AMP-activated protein kinase. Cell Metab. 2, 9-19.

24. Woods, A., Dickerson, K., Heath, R., Hong, S. P., Momcilovic, M., Johnstone, S. R., Carlson, M., Carling, D. (2005) Ca2+/calmodulin-dependent protein kinase kinase-beta acts upstream of AMP-activated protein kinase in mammalian cells. Cell Metab. 2, 21-33.

25. Hurley, R. L., Anderson, K. A., Franzone, J. M., Kemp, B. E., Means, A. R., Witters, L. A. (2005) The Ca2+/calmodulin-dependent protein kinase kinases are AMP-activated protein kinase kinases. J Biol Chem. 280, 29060-6. Epub 2005 Jun 24.

26. Anderson, K. A., Ribar, T. J., Lin, F., Noeldner, P. K., Green, M. F., Muehlbauer, M. J., Witters, L. A., Kemp, B. E., Means, A. R. (2008) Hypothalamic CaMKK2 contributes to the regulation of energy balance. Cell Metab. 7, 377-88.

27. Tamas, P., Hawley, S. A., Clarke, R. G., Mustard, K. J., Green, K., Hardie, D. G., Cantrell, D. A. (2006) Regulation of the energy sensor AMP-activated protein kinase by antigen receptor and Ca2+ in T lymphocytes. J Exp Med. 203, 1665-70. Epub 2006 Jul 3.

28. Stahmann, N., Woods, A., Carling, D., Heller, R. (2006) Thrombin activates AMP-activated protein kinase in endothelial cells via a pathway involving $\mathrm{Ca} 2+/$ calmodulin-dependent protein kinase kinase beta. Mol Cell Biol. 26, 593345.

29. Momcilovic, M., Hong, S. P., Carlson, M. (2006) Mammalian TAK1 activates Snf1 protein kinase in yeast and phosphorylates AMP-activated protein kinase in vitro. J Biol Chem. 281, 25336-43. Epub 2006 Jul 11.

30. Xie, M., Zhang, D., Dyck, J. R., Li, Y., Zhang, H., Morishima, M., Mann, D. L., Taffet, G. E., Baldini, A., Khoury, D. S., Schneider, M. D. (2006) A pivotal role for endogenous TGF-beta-activated kinase-1 in the LKB1/AMP-activated protein kinase energy-sensor pathway. Proc Natl Acad Sci U S A. 103, 17378-83. Epub 2006 Nov 3.

31. Neumann, D., Woods, A., Carling, D., Wallimann, T., Schlattner, U. (2003) Mammalian AMP-activated protein kinase: functional, heterotrimeric complexes by co-expression of subunits in Escherichia coli. Protein Expr Purif. 30, 230-7. 
32. Carling, D., Mayer, F. V., Sanders, M. J., Gamblin, S. J. (2011) AMP-activated protein kinase: nature's energy sensor. Nat Chem Biol. 7, 512-8. doi:

10.1038/nchembio.610.

33. Xiao, B., Sanders, M. J., Underwood, E., Heath, R., Mayer, F. V., Carmena, D., Jing, C., Walker, P. A., Eccleston, J. F., Haire, L. F., Saiu, P., Howell, S. A., Aasland, R., Martin, S. R., Carling, D., Gamblin, S. J. (2011) Structure of mammalian AMPK and its regulation by ADP. Nature. 472, 230-3. Epub 2011 Mar 13.

34. Hardie, D. G., Carling, D., Gamblin, S. J. (2011) AMP-activated protein kinase: also regulated by ADP? Trends Biochem Sci. 36, 470-7. Epub 2011 Jul 23.

35. Hardie, D. G., Scott, J. W., Pan, D. A., Hudson, E. R. (2003) Management of cellular energy by the AMP-activated protein kinase system. FEBS Lett. 546, 113-20.

36. Makowski, L., Brittingham, K. C., Reynolds, J. M., Suttles, J., Hotamisligil, G. S. (2005) The fatty acid-binding protein, aP2, coordinates macrophage cholesterol trafficking and inflammatory activity. Macrophage expression of aP2 impacts peroxisome proliferator-activated receptor gamma and IkappaB kinase activities. J Biol Chem. 280, 12888-95. Epub 2005 Jan 31.

37. Minokoshi, Y., Kim, Y. B., Peroni, O. D., Fryer, L. G., Muller, C., Carling, D., Kahn, B. B. (2002) Leptin stimulates fatty-acid oxidation by activating AMPactivated protein kinase. Nature. 415, 339-43.

38. Minokoshi, Y., Shiuchi, T., Lee, S., Suzuki, A., Okamoto, S. (2008) Role of hypothalamic AMP-kinase in food intake regulation. Nutrition. 24, 786-90. doi: 10.1016/j.nut.2008.06.002.

39. Yamauchi, T., Kamon, J., Minokoshi, Y., Ito, Y., Waki, H., Uchida, S., Yamashita, S., Noda, M., Kita, S., Ueki, K., Eto, K., Akanuma, Y., Froguel, P., Foufelle, F., Ferre, P., Carling, D., Kimura, S., Nagai, R., Kahn, B. B., Kadowaki, T. (2002) Adiponectin stimulates glucose utilization and fatty-acid oxidation by activating AMP-activated protein kinase. Nat Med. 8, 1288-95. Epub 2002 Oct 7.

40. Kubota, N., Yano, W., Kubota, T., Yamauchi, T., Itoh, S., Kumagai, H., Kozono, H., Takamoto, I., Okamoto, S., Shiuchi, T., Suzuki, R., Satoh, H., Tsuchida, A., Moroi, M., Sugi, K., Noda, T., Ebinuma, H., Ueta, Y., Kondo, T., Araki, E., Ezaki, O., Nagai, R., Tobe, K., Terauchi, Y., Ueki, K., Minokoshi, Y., Kadowaki, T. (2007) Adiponectin stimulates AMP-activated protein kinase in the hypothalamus and increases food intake. Cell Metab. 6, 55-68.

41. Jhun, B. S., Jin, Q., Oh, Y. T., Kim, S. S., Kong, Y., Cho, Y. H., Ha, J., Baik, H. H., Kang, I. (2004) 5-Aminoimidazole-4-carboxamide riboside suppresses lipopolysaccharide-induced TNF-alpha production through inhibition of 
phosphatidylinositol 3-kinase/Akt activation in RAW 264.7 murine macrophages. Biochem Biophys Res Commun. 318, 372-80.

42. Kuo, C. L., Ho, F. M., Chang, M. Y., Prakash, E., Lin, W. W. (2008) Inhibition of lipopolysaccharide-induced inducible nitric oxide synthase and cyclooxygenase-2 gene expression by 5-aminoimidazole-4-carboxamide riboside is independent of AMP-activated protein kinase. J Cell Biochem. 103, 931-40.

43. Suzuki, J., Yoshimura, T., Simeonova, M., Takeuchi, K., Murakami, Y., Morizane, Y., Miller, J. W., Sobrin, L., Vavvas, D. G. (2012) Aminoimidazole carboxamide ribonucleotide ameliorates experimental autoimmune uveitis. Invest Ophthalmol Vis Sci. 53, 4158-69. doi: 10.1167/iovs.11-9323. Print 2012.

44. Zhou, G., Myers, R., Li, Y., Chen, Y., Shen, X., Fenyk-Melody, J., Wu, M., Ventre, J., Doebber, T., Fujii, N., Musi, N., Hirshman, M. F., Goodyear, L. J., Moller, D. E. (2001) Role of AMP-activated protein kinase in mechanism of metformin action. J Clin Invest. 108, 1167-74.

45. Shaw, R. J., Lamia, K. A., Vasquez, D., Koo, S. H., Bardeesy, N., Depinho, R. A., Montminy, M., Cantley, L. C. (2005) The kinase LKB1 mediates glucose homeostasis in liver and therapeutic effects of metformin. Science. 310, 1642-6. Epub 2005 Nov 24.

46. Hardie, D. G. (2006) Neither LKB1 nor AMPK are the direct targets of metformin. Gastroenterology. 131, 973; author reply 974-5.

47. Hevener, A. L., He, W., Barak, Y., Le, J., Bandyopadhyay, G., Olson, P., Wilkes, J., Evans, R. M., Olefsky, J. (2003) Muscle-specific Pparg deletion causes insulin resistance. Nat Med. 9, 1491-7. Epub 2003 Nov 16.

48. Gavrilova, O., Haluzik, M., Matsusue, K., Cutson, J. J., Johnson, L., Dietz, K. R., Nicol, C. J., Vinson, C., Gonzalez, F. J., Reitman, M. L. (2003) Liver peroxisome proliferator-activated receptor gamma contributes to hepatic steatosis, triglyceride clearance, and regulation of body fat mass. J Biol Chem. 278, 34268-76. Epub 2003 Jun 11.

49. Fryer, L. G., Parbu-Patel, A., Carling, D. (2002) The Anti-diabetic drugs rosiglitazone and metformin stimulate AMP-activated protein kinase through distinct signaling pathways. J Biol Chem. 277, 25226-32. Epub 2002 May 6.

50. Park, S. J., Ahmad, F., Philp, A., Baar, K., Williams, T., Luo, H., Ke, H., Rehmann, H., Taussig, R., Brown, A. L., Kim, M. K., Beaven, M. A., Burgin, A. B., Manganiello, V., Chung, J. H. (2012) Resveratrol ameliorates aging-related metabolic phenotypes by inhibiting cAMP phosphodiesterases. Cell. 148, 421-33.

51. Zang, M., Xu, S., Maitland-Toolan, K. A., Zuccollo, A., Hou, X., Jiang, B., Wierzbicki, M., Verbeuren, T. J., Cohen, R. A. (2006) Polyphenols stimulate 
AMP-activated protein kinase, lower lipids, and inhibit accelerated atherosclerosis in diabetic LDL receptor-deficient mice. Diabetes. 55, 2180-91.

52. Merrill, G. F., Kurth, E. J., Hardie, D. G., Winder, W. W. (1997) AICA riboside increases AMP-activated protein kinase, fatty acid oxidation, and glucose uptake in rat muscle. Am J Physiol. 273, E1107-12.

53. Kurth-Kraczek, E. J., Hirshman, M. F., Goodyear, L. J., Winder, W. W. (1999) 5' AMP-activated protein kinase activation causes GLUT4 translocation in skeletal muscle. Diabetes. 48, 1667-71.

54. Holmes, B. F., Kurth-Kraczek, E. J., Winder, W. W. (1999) Chronic activation of 5'-AMP-activated protein kinase increases GLUT-4, hexokinase, and glycogen in muscle. J Appl Physiol. 87, 1990-5.

55. Fryer, L. G., Foufelle, F., Barnes, K., Baldwin, S. A., Woods, A., Carling, D. (2002) Characterization of the role of the AMP-activated protein kinase in the stimulation of glucose transport in skeletal muscle cells. Biochem J. 363, 167-74.

56. Jakobsen, S. N., Hardie, D. G., Morrice, N., Tornqvist, H. E. (2001) 5'-AMPactivated protein kinase phosphorylates IRS-1 on Ser-789 in mouse C2C12 myotubes in response to 5-aminoimidazole-4-carboxamide riboside. J Biol Chem. 276, 46912-6. Epub 2001 Oct 11.

57. Koo, S. H., Flechner, L., Qi, L., Zhang, X., Screaton, R. A., Jeffries, S., Hedrick, S., Xu, W., Boussouar, F., Brindle, P., Takemori, H., Montminy, M. (2005) The CREB coactivator TORC2 is a key regulator of fasting glucose metabolism. Nature. 437, 1109-11. Epub 2005 Sep 7.

58. Carling, D. and Hardie, D. G. (1989) The substrate and sequence specificity of the AMP-activated protein kinase. Phosphorylation of glycogen synthase and phosphorylase kinase. Biochim Biophys Acta. 1012, 81-6.

59. Jorgensen, S. B., Nielsen, J. N., Birk, J. B., Olsen, G. S., Viollet, B., Andreelli, F., Schjerling, P., Vaulont, S., Hardie, D. G., Hansen, B. F., Richter, E. A.,

Wojtaszewski, J. F. (2004) The alpha2-5'AMP-activated protein kinase is a site 2 glycogen synthase kinase in skeletal muscle and is responsive to glucose loading. Diabetes. 53, 3074-81.

60. Luiken, J. J., Coort, S. L., Willems, J., Coumans, W. A., Bonen, A., van der Vusse, G. J., Glatz, J. F. (2003) Contraction-induced fatty acid translocase/CD36 translocation in rat cardiac myocytes is mediated through AMP-activated protein kinase signaling. Diabetes. 52, 1627-34.

61. Foretz, M., Ancellin, N., Andreelli, F., Saintillan, Y., Grondin, P., Kahn, A., Thorens, B., Vaulont, S., Viollet, B. (2005) Short-term overexpression of a constitutively active form of AMP-activated protein kinase in the liver leads to mild hypoglycemia and fatty liver. Diabetes. 54, 1331-9. 
62. Henin, N., Vincent, M. F., Gruber, H. E., Van den Berghe, G. (1995) Inhibition of fatty acid and cholesterol synthesis by stimulation of AMP-activated protein kinase. FASEB J. 9, 541-6.

63. Browne, G. J., Finn, S. G., Proud, C. G. (2004) Stimulation of the AMP-activated protein kinase leads to activation of eukaryotic elongation factor 2 kinase and to its phosphorylation at a novel site, serine 398. J Biol Chem. 279, 12220-31. Epub 2004 Jan 5.

64. Bolster, D. R., Crozier, S. J., Kimball, S. R., Jefferson, L. S. (2002) AMPactivated protein kinase suppresses protein synthesis in rat skeletal muscle through down-regulated mammalian target of rapamycin (mTOR) signaling. $\mathrm{J}$ Biol Chem. 277, 23977-80. Epub 2002 May 7.

65. Horman, S., Browne, G., Krause, U., Patel, J., Vertommen, D., Bertrand, L., Lavoinne, A., Hue, L., Proud, C., Rider, M. (2002) Activation of AMP-activated protein kinase leads to the phosphorylation of elongation factor 2 and an inhibition of protein synthesis. Curr Biol. 12, 1419-23.

66. Chan, A. Y., Soltys, C. L., Young, M. E., Proud, C. G., Dyck, J. R. (2004) Activation of AMP-activated protein kinase inhibits protein synthesis associated with hypertrophy in the cardiac myocyte. J Biol Chem. 279, 32771-9. Epub 2004 May 24.

67. Inoki, K., Zhu, T., Guan, K. L. (2003) TSC2 mediates cellular energy response to control cell growth and survival. Cell. 115, 577-90.

68. Gwinn, D. M., Shackelford, D. B., Egan, D. F., Mihaylova, M. M., Mery, A., Vasquez, D. S., Turk, B. E., Shaw, R. J. (2008) AMPK phosphorylation of raptor mediates a metabolic checkpoint. Mol Cell. 30, 214-26.

69. Liu, Y., Wan, Q., Guan, Q., Gao, L., Zhao, J. (2006) High-fat diet feeding impairs both the expression and activity of AMPKa in rats' skeletal muscle. Biochem Biophys Res Commun. 339, 701-7. Epub 2005 Nov 21.

70. Steinberg, G. R., Michell, B. J., van Denderen, B. J., Watt, M. J., Carey, A. L., Fam, B. C., Andrikopoulos, S., Proietto, J., Gorgun, C. Z., Carling, D., Hotamisligil, G. S., Febbraio, M. A., Kay, T. W., Kemp, B. E. (2006) Tumor necrosis factor alpha-induced skeletal muscle insulin resistance involves suppression of AMP-kinase signaling. Cell Metab. 4, 465-74.

71. Sriwijitkamol, A., Ivy, J. L., Christ-Roberts, C., DeFronzo, R. A., Mandarino, L. J., Musi, N. (2006) LKB1-AMPK signaling in muscle from obese insulin-resistant Zucker rats and effects of training. Am J Physiol Endocrinol Metab. 290, E92532. Epub 2005 Dec 13.

72. Bergeron, R., Previs, S. F., Cline, G. W., Perret, P., Russell, R. R., 3rd, Young, L. H., Shulman, G. I. (2001) Effect of 5-aminoimidazole-4-carboxamide-1-beta-D- 
ribofuranoside infusion on in vivo glucose and lipid metabolism in lean and obese Zucker rats. Diabetes. 50, 1076-82.

73. Koistinen, H. A., Galuska, D., Chibalin, A. V., Yang, J., Zierath, J. R., Holman, G. D., Wallberg-Henriksson, H. (2003) 5-amino-imidazole carboxamide riboside increases glucose transport and cell-surface GLUT4 content in skeletal muscle from subjects with type 2 diabetes. Diabetes. 52, 1066-72.

74. Steinberg, G. R., Smith, A. C., Van Denderen, B. J., Chen, Z., Murthy, S., Campbell, D. J., Heigenhauser, G. J., Dyck, D. J., Kemp, B. E. (2004) AMPactivated protein kinase is not down-regulated in human skeletal muscle of obese females. J Clin Endocrinol Metab. 89, 4575-80.

75. Wijngaarden, M. A., van der Zon, G. C., Willems van Dijk, K. W., Pijl, H., Guigas, B. (2013) Effects of prolonged fasting on AMPK signaling, gene expression and mitochondrial respiratory-chain content in skeletal muscle from lean and obese individuals. Am J Physiol Endocrinol Metab 19, 19.

76. Russell, R. R., 3rd, Bergeron, R., Shulman, G. I., Young, L. H. (1999) Translocation of myocardial GLUT-4 and increased glucose uptake through activation of AMPK by AICAR. Am J Physiol. 277, H643-9.

77. Kudo, N., Barr, A. J., Barr, R. L., Desai, S., Lopaschuk, G. D. (1995) High rates of fatty acid oxidation during reperfusion of ischemic hearts are associated with a decrease in malonyl-CoA levels due to an increase in 5'-AMP-activated protein kinase inhibition of acetyl-CoA carboxylase. J Biol Chem. 270, 17513-20.

78. Curtis, R., O'Connor, G., DiStefano, P. S. (2006) Aging networks in Caenorhabditis elegans: AMP-activated protein kinase (aak-2) links multiple aging and metabolism pathways. Aging Cell. 5, 119-26.

79. Ji, H., Ramsey, M. R., Hayes, D. N., Fan, C., McNamara, K., Kozlowski, P., Torrice, C., Wu, M. C., Shimamura, T., Perera, S. A., Liang, M. C., Cai, D., Naumov, G. N., Bao, L., Contreras, C. M., Li, D., Chen, L., Krishnamurthy, J., Koivunen, J., Chirieac, L. R., Padera, R. F., Bronson, R. T., Lindeman, N. I., Christiani, D. C., Lin, X., Shapiro, G. I., Janne, P. A., Johnson, B. E., Meyerson, M., Kwiatkowski, D. J., Castrillon, D. H., Bardeesy, N., Sharpless, N. E., Wong, K. K. (2007) LKB1 modulates lung cancer differentiation and metastasis. Nature. 448, 807-10. Epub 2007 Aug 5.

80. Contreras, C. M., Gurumurthy, S., Haynie, J. M., Shirley, L. J., Akbay, E. A., Wingo, S. N., Schorge, J. O., Broaddus, R. R., Wong, K. K., Bardeesy, N., Castrillon, D. H. (2008) Loss of Lkb1 provokes highly invasive endometrial adenocarcinomas. Cancer Res. 68, 759-66.

81. Swinnen, J. V., Beckers, A., Brusselmans, K., Organe, S., Segers, J., Timmermans, L., Vanderhoydonc, F., Deboel, L., Derua, R., Waelkens, E., De Schrijver, E., Van de Sande, T., Noel, A., Foufelle, F., Verhoeven, G. (2005) 
Mimicry of a cellular low energy status blocks tumor cell anabolism and suppresses the malignant phenotype. Cancer Res. 65, 2441-8.

82. Sengupta, T. K., Leclerc, G. M., Hsieh-Kinser, T. T., Leclerc, G. J., Singh, I., Barredo, J. C. (2007) Cytotoxic effect of 5-aminoimidazole-4-carboxamide-1beta-4-ribofuranoside (AICAR) on childhood acute lymphoblastic leukemia (ALL) cells: implication for targeted therapy. Mol Cancer. 6, 46.

83. Evans, J. M., Donnelly, L. A., Emslie-Smith, A. M., Alessi, D. R., Morris, A. D. (2005) Metformin and reduced risk of cancer in diabetic patients. BMJ. 330, 1304-5. Epub 2005 Apr 22.

84. Anisimov, V. N., Berstein, L. M., Egormin, P. A., Piskunova, T. S., Popovich, I. G., Zabezhinski, M. A., Kovalenko, I. G., Poroshina, T. E., Semenchenko, A. V., Provinciali, M., Re, F., Franceschi, C. (2005) Effect of metformin on life span and on the development of spontaneous mammary tumors in HER-2/neu transgenic mice. Exp Gerontol. 40, 685-93.

85. Memmott, R. M. and Dennis, P. A. (2009) LKB1 and mammalian target of rapamycin as predictive factors for the anticancer efficacy of metformin. J Clin Oncol. 27, e226; author reply e227. Epub 2009 Oct 26.

86. Kourelis, T. V. and Siegel, R. D. (2011) Metformin and cancer: new applications for an old drug. Med Oncol 8, 8 .

87. Kalender, A., Selvaraj, A., Kim, S. Y., Gulati, P., Brule, S., Viollet, B., Kemp, B. E., Bardeesy, N., Dennis, P., Schlager, J. J., Marette, A., Kozma, S. C., Thomas, G. (2010) Metformin, independent of AMPK, inhibits mTORC1 in a rag GTPasedependent manner. Cell Metab. 11, 390-401.

88. Shackelford, D. B. and Shaw, R. J. (2009) The LKB1-AMPK pathway: metabolism and growth control in tumour suppression. Nat Rev Cancer. 9, 56375.

89. Park, H. U., Suy, S., Danner, M., Dailey, V., Zhang, Y., Li, H., Hyduke, D. R., Collins, B. T., Gagnon, G., Kallakury, B., Kumar, D., Brown, M. L., Fornace, A., Dritschilo, A., Collins, S. P. (2009) AMP-activated protein kinase promotes human prostate cancer cell growth and survival. Mol Cancer Ther. 8, 733-41.

90. Frigo, D. E., Howe, M. K., Wittmann, B. M., Brunner, A. M., Cushman, I., Wang, Q., Brown, M., Means, A. R., McDonnell, D. P. (2011) CaM kinase kinase betamediated activation of the growth regulatory kinase AMPK is required for androgen-dependent migration of prostate cancer cells. Cancer Res. 71, 528-37. Epub 2010 Nov 22.

91. Salminen, A., Hyttinen, J. M., Kaarniranta, K. (2011) AMP-activated protein kinase inhibits NF-kappaB signaling and inflammation: impact on healthspan and lifespan. J Mol Med 23, 23. 
92. Hotamisligil, G. S. and Erbay, E. (2008) Nutrient sensing and inflammation in metabolic diseases. Nat Rev Immunol. 8, 923-34. doi: 10.1038/nri2449.

93. O'Neill, L. A. and Hardie, D. G. (2013) Metabolism of inflammation limited by AMPK and pseudo-starvation. Nature. 493, 346-55. doi: 10.1038/nature11862.

94. Suttles, J. and Stout, R. D. (2009) Macrophage CD40 signaling: a pivotal regulator of disease protection and pathogenesis. Semin Immunol. 21, 257-64. doi: 10.1016/j.smim.2009.05.011. Epub 2009 Jun 21.

95. Kilinc, M. O., Mukundan, L., Yolcu, E. S., Singh, N. P., Suttles, J., Shirwan, H. (2006) Generation of a multimeric form of CD40L with potent immunostimulatory activity using streptavidin as a chaperon. Exp Mol Pathol. 80, 252-61. Epub 2006 Feb 17.

96. Krawczyk, C. M., Holowka, T., Sun, J., Blagih, J., Amiel, E., DeBerardinis, R. J., Cross, J. R., Jung, E., Thompson, C. B., Jones, R. G., Pearce, E. J. (2010) Tolllike receptor-induced changes in glycolytic metabolism regulate dendritic cell activation. Blood. 115, 4742-9. Epub 2010 Mar 29.

97. Bai, A., Ma, A. G., Yong, M., Weiss, C. R., Ma, Y., Guan, Q., Bernstein, C. N., Peng, Z. (2010) AMPK agonist downregulates innate and adaptive immune responses in TNBS-induced murine acute and relapsing colitis. Biochem Pharmacol. 80, 1708-17. Epub 2010 Aug 24.

98. Nath, N., Giri, S., Prasad, R., Salem, M. L., Singh, A. K., Singh, I. (2005) 5aminoimidazole-4-carboxamide ribonucleoside: a novel immunomodulator with therapeutic efficacy in experimental autoimmune encephalomyelitis. J Immunol. $175,566-74$.

99. Giri, S., Nath, N., Smith, B., Viollet, B., Singh, A. K., Singh, I. (2004) 5aminoimidazole-4-carboxamide-1-beta-4-ribofuranoside inhibits proinflammatory response in glial cells: a possible role of AMP-activated protein kinase. J Neurosci. 24, 479-87.

100. Pilon, G., Dallaire, P., Marette, A. (2004) Inhibition of inducible nitric-oxide synthase by activators of AMP-activated protein kinase: a new mechanism of action of insulin-sensitizing drugs. J Biol Chem. 279, 20767-74. Epub 2004 Feb 25.

101. Akbar, D. H. (2003) Effect of metformin and sulfonylurea on C-reactive protein level in well-controlled type 2 diabetics with metabolic syndrome. Endocrine. 20, 215-8.

102. Dandona, P., Aljada, A., Ghanim, H., Mohanty, P., Tripathy, C., Hofmeyer, D., Chaudhuri, A. (2004) Increased plasma concentration of macrophage migration inhibitory factor (MIF) and MIF mRNA in mononuclear cells in the obese and the suppressive action of metformin. J Clin Endocrinol Metab. 89, 5043-7. 
103. Lim, C. T., Kola, B., Korbonits, M. (2010) AMPK as a mediator of hormonal signalling. J Mol Endocrinol. 44, 87-97. Epub 2009 Jul 22.

104. Hwang, J. T., Kwon, D. Y., Yoon, S. H. (2009) AMP-activated protein kinase: a potential target for the diseases prevention by natural occurring polyphenols. $\mathrm{N}$ Biotechnol. 26, 17-22. Epub 2009 Apr 2.

105. Richter, E. A. and Ruderman, N. B. (2009) AMPK and the biochemistry of exercise: implications for human health and disease. Biochem J. 418, 261-75.

106. Sag, D., Carling, D., Stout, R. D., Suttles, J. (2008) Adenosine 5'-monophosphateactivated protein kinase promotes macrophage polarization to an antiinflammatory functional phenotype. J Immunol. 181, 8633-41.

107. Yang, Z., Kahn, B. B., Shi, H., Xue, B. Z. (2010) Macrophage alpha1 AMPactivated protein kinase (alpha1AMPK) antagonizes fatty acid-induced inflammation through SIRT1. J Biol Chem. 285, 19051-9. Epub 2010 Apr 26.

108. Galic, S., Fullerton, M. D., Schertzer, J. D., Sikkema, S., Marcinko, K., Walkley, C. R., Izon, D., Honeyman, J., Chen, Z. P., van Denderen, B. J., Kemp, B. E., Steinberg, G. R. (2011) Hematopoietic AMPK betal reduces mouse adipose tissue macrophage inflammation and insulin resistance in obesity. J Clin Invest. 121, 4903-15. doi: 10.1172/JCI58577. Epub 2011 Nov 14.

109. Mukundan, L., Bishop, G. A., Head, K. Z., Zhang, L., Wahl, L. M., Suttles, J. (2005) TNF receptor-associated factor 6 is an essential mediator of CD40activated proinflammatory pathways in monocytes and macrophages. J Immunol. 174, 1081-90.

110. Kroemer, G., Marino, G., Levine, B. (2010) Autophagy and the integrated stress response. Mol Cell. 40, 280-93. doi: 10.1016/j.molcel.2010.09.023.

111. Takeda-Watanabe, A., Kitada, M., Kanasaki, K., Koya, D. (2012) SIRT1 inactivation induces inflammation through the dysregulation of autophagy in human THP-1 cells. Biochem Biophys Res Commun. 427, 191-6. doi: 10.1016/j.bbrc.2012.09.042. Epub 2012 Sep 17.

112. Liao, X., Sluimer, J. C., Wang, Y., Subramanian, M., Brown, K., Pattison, J. S., Robbins, J., Martinez, J., Tabas, I. (2012) Macrophage autophagy plays a protective role in advanced atherosclerosis. Cell Metab. 15, 545-53. doi: 10.1016/j.cmet.2012.01.022. Epub 2012 Mar 22.

113. Cao, Y., Li, H., Liu, H., Zheng, C., Ji, H., Liu, X. (2010) The serine/threonine kinase LKB1 controls thymocyte survival through regulation of AMPK activation and Bcl-XL expression. Cell Res. 20, 99-108. Epub 2009 Dec 22. 
114. Tamas, P., Macintyre, A., Finlay, D., Clarke, R., Feijoo-Carnero, C., Ashworth, A., Cantrell, D. (2010) LKB1 is essential for the proliferation of T-cell progenitors and mature peripheral T cells. Eur J Immunol. 40, 242-53.

115. Rolf, J., Zarrouk, M., Finlay, D. K., Foretz, M., Viollet, B., Cantrell, D. A. (2013) AMPKalpha1: A glucose sensor that controls CD8 T-cell memory. Eur J Immunol. 43, 889-96. doi: 10.1002/eji.201243008. Epub 2013 Feb 13.

116. MacIver, N. J., Blagih, J., Saucillo, D. C., Tonelli, L., Griss, T., Rathmell, J. C., Jones, R. G. (2011) The liver kinase B1 is a central regulator of T cell development, activation, and metabolism. J Immunol. 187, 4187-98. doi: 10.4049/jimmunol.1100367. Epub 2011 Sep 19.

117. Hashimoto, D., Miller, J., Merad, M. (2011) Dendritic cell and macrophage heterogeneity in vivo. Immunity. 35, 323-35. doi: 10.1016/j.immuni.2011.09.007.

118. Laskin, D. L., Weinberger, B., Laskin, J. D. (2001) Functional heterogeneity in liver and lung macrophages. J Leukoc Biol. 70, 163-70.

119. Guillemin, G. J. and Brew, B. J. (2004) Microglia, macrophages, perivascular macrophages, and pericytes: a review of function and identification. J Leukoc Biol. 75, 388-97. Epub 2003 Nov 11.

120. Stout, R. D., Watkins, S. K., Suttles, J. (2009) Functional plasticity of macrophages: in situ reprogramming of tumor-associated macrophages. J Leukoc Biol. 86, 1105-9. Epub 2009 Jul 15.

121. Lawrence, T. and Natoli, G. (2011) Transcriptional regulation of macrophage polarization: enabling diversity with identity. Nat Rev Immunol. 11, 750-61. doi: 10.1038/nri3088.

122. O'Shea, J. J. and Murray, P. J. (2008) Cytokine signaling modules in inflammatory responses. Immunity. 28, 477-87.

123. Huitinga, I., Ruuls, S. R., Jung, S., Van Rooijen, N., Hartung, H. P., Dijkstra, C. D. (1995) Macrophages in T cell line-mediated, demyelinating, and chronic relapsing experimental autoimmune encephalomyelitis in Lewis rats. Clin Exp Immunol. 100, 344-51.

124. Stout, R. D. and Suttles, J. (1997) T cell signaling of macrophage function in inflammatory disease. Front Biosci. 2, d197-206.

125. Ridley, M. G., Kingsley, G., Pitzalis, C., Panayi, G. S. (1990) Monocyte activation in rheumatoid arthritis: evidence for in situ activation and differentiation in joints. Br J Rheumatol. 29, 84-8.

126. Gordon, S. and Martinez, F. O. (2010) Alternative activation of macrophages: mechanism and functions. Immunity. 32, 593-604. 
127. Varin, A., Mukhopadhyay, S., Herbein, G., Gordon, S. (2010) Alternative activation of macrophages by IL-4 impairs phagocytosis of pathogens but potentiates microbial-induced signalling and cytokine secretion. Blood. 115, 35362. Epub 2009 Oct 30.

128. Martinez, F. O., Sica, A., Mantovani, A., Locati, M. (2008) Macrophage activation and polarization. Front Biosci. 13, 453-61.

129. Huang, J. T., Welch, J. S., Ricote, M., Binder, C. J., Willson, T. M., Kelly, C., Witztum, J. L., Funk, C. D., Conrad, D., Glass, C. K. (1999) Interleukin-4dependent production of PPAR-gamma ligands in macrophages by 12/15lipoxygenase. Nature. 400, 378-82.

130. Stout, R. D. and Suttles, J. (2004) Functional plasticity of macrophages: reversible adaptation to changing microenvironments. J Leukoc Biol. 76, 509-13. Epub 2004 Jun 24.

131. Wells, C. A., Ravasi, T., Faulkner, G. J., Carninci, P., Okazaki, Y., Hayashizaki, Y., Sweet, M., Wainwright, B. J., Hume, D. A. (2003) Genetic control of the innate immune response. BMC Immunol. 4, 5. Epub 2003 Jun 26.

132. Porcheray, F., Viaud, S., Rimaniol, A. C., Leone, C., Samah, B., DereuddreBosquet, N., Dormont, D., Gras, G. (2005) Macrophage activation switching: an asset for the resolution of inflammation. Clin Exp Immunol. 142, 481-9.

133. Hausser, G., Ludewig, B., Gelderblom, H. R., Tsunetsugu-Yokota, Y., Akagawa, K., Meyerhans, A. (1997) Monocyte-derived dendritic cells represent a transient stage of differentiation in the myeloid lineage. Immunobiology. 197, 534-42.

134. Liu, B. and Hong, J. S. (2003) Role of microglia in inflammation-mediated neurodegenerative diseases: mechanisms and strategies for therapeutic intervention. J Pharmacol Exp Ther. 304, 1-7.

135. Satpathy, A. T., Wu, X., Albring, J. C., Murphy, K. M. (2012) Re(de)fining the dendritic cell lineage. Nat Immunol. 13, 1145-54. doi: 10.1038/ni.2467. Epub 2012 Nov 16.

136. Palucka, K. and Banchereau, J. (2012) Cancer immunotherapy via dendritic cells. Nat Rev Cancer. 12, 265-77. doi: 10.1038/nrc3258.

137. Schmidt, S. V., Nino-Castro, A. C., Schultze, J. L. (2012) Regulatory dendritic cells: there is more than just immune activation. Front Immunol 3, 274. Epub 2012 Sep 4.

138. Robinson, S. P., Patterson, S., English, N., Davies, D., Knight, S. C., Reid, C. D. (1999) Human peripheral blood contains two distinct lineages of dendritic cells. Eur J Immunol. 29, 2769-78. 
139. Diao, J., Mikhailova, A., Tang, M., Gu, H., Zhao, J., Cattral, M. S. (2012)

Immunostimulatory conventional dendritic cells evolve into regulatory macrophage-like cells. Blood. 119, 4919-27. Epub 2012 Apr 6.

140. Nestle, F. O., Conrad, C., Tun-Kyi, A., Homey, B., Gombert, M., Boyman, O., Burg, G., Liu, Y. J., Gilliet, M. (2005) Plasmacytoid predendritic cells initiate psoriasis through interferon-alpha production. J Exp Med. 202, 135-43.

141. Blanco, P., Palucka, A. K., Gill, M., Pascual, V., Banchereau, J. (2001) Induction of dendritic cell differentiation by IFN-alpha in systemic lupus erythematosus. Science. 294, 1540-3.

142. Upham, J. W. (2003) The role of dendritic cells in immune regulation and allergic airway inflammation. Respirology. 8, 140-8.

143. Tezuka, H. and Ohteki, T. (2010) Regulation of intestinal homeostasis by dendritic cells. Immunol Rev. 234, 247-58. doi: 10.1111/j.01052896.2009.00872.x.

144. Steinman, R. M., Turley, S., Mellman, I., Inaba, K. (2000) The induction of tolerance by dendritic cells that have captured apoptotic cells. J Exp Med. 191, 411-6.

145. Liu, K., Iyoda, T., Saternus, M., Kimura, Y., Inaba, K., Steinman, R. M. (2002) Immune tolerance after delivery of dying cells to dendritic cells in situ. J Exp Med. 196, 1091-7.

146. Sauter, B., Albert, M. L., Francisco, L., Larsson, M., Somersan, S., Bhardwaj, N. (2000) Consequences of cell death: exposure to necrotic tumor cells, but not primary tissue cells or apoptotic cells, induces the maturation of immunostimulatory dendritic cells. J Exp Med. 191, 423-34.

147. Sallusto, F., Palermo, B., Lenig, D., Miettinen, M., Matikainen, S., Julkunen, I., Forster, R., Burgstahler, R., Lipp, M., Lanzavecchia, A. (1999) Distinct patterns and kinetics of chemokine production regulate dendritic cell function. Eur J Immunol. 29, 1617-25.

148. Kalinski, P., Hilkens, C. M., Wierenga, E. A., Kapsenberg, M. L. (1999) T-cell priming by type- 1 and type- 2 polarized dendritic cells: the concept of a third signal. Immunol Today. 20, 561-7.

149. Feili-Hariri, M., Falkner, D. H., Morel, P. A. (2005) Polarization of naive T cells into Th1 or Th2 by distinct cytokine-driven murine dendritic cell populations: implications for immunotherapy. J Leukoc Biol. 78, 656-64. Epub 2005 Jun 16.

150. O'Garra, A. (1998) Cytokines induce the development of functionally heterogeneous T helper cell subsets. Immunity. 8, 275-83. 
151. Shortman, K. and Liu, Y. J. (2002) Mouse and human dendritic cell subtypes. Nat Rev Immunol. 2, 151-61.

152. Sabatte, J., Maggini, J., Nahmod, K., Amaral, M. M., Martinez, D., Salamone, G., Ceballos, A., Giordano, M., Vermeulen, M., Geffner, J. (2007) Interplay of pathogens, cytokines and other stress signals in the regulation of dendritic cell function. Cytokine Growth Factor Rev. 18, 5-17. Epub 2007 Feb 26.

153. O'Shea, J. J. and Paul, W. E. (2010) Mechanisms underlying lineage commitment and plasticity of helper CD4+ T cells. Science. 327, 1098-102. doi: 10.1126/science. 1178334 .

154. Nakayamada, S., Takahashi, H., Kanno, Y., O'Shea, J. J. (2012) Helper T cell diversity and plasticity. Curr Opin Immunol. 24, 297-302. doi: 10.1016/j.coi.2012.01.014. Epub 2012 Feb 15.

155. Zhou, L., Chong, M. M., Littman, D. R. (2009) Plasticity of CD4+ T cell lineage differentiation. Immunity. 30, 646-55. doi: 10.1016/j.immuni.2009.05.001.

156. Stout, R. D. and Suttles, J. (1996) The many roles of CD40 in cell-mediated inflammatory responses. Immunol Today. 17, 487-92.

157. Caux, C., Massacrier, C., Vanbervliet, B., Dubois, B., Van Kooten, C., Durand, I., Banchereau, J. (1994) Activation of human dendritic cells through CD40 crosslinking. J Exp Med. 180, 1263-72.

158. Bennett, S. R., Carbone, F. R., Karamalis, F., Flavell, R. A., Miller, J. F., Heath, W. R. (1998) Help for cytotoxic-T-cell responses is mediated by CD40 signalling. Nature. 393, 478-80.

159. Ridge, J. P., Di Rosa, F., Matzinger, P. (1998) A conditioned dendritic cell can be a temporal bridge between a CD4+ T-helper and a T-killer cell. Nature. 393, 4748.

160. Schoenberger, S. P., Toes, R. E., van der Voort, E. I., Offringa, R., Melief, C. J. (1998) T-cell help for cytotoxic T lymphocytes is mediated by CD40-CD40L interactions. Nature. 393, 480-3.

161. Viollet, B., Andreelli, F., Jorgensen, S. B., Perrin, C., Flamez, D., Mu, J., Wojtaszewski, J. F., Schuit, F. C., Birnbaum, M., Richter, E., Burcelin, R., Vaulont, S. (2003) Physiological role of AMP-activated protein kinase (AMPK): insights from knockout mouse models. Biochem Soc Trans. 31, 216-9.

162. Reynolds, J. M., Liu, Q., Brittingham, K. C., Liu, Y., Gruenthal, M., Gorgun, C. Z., Hotamisligil, G. S., Stout, R. D., Suttles, J. (2007) Deficiency of fatty acidbinding proteins in mice confers protection from development of experimental autoimmune encephalomyelitis. J Immunol. 179, 313-21. 
163. Meares, G. P., Qin, H., Liu, Y., Holdbrooks, A. T., Benveniste, E. N. (2013) AMP-activated protein kinase restricts IFN-gamma signaling. J Immunol. 190, 372-80. doi: 10.4049/jimmunol.1202390. Epub 2012 Nov 23.

164. Mukundan, L., Milhorn, D. M., Matta, B., Suttles, J. (2004) CD40-mediated activation of vascular smooth muscle cell chemokine production through a Srcinitiated, MAPK-dependent pathway. Cell Signal. 16, 375-84.

165. Tsukamoto, N., Kobayashi, N., Azuma, S., Yamamoto, T., Inoue, J. (1999) Two differently regulated nuclear factor kappaB activation pathways triggered by the cytoplasmic tail of CD40. Proc Natl Acad Sci U S A. 96, 1234-9.

166. Aicher, A., Shu, G. L., Magaletti, D., Mulvania, T., Pezzutto, A., Craxton, A., Clark, E. A. (1999) Differential role for p38 mitogen-activated protein kinase in regulating CD40-induced gene expression in dendritic cells and B cells. $\mathrm{J}$ Immunol. 163, 5786-95.

167. Pearson, L. L., Castle, B. E., Kehry, M. R. (2001) CD40-mediated signaling in monocytic cells: up-regulation of tumor necrosis factor receptor-associated factor mRNAs and activation of mitogen-activated protein kinase signaling pathways. Int Immunol. 13, 273-83.

168. Suttles, J., Milhorn, D. M., Miller, R. W., Poe, J. C., Wahl, L. M., Stout, R. D. (1999) CD40 signaling of monocyte inflammatory cytokine synthesis through an ERK1/2-dependent pathway. A target of interleukin (il)-4 and il-10 antiinflammatory action. J Biol Chem. 274, 5835-42.

169. Motoshima, H., Goldstein, B. J., Igata, M., Araki, E. (2006) AMPK and cell proliferation--AMPK as a therapeutic target for atherosclerosis and cancer. J Physiol. 574, 63-71. Epub 2006 Apr 13.

170. Grimes, C. A. and Jope, R. S. (2001) CREB DNA binding activity is inhibited by glycogen synthase kinase-3 beta and facilitated by lithium. J Neurochem. 78, 1219-32.

171. Martin, M., Rehani, K., Jope, R. S., Michalek, S. M. (2005) Toll-like receptormediated cytokine production is differentially regulated by glycogen synthase kinase 3. Nat Immunol. 6, 777-84. Epub 2005 Jul 10.

172. Alessi, D. R., Deak, M., Casamayor, A., Caudwell, F. B., Morrice, N., Norman, D. G., Gaffney, P., Reese, C. B., MacDougall, C. N., Harbison, D., Ashworth, A., Bownes, M. (1997) 3-Phosphoinositide-dependent protein kinase-1 (PDK1): structural and functional homology with the Drosophila DSTPK61 kinase. Curr Biol. 7, 776-89.

173. Stephens, L., Anderson, K., Stokoe, D., Erdjument-Bromage, H., Painter, G. F., Holmes, A. B., Gaffney, P. R., Reese, C. B., McCormick, F., Tempst, P., Coadwell, J., Hawkins, P. T. (1998) Protein kinase B kinases that mediate 
phosphatidylinositol 3,4,5-trisphosphate-dependent activation of protein kinase B. Science. 279, 710-4.

174. Sarbassov, D. D., Guertin, D. A., Ali, S. M., Sabatini, D. M. (2005)

Phosphorylation and regulation of Akt/PKB by the rictor-mTOR complex.

Science. 307, 1098-101.

175. Inoki, K., Li, Y., Zhu, T., Wu, J., Guan, K. L. (2002) TSC2 is phosphorylated and inhibited by Akt and suppresses mTOR signalling. Nat Cell Biol. 4, 648-57.

176. Manning, B. D., Tee, A. R., Logsdon, M. N., Blenis, J., Cantley, L. C. (2002) Identification of the tuberous sclerosis complex-2 tumor suppressor gene product tuberin as a target of the phosphoinositide 3-kinase/akt pathway. Mol Cell. 10, $151-62$.

177. Tee, A. R., Fingar, D. C., Manning, B. D., Kwiatkowski, D. J., Cantley, L. C., Blenis, J. (2002) Tuberous sclerosis complex-1 and -2 gene products function together to inhibit mammalian target of rapamycin (mTOR)-mediated downstream signaling. Proc Natl Acad Sci U S A. 99, 13571-6. Epub 2002 Sep 23.

178. Zhang, H. H., Lipovsky, A. I., Dibble, C. C., Sahin, M., Manning, B. D. (2006) S6K1 regulates GSK3 under conditions of mTOR-dependent feedback inhibition of Akt. Mol Cell. 24, 185-97.

179. Bae, H. B., Zmijewski, J. W., Deshane, J. S., Tadie, J. M., Chaplin, D. D., Takashima, S., Abraham, E. (2011) AMP-activated protein kinase enhances the phagocytic ability of macrophages and neutrophils. FASEB J. 25, 4358-68. doi: 10.1096/fj.11-190587. Epub 2011 Sep 1.

180. Jemal, A., Siegel, R., Ward, E., Hao, Y., Xu, J., Murray, T., Thun, M. J. (2008) Cancer statistics, 2008. CA Cancer J Clin. 58, 71-96. doi: 10.3322/CA.2007.0010. Epub 2008 Feb 20.

181. Doll, S. R. (2000) Smoking and lung cancer. Am J Respir Crit Care Med. 162, 46.

182. Balkwill, F., Charles, K. A., Mantovani, A. (2005) Smoldering and polarized inflammation in the initiation and promotion of malignant disease. Cancer Cell. 7, 211-7.

183. Condeelis, J. and Pollard, J. W. (2006) Macrophages: obligate partners for tumor cell migration, invasion, and metastasis. Cell. 124, 263-6.

184. Meylan, E., Dooley, A. L., Feldser, D. M., Shen, L., Turk, E., Ouyang, C., Jacks, T. (2009) Requirement for NF-kappaB signalling in a mouse model of lung adenocarcinoma. Nature. 462, 104-7. doi: 10.1038/nature08462. Epub 2009 Oct 21. 
185. Mantovani, A., Garlanda, C., Allavena, P. (2010) Molecular pathways and targets in cancer-related inflammation. Ann Med. 42, 161-70. doi:

$10.3109 / 07853890903405753$.

186. Lewis, C. E. and Pollard, J. W. (2006) Distinct role of macrophages in different tumor microenvironments. Cancer Res. 66, 605-12.

187. Lazennec, G. and Richmond, A. (2010) Chemokines and chemokine receptors: new insights into cancer-related inflammation. Trends Mol Med. 16, 133-44. doi: 10.1016/j.molmed.2010.01.003. Epub 2010 Feb 15.

188. Barleon, B., Sozzani, S., Zhou, D., Weich, H. A., Mantovani, A., Marme, D. (1996) Migration of human monocytes in response to vascular endothelial growth factor (VEGF) is mediated via the VEGF receptor flt-1. Blood. 87, 3336-43.

189. Lewis, J. S., Landers, R. J., Underwood, J. C., Harris, A. L., Lewis, C. E. (2000) Expression of vascular endothelial growth factor by macrophages is up-regulated in poorly vascularized areas of breast carcinomas. J Pathol. 192, 150-8.

190. Schioppa, T., Uranchimeg, B., Saccani, A., Biswas, S. K., Doni, A., Rapisarda, A., Bernasconi, S., Saccani, S., Nebuloni, M., Vago, L., Mantovani, A., Melillo, G., Sica, A. (2003) Regulation of the chemokine receptor CXCR4 by hypoxia. J Exp Med. 198, 1391-402.

191. Bingle, L., Brown, N. J., Lewis, C. E. (2002) The role of tumour-associated macrophages in tumour progression: implications for new anticancer therapies. $\mathrm{J}$ Pathol. 196, 254-65.

192. Mantovani, A., Sozzani, S., Locati, M., Allavena, P., Sica, A. (2002) Macrophage polarization: tumor-associated macrophages as a paradigm for polarized M2 mononuclear phagocytes. Trends Immunol. 23, 549-55.

193. Murdoch, C., Muthana, M., Coffelt, S. B., Lewis, C. E. (2008) The role of myeloid cells in the promotion of tumour angiogenesis. Nat Rev Cancer. 8, 61831. doi: 10.1038/nrc2444. Epub 2008 Jul 17.

194. Leek, R. D., Lewis, C. E., Whitehouse, R., Greenall, M., Clarke, J., Harris, A. L. (1996) Association of macrophage infiltration with angiogenesis and prognosis in invasive breast carcinoma. Cancer Res. 56, 4625-9.

195. Hanada, T., Nakagawa, M., Emoto, A., Nomura, T., Nasu, N., Nomura, Y. (2000) Prognostic value of tumor-associated macrophage count in human bladder cancer. Int J Urol. 7, 263-9.

196. Wyckoff, J., Wang, W., Lin, E. Y., Wang, Y., Pixley, F., Stanley, E. R., Graf, T., Pollard, J. W., Segall, J., Condeelis, J. (2004) A paracrine loop between tumor cells and macrophages is required for tumor cell migration in mammary tumors. Cancer Res. 64, 7022-9. 
197. Goswami, S., Sahai, E., Wyckoff, J. B., Cammer, M., Cox, D., Pixley, F. J., Stanley, E. R., Segall, J. E., Condeelis, J. S. (2005) Macrophages promote the invasion of breast carcinoma cells via a colony-stimulating factor-1/epidermal growth factor paracrine loop. Cancer Res. 65, 5278-83.

198. Lin, E. Y., Gouon-Evans, V., Nguyen, A. V., Pollard, J. W. (2002) The macrophage growth factor CSF-1 in mammary gland development and tumor progression. J Mammary Gland Biol Neoplasia. 7, 147-62.

199. Leek, R. D. and Harris, A. L. (2002) Tumor-associated macrophages in breast cancer. J Mammary Gland Biol Neoplasia. 7, 177-89.

200. McDermott, R. S., Deneux, L., Mosseri, V., Vedrenne, J., Clough, K., Fourquet, A., Rodriguez, J., Cosset, J. M., Sastre, X., Beuzeboc, P., Pouillart, P., Scholl, S. M. (2002) Circulating macrophage colony stimulating factor as a marker of tumour progression. Eur Cytokine Netw. 13, 121-7.

201. Lin, E. Y., Nguyen, A. V., Russell, R. G., Pollard, J. W. (2001) Colonystimulating factor 1 promotes progression of mammary tumors to malignancy. $\mathrm{J}$ Exp Med. 193, 727-40.

202. Hiratsuka, S., Nakamura, K., Iwai, S., Murakami, M., Itoh, T., Kijima, H., Shipley, J. M., Senior, R. M., Shibuya, M. (2002) MMP9 induction by vascular endothelial growth factor receptor-1 is involved in lung-specific metastasis. Cancer Cell. 2, 289-300.

203. Oberg, A., Samii, S., Stenling, R., Lindmark, G. (2002) Different occurrence of $\mathrm{CD} 8+, \mathrm{CD} 45 \mathrm{R} 0+$, and CD68+ immune cells in regional lymph node metastases from colorectal cancer as potential prognostic predictors. Int J Colorectal Dis. 17, 25-9.

204. Elgert, K. D., Alleva, D. G., Mullins, D. W. (1998) Tumor-induced immune dysfunction: the macrophage connection. J Leukoc Biol. 64, 275-90.

205. Sunderkotter, C., Goebeler, M., Schulze-Osthoff, K., Bhardwaj, R., Sorg, C. (1991) Macrophage-derived angiogenesis factors. Pharmacol Ther 51, 195-216.

206. Ben-Baruch, A. (2006) Inflammation-associated immune suppression in cancer: the roles played by cytokines, chemokines and additional mediators. Semin Cancer Biol. 16, 38-52. Epub 2005 Aug 31.

207. Todd, R., Lingen, M. W., Kuo, W. P. (2002) Gene expression profiling using laser capture microdissection. Expert Rev Mol Diagn. 2, 497-507.

208. Trinchieri, G. and Gerosa, F. (1996) Immunoregulation by interleukin-12. J Leukoc Biol. 59, 505-11. 
209. Wojtowicz-Praga, S. (1997) Reversal of tumor-induced immunosuppression: a new approach to cancer therapy. J Immunother. 20, 165-77.

210. Zeineddine, N. S., Avina, M. D., Williams, C. C., Wepsic, H. T., Jadus, M. R. (1999) Macrophages that kill glioma cells expressing the membrane form of macrophage colony stimulating factor are resistant to prostaglandin E2 and interleukin-10. Immunol Lett. 70, 63-8.

211. Serafini, P., Borrello, I., Bronte, V. (2006) Myeloid suppressor cells in cancer: recruitment, phenotype, properties, and mechanisms of immune suppression. Semin Cancer Biol. 16, 53-65. Epub 2005 Sep 15.

212. Valenti, R., Huber, V., Iero, M., Filipazzi, P., Parmiani, G., Rivoltini, L. (2007) Tumor-released microvesicles as vehicles of immunosuppression. Cancer Res. 67, 2912-5.

213. Nagaraj, S. and Gabrilovich, D. I. (2012) Regulation of suppressive function of myeloid-derived suppressor cells by CD4+ T cells. Semin Cancer Biol. 22, 282-8. doi: 10.1016/j.semcancer.2012.01.010. Epub 2012 Jan 31.

214. Pan, P. Y., Ma, G., Weber, K. J., Ozao-Choy, J., Wang, G., Yin, B., Divino, C. M., Chen, S. H. (2010) Immune stimulatory receptor CD40 is required for T-cell suppression and $\mathrm{T}$ regulatory cell activation mediated by myeloid-derived suppressor cells in cancer. Cancer Res. 70, 99-108. doi: 10.1158/00085472.CAN-09-1882. Epub 2009 Dec 8.

215. Bunt, S. K., Clements, V. K., Hanson, E. M., Sinha, P., Ostrand-Rosenberg, S. (2009) Inflammation enhances myeloid-derived suppressor cell cross-talk by signaling through Toll-like receptor 4. J Leukoc Biol. 85, 996-1004. doi: 10.1189/jlb.0708446. Epub 2009 Mar 4.

216. Kusmartsev, S., Nagaraj, S., Gabrilovich, D. I. (2005) Tumor-associated CD8+ T cell tolerance induced by bone marrow-derived immature myeloid cells. J Immunol. 175, 4583-92.

217. Nagaraj, S., Nelson, A., Youn, J. I., Cheng, P., Quiceno, D., Gabrilovich, D. I. (2012) Antigen-specific CD4(+) T cells regulate function of myeloid-derived suppressor cells in cancer via retrograde MHC class II signaling. Cancer Res. 72, 928-38. doi: 10.1158/0008-5472.CAN-11-2863. Epub 2012 Jan 11.

218. Rosenberg, S. A., Yang, J. C., Restifo, N. P. (2004) Cancer immunotherapy: moving beyond current vaccines. Nat Med. 10, 909-15.

219. Tsung, K., Dolan, J. P., Tsung, Y. L., Norton, J. A. (2002) Macrophages as effector cells in interleukin 12-induced T cell-dependent tumor rejection. Cancer Res. 62, 5069-75. 
220. Guiducci, C., Vicari, A. P., Sangaletti, S., Trinchieri, G., Colombo, M. P. (2005)

Redirecting in vivo elicited tumor infiltrating macrophages and dendritic cells towards tumor rejection. Cancer Res. 65, 3437-46.

221. Buhtoiarov, I. N., Lum, H., Berke, G., Paulnock, D. M., Sondel, P. M., Rakhmilevich, A. L. (2005) CD40 ligation activates murine macrophages via an IFN-gamma-dependent mechanism resulting in tumor cell destruction in vitro. $\mathrm{J}$ Immunol. 174, 6013-22.

222. Buhtoiarov, I. N., Lum, H. D., Berke, G., Sondel, P. M., Rakhmilevich, A. L. (2006) Synergistic activation of macrophages via CD40 and TLR9 results in T cell independent antitumor effects. J Immunol. 176, 309-18.

223. Watkins, S. K., Egilmez, N. K., Suttles, J., Stout, R. D. (2007) IL-12 rapidly alters the functional profile of tumor-associated and tumor-infiltrating macrophages in vitro and in vivo. J Immunol. 178, 1357-62.

224. Day, C. P., Carter, J., Bonomi, C., Hollingshead, M., Merlino, G. (2012) Preclinical therapeutic response of residual metastatic disease is distinct from its primary tumor of origin. Int J Cancer. 130, 190-9. doi: 10.1002/ijc.25978. Epub 2011 Apr 20.

225. Hume, D. A. (2011) Applications of myeloid-specific promoters in transgenic mice support in vivo imaging and functional genomics but do not support the concept of distinct macrophage and dendritic cell lineages or roles in immunity. J Leukoc Biol. 89, 525-38. doi: 10.1189/jlb.0810472. Epub 2010 Dec 17.

226. Stout, R. D., Jiang, C., Matta, B., Tietzel, I., Watkins, S. K., Suttles, J. (2005) Macrophages sequentially change their functional phenotype in response to changes in microenvironmental influences. J Immunol. 175, 342-9.

227. Murdoch, C., Giannoudis, A., Lewis, C. E. (2004) Mechanisms regulating the recruitment of macrophages into hypoxic areas of tumors and other ischemic tissues. Blood. 104, 2224-34. Epub 2004 Jul 1.

228. Martin, M. J., Hayward, R., Viros, A., Marais, R. (2012) Metformin accelerates the growth of BRAF V600E-driven melanoma by upregulating VEGF-A. Cancer Discov. 2, 344-55. doi: 10.1158/2159-8290.CD-11-0280. Epub 2012 Mar 31.

229. Laoui, D., Movahedi, K., Van Overmeire, E., Van den Bossche, J., Schouppe, E., Mommer, C., Nikolaou, A., Morias, Y., De Baetselier, P., Van Ginderachter, J. A. (2011) Tumor-associated macrophages in breast cancer: distinct subsets, distinct functions. Int J Dev Biol 55, 861-7. doi: 10.1387/ijdb.113371dl.

230. Laoui, D., Van Overmeire, E., Movahedi, K., Van den Bossche, J., Schouppe, E., Mommer, C., Nikolaou, A., Morias, Y., De Baetselier, P., Van Ginderachter, J. A. (2011) Mononuclear phagocyte heterogeneity in cancer: different subsets and 
activation states reaching out at the tumor site. Immunobiology. 216, 1192-202. doi: 10.1016/j.imbio.2011.06.007. Epub 2011 Jun 30.

231. Saccani, A., Schioppa, T., Porta, C., Biswas, S. K., Nebuloni, M., Vago, L., Bottazzi, B., Colombo, M. P., Mantovani, A., Sica, A. (2006) p50 nuclear factorkappaB overexpression in tumor-associated macrophages inhibits M1 inflammatory responses and antitumor resistance. Cancer Res. 66, 11432-40.

232. Sica, A., Saccani, A., Bottazzi, B., Polentarutti, N., Vecchi, A., van Damme, J., Mantovani, A. (2000) Autocrine production of IL-10 mediates defective IL-12 production and NF-kappa B activation in tumor-associated macrophages. $\mathrm{J}$ Immunol. 164, 762-7.

233. Kaplan, R. N., Riba, R. D., Zacharoulis, S., Bramley, A. H., Vincent, L., Costa, C., MacDonald, D. D., Jin, D. K., Shido, K., Kerns, S. A., Zhu, Z., Hicklin, D., Wu, Y., Port, J. L., Altorki, N., Port, E. R., Ruggero, D., Shmelkov, S. V., Jensen, K. K., Rafii, S., Lyden, D. (2005) VEGFR1-positive haematopoietic bone marrow progenitors initiate the pre-metastatic niche. Nature. $438,820-7$.

234. Erler, J. T., Bennewith, K. L., Cox, T. R., Lang, G., Bird, D., Koong, A., Le, Q. T., Giaccia, A. J. (2009) Hypoxia-induced lysyl oxidase is a critical mediator of bone marrow cell recruitment to form the premetastatic niche. Cancer Cell. 15, 35-44. doi: 10.1016/j.ccr.2008.11.012.

235. Wong, S. C., Puaux, A. L., Chittezhath, M., Shalova, I., Kajiji, T. S., Wang, X., Abastado, J. P., Lam, K. P., Biswas, S. K. (2010) Macrophage polarization to a unique phenotype driven by B cells. Eur J Immunol. 40, 2296-307. doi: 10.1002/eji.200940288.

236. Andreu, P., Johansson, M., Affara, N. I., Pucci, F., Tan, T., Junankar, S., Korets, L., Lam, J., Tawfik, D., DeNardo, D. G., Naldini, L., de Visser, K. E., De Palma, M., Coussens, L. M. (2010) FcRgamma activation regulates inflammationassociated squamous carcinogenesis. Cancer Cell. 17, 121-34. doi: 10.1016/j.ccr.2009.12.019. Epub 2010 Feb 4.

237. Serafini, P., Mgebroff, S., Noonan, K., Borrello, I. (2008) Myeloid-derived suppressor cells promote cross-tolerance in B-cell lymphoma by expanding regulatory T cells. Cancer Res. 68, 5439-49. doi: 10.1158/0008-5472.CAN-076621.

238. Lu, T., Ramakrishnan, R., Altiok, S., Youn, J. I., Cheng, P., Celis, E., Pisarev, V., Sherman, S., Sporn, M. B., Gabrilovich, D. (2011) Tumor-infiltrating myeloid cells induce tumor cell resistance to cytotoxic T cells in mice. J Clin Invest. 121, 4015-29. doi: 10.1172/JCI45862. Epub 2011 Sep 12.

239. Singh, B. N., Shankar, S., Srivastava, R. K. (2011) Green tea catechin, epigallocatechin-3-gallate (EGCG): mechanisms, perspectives and clinical 
applications. Biochem Pharmacol. 82, 1807-21. doi: 10.1016/j.bcp.2011.07.093. Epub 2011 Jul 30.

240. Whitlock, N. C. and Baek, S. J. (2012) The anticancer effects of resveratrol: modulation of transcription factors. Nutr Cancer 64, 493-502. doi: 10.1080/01635581.2012.667862. Epub 2012 Apr 6.

241. Bodmer, M., Meier, C., Krahenbuhl, S., Jick, S. S., Meier, C. R. (2010) Longterm metformin use is associated with decreased risk of breast cancer. Diabetes Care. 33, 1304-8. doi: 10.2337/dc09-1791. Epub 2010 Mar 18.

242. Cheng, S. W., Fryer, L. G., Carling, D., Shepherd, P. R. (2004) Thr2446 is a novel mammalian target of rapamycin (mTOR) phosphorylation site regulated by nutrient status. J Biol Chem. 279, 15719-22. Epub 2004 Feb 17.

243. Foretz, M., Carling, D., Guichard, C., Ferre, P., Foufelle, F. (1998) AMPactivated protein kinase inhibits the glucose-activated expression of fatty acid synthase gene in rat hepatocytes. J Biol Chem. 273, 14767-71.

244. Woods, A., Azzout-Marniche, D., Foretz, M., Stein, S. C., Lemarchand, P., Ferre, P., Foufelle, F., Carling, D. (2000) Characterization of the role of AMP-activated protein kinase in the regulation of glucose-activated gene expression using constitutively active and dominant negative forms of the kinase. Mol Cell Biol. 20, 6704-11.

245. Dandapani, M. and Hardie, D. G. (2013) AMPK: opposing the metabolic changes in both tumour cells and inflammatory cells? Biochem Soc Trans. 41, 687-93. doi: 10.1042/BST20120351. 


\section{CURriculum Vitae}

Kelly Casey Carroll

Department of Microbiology and Immunology

University of Louisville School of Medicine

Louisville, KY 40292

Phone: 502-419-1937

E-mail: kelly.carroll@1ouisville.edu

Place of Birth: Louisville, KY

\section{Citizenship: US}

\section{Education:}

2009

B.S. Biochemistry and Molecular Biology

Bellarmine University, Louisville, KY, 3.6 GPA

2011 M.S. Microbiology and Immunology

University of Louisville, Louisville, KY, 4.0 GPA

2009-present Ph.D. Candidate, Microbiology and Immunology

University of Louisville, KY, 4.0 GPA

\section{Research Experience:}

Summer 2007 Student Researcher, Kentucky Biomedical Research Infrastructure Network, University of Louisville School of Medicine, Louisville, KY

Mentor: Chuan Hu, Ph.D.

Studied vesicular trafficking in cancer metastasis and angiogenesis.

2008-2009 Student Researcher, Department of Biochemistry and Molecular Biology, Bellarmine University, Louisville, KY

Mentor: Mary Huff, Ph.D.

Investigated the action of cadmium chloride and sodium arsenate as environmental estrogens via the non-genomic estrogen receptor pathway. 
Summer 2009 Graduate Research Intern, Department of Microbiology and Immunology, University of Louisville School of Medicine, Louisville, KY

Mentor: Pascale Alard, Ph.D.

Investigated the contribution of $\beta$-catenin expression by antigen presenting cells from non-obese diabetic (NOD) mice to diabetes pathogenesis.

2009-present Graduate Student, Department of Microbiology and Immunology, University of Louisville School of Medicine, Louisville, KY Mentor: Jill Suttles, Ph.D.

Investigation of the role of AMP-activated protein kinase (AMPK) in the regulation of macrophage and dendritic cell inflammatory activity and its contribution to the development of proinflammatory $\mathrm{T}$ cell responses. Evaluation of the effect of myeloid cell-expressed AMPK $\alpha 1$ on tumor growth and metastasis.

\section{Teaching Experience:}

Fall 2012 Adjunct Faculty, Department of Chemistry, Bellarmine University, Louisville, KY

Course: Health Science Chemistry; This course is aimed at students interested in pursuing health science careers and is designed to show the interconnectedness of the physical and life sciences. Basic concepts in general, organic, and biological chemistry were covered.

\section{Honors and Awards:}

2005-2009 Academic Deans List, Bellarmine University, Louisville, KY

2005-2009 Monsignor Horrigan Scholarship Recipient, Bellarmine University, Louisville, KY

2005-2009 Honors Program, Bellarmine University, Louisville, KY

2006 Presidential Scholarship Winner, Bellarmine University, Louisville, KY

2009 Graduate Fellow, Integrated Programs in Biomedical Science, University of Louisville, Louisville, KY Undergraduate Research Conference, University of Evansville, Evansville, IN 
Society of Leukocyte Biology Travel Award, Award funded travel to the annual meeting of the Society of Leukocyte Biology, Kansas City, MO

Poster Presentation Finalist, Research! Louisville, Louisville, KY

2012

University of Louisville Travel Award, Award funded travel to the annual meeting of the Society of Leukocyte Biology, Maui, HI

\section{Memberships and Service:}

2008-present Member, Kentucky Academy of Science

2009-present Member, Microbiology and Immunology Student Organization, University of Louisville

2010-present Prospective Student Host, University of Louisville Microbiology and Immunology Program

2010-present Student Advisor to First year Students, University of Louisville Microbiology and Immunology Program

2010-2011 Treasurer, Microbiology and Immunology Student Organization, University of Louisville

2011-present Member, Society of Leukocyte Biology

$2011 \quad$ Volunteer, Be the Match bone marrow donor drive, University of Louisville

2012

Mentor, Assisted middle school students in completion of a science fair project where the $\mathrm{pH}$ of household chemicals was determined using both a $\mathrm{pH}$ meter and test strips.

\section{Publications:}

Carroll, K.C., B. Viollet, and J. Suttles. 2013. AMPK $\alpha 1$ deficiency amplifies proinflammatory myeloid APC activity and CD40 signaling. J. Leuk. Biol. Epub July 2013.

*The JLB editor has stated that this paper will be featured in the Frontline Science Section as

"Leading Edge Research" with a dedicated editorial.

In Preparation: 
Carroll, K.C., Suttles, J. 2013. Deficiency of myeloid cell AMPKa1 decreases tumor growth and metastasis.

Published Abstracts:

Carroll, K.C., Li, B., and J. Suttles. Regulation of myeloid APC activity by AMP-activated protein kinase. 2011. J. Leuk. Biol. S40. Abst. 115.

Carroll, K. and J. Suttles. AMP-activated protein kinase regulates myeloid APC activity. 2012. J. Leuk. Biol. S54 Abst. 134.

\section{Poster Presentations:}

2009 Poster presentation, "Environmental estrogens cadmium chloride and sodium arsenate and the estrogen receptor pathway," Math, Engineering, and Science Undergraduate Research Conference, Evansville, IN

2009 Poster presentation, "Environmental estrogens cadmium chloride and sodium arsenate and the estrogen receptor pathway," Bellarmine University Research Week, Louisville, KY

2011 Poster presentation, "Regulation of myeloid APC activity by AMPactivated protein kinase," Society of Leukocyte Biology annual meeting, Kansas City, MO

2011 Poster presentation, "Regulation of myeloid APC activity by AMPactivated protein kinase," Research! Louisville annual meeting, Louisville, KY

2012 Poster presentation, "AMP-activated protein kinase regulates myeloid APC activity," Society of Leukocyte Biology annual meeting, Maui, HI 